Rheinische Schriften zur Rechtsgeschichte

Martin Avenarius (Hrsg.)

Hermeneutik der Quellentexte des Römischen Rechts

Sonderdruck

- nicht im Buchhandel erhältlich - 
Die Deutsche Nationalbibliothek verzeichnet diese Publikation in der Deutschen Nationalbibliografie; detaillierte bibliografische Daten sind im Internet über http://www.d-nb.de abrufbar.

ISBN 978-3-8329-3407-1

1. Auflage 2008

(c) Nomos Verlagsgesellschaft, Baden-Baden 2008. Printed in Germany. Alle Rechte, auch die des Nachdrucks von Auszügen, der fotomechanischen Wiedergabe und der Übersetzung, vorbehalten. Gedruckt auf alterungsbeständigem Papier. 


\title{
Wandlungen im Verständnis der Epitome Iuliani von der Spätantike bis zur Gegenwart*
}

\author{
Wolfgang Kaiser
}

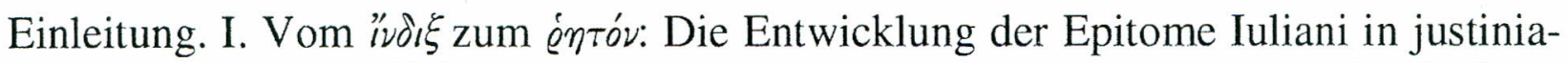
nischer Zeit. 1.Der $i \nu \delta \xi \xi$ des antecessor Iulianus. 2. Die Gleichstellung des ${ }^{\prime} \nu d \xi \xi$ mit dem éntóv. 3. Anhänge zur Epitome Iuliani. 4. Die Epitome Iuliani im Westen. II. Die Epitome Iuliani im westlichen Frühmittelalter. III. Konkurrenz durch das Authenticum: Die Epitome Iuliani im Hochmittelalter. 1. Zur Gestalt hochmittelalterlicher Handschriften der Epitome Iuliani. 2. Das Verhältnis der Epitome Iuliani zum Authenticum. Zugleich zur Kenntnis der Epitome bei den Glossatoren. 3. Zitierweise und Wissen um den Verfasser. IV. Die Wiedergewinnung des Textes und das neue Verständnis der Epitome im 16. Jhd. 1. Handschriften der Humanisten. 2. Editionen der Epitome Iuliani. 3. Das äußere Erscheinungsbild der Editionen. 4. Die Person Julians und der Zweck der Epitome. 5. Ausblick: Der Usus modernus. V. Die historische Rechtsschule und das 19. Jahrhundert. 1. Handschriftenforschung. 2. Das Verständnis der Epitome Iuliani.

\section{Einleitung}

Die (sogenannte) Epitome Iuliani ${ }^{1}$ stellt heute für das römische Recht nur eine „Nebenquelle" dar ${ }^{2}$. Die Epitome erweitert - von einer Ausnahme abgesehen - die Kenntnis der griechischen oder lateinischen Novellen Justinians nicht ${ }^{3}$. Allerdings

* Herrn Rechtsreferendar Andreas McDougall bin ich für seine vielfältige Hilfe sehr zu Dank verpflichtet. - Folgende Editionen werden abgekürzt zitiert: ed. Schöll-Kroll = Corpus iuris, Bd. 3: Novellae, edd. R. Schöll-W. Kroll, 4. Aufl., Berlin 1912; ed. Zachariae = Novellae constitutiones imperatorum post Justinianum quae supersunt collatae et ordine chronologico digestae, ed. K. E. Zachariae von Lingenthal, Ius Graeco-romanum 3, Leipzig 1857.

1 Der Name ist bereits um die Mitte des 16. Jhds. üblich, s. unten Fn. 313. In der Literatur begegnet das Werk auch als „Novellenauszug des Julian“ oder einfach nur als ,Julian“.

2 S. an neuerer Literatur zur Epitome Iuliani D. Liebs, Die Jurisprudenz im spätantiken Italien, Berlin 1987, S. 230-266; W. Kaiser, Die Epitome Iuliani. Beiträge zum römischen Recht im frühen Mittelalter und zum byzantinischen Rechtsunterricht, Frankfurt a. M. 2004 (dazu die Rezension von D. Liebs in SZ 123 (2006), S. 400-412; Verzeichnis von Druckfehlern dort S. 412 Fn. 26); vgl. auch W. Kaiser, Authentizität und Geltung spätantiker Kaisergesetze. Studien zu den sogenannten Sacra privilegia concilii Vizaceni, München 2007, S. 535 s. v. Epitome Iuliani.

3 Die Ausnahme bildet Ep. Iul. Const. 38 (Coll. CLXVIII Novv. 41), eine lateinische Novelle Justinians an den Quaestor exercitus Bonus aus dem Jahre 536. In der Coll. CLXVIII Novv. war die Novelle vorhanden, der (lateinische!) Text ist aber ausgefallen und nicht mehr an- 
enthalten die verschiedenen Anhänge zur Epitome (dazu unten S. 307) mehrere, anderweitig nicht mehr erhaltene lateinische Novellen Justinians ${ }^{4}$, Justins II. sowie Tiberius II. ${ }^{5}$ Von großem Interesse ist die Epitome Iuliani jedoch für die Kenntnis des justinianischen Rechtsunterrichts. Ihre Fortwirkung im Westen war, insbesondere im Frühmittelalter, beträchtlich. Die Handschriften der Epitome Iuliani nehmen was Reichtum und Vielfalt des Inhalts betrifft - eine Sonderstellung innerhalb der frühmittelalterlichen Überlieferung justinianischer Texte ein.

Die ausführlichste Darstellung der Epitome und ihrer Wirkungsgeschichte sowie von Handschriften und Editionen bietet nach wie vor die Vorrede von Gustav Hänel ${ }^{6}$ zu seiner kritischen Edition aus dem Jahre 18737. Grundlegend für die Erforschung der Epitome waren zu Beginn des 19. Jahrhunderts die Arbeiten von Friedrich Carl von Savigny $(1822 ; 1834)$, Christian Haubold ${ }^{8}(1819)$ und Friedrich August Biener $(1824)^{9}$.

derweitig überliefert. Die Novelle erwähnen auch Athanasius und Theodorus, s. Schöll-Kroll, S. 261. Nicht mehr zutreffend sind insoweit die Bemerkungen bei Biener (u. Fn. 9), S. 81 sowie Hänel, Iuliani epitome (s. unten Fn. 7), S. 69 zu Cap. 166. Ep. Iul. Const. 29 (Novelle vom 23. Juli 535) findet sich zwar weder in der Coll. CLXVIII Novv. noch im Authenticum, der griechische Text ist jedoch als drittes der sogenannten Edikte Justinians erhalten, s. bereits Biener, S. 81; Hänel, S. 50 zu Cap. 202, Schöll-Kroll, S. 760.

So ein undatiertes lateinisches Reskript Justinians über Teilleistungen auf verzinsliche Darlehen (Coll. CLXVIII Novv. 138; ed. Schöll-Kroll, S. 700, 1-10) sowie die Novellen Justinians vom 7. April 540 an den PPO Illyriae Domnicus (ed. Schöll-Kroll, S. 796, 2-20), vom 6. August 552 an den PPO Africae Paulus (ed. Schöll-Kroll, S. 799, 1-9), vom 13. August 554 an einen unbekannten Adressaten (ed. Schöll-Kroll, S. 799, 1-802, 48; s. dazu Kaiser, Die Epitome Iuliani [o. Fn. 2], S. 350-351), wohl aus dem Jahre 555 an Narses, Pamphronius und den Senat von Rom (ed. Schöll-Kroll, S. 803, 1-23; s. zur Datierung Kaiser, S. 369), vom 22. September 558 an den PPO Africae Johannes (ed. Schöll-Kroll, S. 803, 25-44).

So die Novelle Justins II. vom 1. März 570 an den PPO Africae Theodorus (ed. Zachariae, S. 13-14) und die Novelle Tiberius II. vom 11. Juli 582 an den PPO Africae Theodorus (ed. Zachariae, S. 30-31).

Zu Gustav Hänel $(* 1792, \uparrow 1878)$ s. A. Hänel-E. Landsberg, Art. Hänel, Gustav Friedrich, in: Allgemeine deutsche Biographie, Bd. 49, Leipzig 1904, S. 751-755.

$7 \quad$ Iuliani epitome Latina Novellarum Iustiniani, ed. G. Hänel, Leipzig 1873.

$8 \quad$ Zu Christian Gottlieb Haubold $(* 1766, \dagger 1824)$ s. Teichmann, Art. Haubold, Christian Gottlieb, in: Allgemeine deutsche Biographie, Bd. 11, Leipzig 1880, S. 39-42 sowie G. Fikentscher-Schubart, Art. Haubold, Christian Gottlieb, in: Neue deutsche Biographie, Bd. 8, Berlin 1969, S. 72-73.

9 F. C. von Savigny, Geschichte des römischen Rechts im Mittelalter, Bd. 3, 1. Aufl. Heidelberg 1822, S. 453-466, 2. Aufl., Heidelberg 1834, S. 490-504; D. (!) Haubold, Beytrag zur Litterar-Geschichte des Novellen-Auszugs von Julian, in: Zeitschrift für geschichtliche Rechtswissenschaft 4, Heft 2 (1819), S. 133-188 mit Nachtrag in Heft 3 (1820), S. 491-494; G. Hänel, Nachtrag zu Haubolds Litterar-Geschichte des Novellen-Auszuges von Julian, in: Zeitschrift für historische Rechtswissenschaft 8 (1835), S. 357-360; F. A. Biener, Geschichte der Novellen Justinians, Berlin 1824 (Nachdruck Aalen 1970), S. 70-84, 232-242, 289-291, 299-303 sowie S. 318 ff. passim (Verzeichnis der Ausgaben der Novellen). - Haubold konnte die Aufzeichnungen Savignys zu den Pariser Handschriften benutzen, s. Haubold, S. 137 Fn. 9. 
Wie bei keinem anderen Werk aus justinianischer Zeit war das Verständnis des Novellenindex des antecessor Iulianus im Laufe der Jahrhunderte einem Wandel unterworfen, der im folgenden skizziert werden soll.

\section{Vom ǐdı'zum éntóv: Die Entwicklung der Epitome Iuliani in justinianischer Zeit}

\section{Der ${ }^{i} \nu \delta_{1} \xi$ des antecessor Iulianus}

Die Epitome Iuliani stammt aus dem justinianischen Rechtsunterricht ${ }^{10}$. Es handelt sich um einen Index ( ${ }^{\prime}\left(\nu \partial_{1} \xi\right)$, d. h. eine Einführungsvorlesung ${ }^{11}$, zu einer Sammlung mit 124 Novellen Justinians ${ }^{12}$, deren jüngste vom 1. Juni 555 datiert (Ep. Iul. Const. $118^{13}$, Coll. CLXVIII Novv. 159, Auth. 126). Dies zeigt etwa die Protheoria ${ }^{14}$, mit der das Werk beginnt ${ }^{15}$.

Die Vorlesung fand in Konstantinopel statt $^{16}$; sie hielt der antecessor und vir eloquentissimus Iulianus, der als Rechtslehrer in Berytos und Konstantinopel tätig war $^{17}$. Sein voller Name und seine näheren Lebensumstände sind nicht bekannt ${ }^{18}$. Die Abfassungszeit fällt in die Regierungszeit Justinians, den Julian als imperator

10 Zum justinianischen Rechtsunterricht vgl. nur die Arbeiten von H. J. Scheltema, jetzt vereint in: H. J. Scheltema, Opera minora ad historiam iuris pertinentia, Groningen 2004, sowie die Darstellung bei P. Pieler, Byzantinische Rechtsliteratur, in: H. Hunger, Die hochsprachliche profane Literatur der Byzantiner, Bd. 2 (HdA 12, 5, 2), München 1978, S. 341-480, 400-428. S. dazu H. J. Scheltema, Subseciva XIII: Die Epitome Novellarum Julians, jetzt in: Opera minora (o. Fn. 10), S. 142-144.

12 Zu der benutzten Novellensammlung s. P. Krüger, Geschichte der Quellen und der Literatur des Römischen Rechts, 2. Aufl., München - Leipzig 1912, S. 401; Kaiser, Die Epitome Iuliani (o. Fn. 2), S. 184-187, dort auch weitere Details zur Anordnung der Novellen.

Zur Reihenfolge von Ep. Iul. Const. 117 und 118 s. nur Kaiser, Die Epitome Iuliani (o. Fn. 2), S. 186, 286.

14 Zu den Protheoriae s. nur Pieler (o. Fn. 10), S. 405.

15 Julian resümiert den Rechtszustand für die Lex Falcidia nach Digesten und Codex, bevor er auf die Reformkonstitution Justinians vom 1. Januar 535 (Ep. Iul. Const. 1, Coll. CLXVIII Novv. 1) eingeht, s. Ep. Iul. Cap. 1: Et in Digestis et in Constitutionibus didicimus, parentibus quidem et liberis, nec non fratribus et patronis certam quandam portionem ex nostra deberi substantia, quam necesse est omni modo relinquere eis, nisi forte ingrati circa nos apparuerint ... His itaque eo modo discretis, videamus caput constitutionis propositum. Eius vis ac potestas talis est: ... (ed. Hänel, S. 21, 7-12).

$16 \mathrm{Zu}$ der Bezeichnung von Konstantinopel als haec civitas oder haec regia civitas etc. nur Kaiser, Die Epitome Iuliani (o. Fn. 2), S. 178-179 mit weiteren Literaturhinweisen. Die Abfassung der Epitome Iuliani in Konstantinopel war bereits den Humanisten bekannt, s. unten S. 344.

17 S. nur das Lobgedicht des Theaetetus Scholasticus auf Julian in der Anthologia Graeca (Anth. Gr. XVI 32b). Von Julian selbst stammen drei Spottgedichte auf nicht näher bestimmbare Dritte (Anth. Gr. 367-369), s. dazu Kaiser, Die Epitome Iuliani (o. Fn. 2), S. 177-178. Eine Verbindung zwischen den drei Gedichten und Julian stellte erstmals Miraeus im Jahre 1561 her, s. unten S. 344. 
noster bezeichnet ${ }^{19}$. Julian hielt die Einführung mehrfach ab; die früheste (erschließbare) Fassung stammt aus dem Jahr $548^{20}$, die letzte faßbare aus dem Jahre $556^{21}$.

Spätantike Handschriften oder Fragmente der Epitome Iuliani haben sich - anders als für die Digesten und den $\operatorname{Codex}^{22}-$ nicht erhalten. Allerdings bilden die frühmittelalterlichen Handschriften den - uneinheitlichen - spätantiken Entwicklungsstand der Epitome Iuliani $a^{23}$. Es lassen sich noch vier Textgruppen unterscheiden, die in die Spätantike zurückreichen ${ }^{24}$.

Die Epitome verfügt in allen Handschriften über eine fortlaufende Konstitutionenzählung sowie eine fortlaufende Kapitelnumerierung und Kapitelrubriken (s. hierzu aber sogleich). Ein Teil der Handschriften zählt zusätzlich die Kapitel je nach Konstitution ${ }^{25}$. Eine frühere Ausgabe der Epitome besaß auch Konstitutionenrubriken $^{26}$. Allen Handschriften ist die (unrichtige) Verselbständigung von Cap. 124 zu einer Konstitution ("Const. 35") gemeinsam, die wohl auf die zugrundeliegende Novellensammlung zurückgeht ${ }^{27}$. Die überwiegende Zahl der frühmittelalterlichen Handschriften teilt die Epitome hinter Const. 62 in etwa zwei gleich große Teile (partes oder libri). Ob diese Teilung noch der Spätantike oder erst dem Frühmittalter angehört, läßt sich derzeit nicht bestimmen ${ }^{28}$.

Julian faßt die Novellen zumeist stark zusammen ${ }^{29}$. Er übergeht die Inskriptionen und (überwiegend) das Prooemium ${ }^{30}$, ebenso fehlt der Epilog mit dem Ausführungsbefehl. Julian merkt bei der Erörterung einer Novelle frühere oder spätere einschlä-

S. Kaiser, Die Epitome Iuliani (o. Fn. 2), S. 180.

Zu den Auflagen der Epitome s. schon Liebs (o. Fn. 2), S. 221, 233 sowie Kaiser, Die Epitome Iuliani (o. Fn. 2), S. 179, 212-214.

Dies ergibt sich aus Verweisen Julians in den Paragraphae auf die Novelle vom 1. Mai 556, s. Kaiser, Die Epitome Iuliani (o. Fn. 2), S. 214, 257.

Für die Digesten s. hauptsächlich den Codex Florentinus Digestorum sowie verschiedene Fragmente auf Papyrus und Pergament, dazu W. Kaiser, Art. Digesten (Überlieferung), in: Der Neue Pauly, Bd. 13, Stuttgart-Weimar 1999, Sp. 845-852; ders., Schreiber und Korrektoren des Codex Florentinus, in: ZRG RA 118 (2001), S. 133-219 passim; zur Codexüberlieferung s. Kaiser, Die Epitome Iuliani (o. Fn. 2), S. 969 s. v. Codex Iustinianus/Überlieferung; nunmehr auch Ch. Radding-A. Ciaralli, The Corpus Iuris in the Middle Ages. Manuscripts and Transmission from the Sixth Century to the Juristic Revival, Leiden - Boston 2007, S. $133-169$.

S. zu den frühmittelalterlichen Handschriften unten Fn. 67.

S. Kaiser, Die Epitome Iuliani (o. Fn. 2), S. 23-36 (Textgruppe A), 37-105 (Textgruppe B), 106-121 (Textgruppe C), 122-167 (Textgruppe D).

S. Kaiser, Die Epitome Iuliani (o. Fn. 2), S. 195-199.

S. Kaiser, Die Epitome Iuliani (o. Fn. 2), S. 205-214.

S. Kaiser, Die Epitome Iuliani (o. Fn. 2), S. 191-192.

S. dazu Kaiser, Die Epitome Iuliani (o. Fn. 2), S. 202-205.

Die Verkürzungen fielen - durch den Vergleich mit dem Authenticum - bereits den Glossatoren auf, s. unten S. 314 (Albericus de Rosate). Auch die Humanisten setzen sich mit der Arbeitsweise Julians auseinander, s. unten S. 320, 344-346.

$\mathrm{Zu}$ den vier Inskriptionen und zwei Prooemien in der Hs. Berlin Staatsbibl. lat. fol. $269 \mathrm{~s}$. Kaiser, Die Epitome Iuliani (o. Fn. 2), S. 240-246. 
gige Novellen an und zitiert auch Institutionen und $\operatorname{Codex}^{31}$. Explizit aufgehobene Novellen bespricht er nur noch kursorisch ${ }^{32}$.

Der Index, dessen Veröffentlichung wohl auf Julian selbst, nicht auf seine Zuhörer zurückgeht ${ }^{33}$, scheint keinen „offiziellen“ Titel besessen zu haben. Eine handschriftliche Tradition gibt im Incipit an, der antecessor Julian aus Konstantinopel habe die Novellen Justinians aus dem Griechischen in das Lateinische übersetzt ${ }^{34}$. Dieses Incipit läßt sich bis in das Hochmittelalter verfolgen ${ }^{35}$. In anderen Handschriften fehlt ein Incipit, das dort vorhandene Explicit vermerkt nur, daß es sich um Konstitutionen Justinians handelt, die nach dem Codex erlassen wurden ${ }^{36}$. Daß Julian die Novellen nur verkürzt wiedergibt, bringen weder das Incipit noch das Explicit zum Ausdruck. Dies erleichterte die frühmittelalterliche Gleichsetzung der Epitome mit dem genuinen Novellentext (s. unten S. 310-311).

Die (lateinischen) indices bezweckten, lateinischsprachige Studenten, die im Osten studierten ${ }^{37}$, in die ganz überwiegend griechischen Novellen einzuführen, die in Sammlungen dem Unterricht zugrundelagen ${ }^{38}$. Für die lateinischen Rechtsbücher (Institutionen, Digesten und Codex) existierten griechische indices ${ }^{39}$.

31 S. dazu nur Kaiser, Die Epitome Iuliani (o. Fn. 2), S. 178.

32 S. dazu nur Kaiser, Die Epitome Iuliani (o. Fn. 2), S. 180-181.

33 S. Kaiser, Die Epitome Iuliani (o. Fn. 2), S. 179-180. Hingegen dürften der Überlieferung der Institutionenparaphrase des Theophilos, des Digestenindex des Stephanos, der Codexkurse des Thalelaios etc. Studentenmitschriften zugrundeliegen, s. H. J. Scheltema, L'enseignement de droit des antécesseurs, Leiden 1970 (=Opera minora [o. Fn. 11], S. 58-110), S. 19, 25, 40. S. das Incipit nach den Hss. Vercelli Bibl. Cap. CXXII, Leipzig UB Hänel 6 und Wien ÖNB 2160: Incipiunt constitutiones novellae (novellarum Hss.) Iustiniani perpetui augusti de Graeco in Latino translatae (translatas Hss.) per Iulianum virum eloquentisissimum antecessorum civitatis Constantinopolitanae feliciter. Dazu genauer Kaiser, Die Epitome Iuliani (o. Fn. 2), S. 173-175 (dort auch zu Handschriftenvarianten und zu einem weiteren, abweichenden Incipit zum Kapitelverzeichnis in der Hs. Berlin Staatsbibl. lat. fol. 269).

36 Das Explicit lautet (in den Hss. Paris BN lat. 4568 und Mailand Trivulz. 688): In eadem constitutione finiuntur novellae constitutiones, quae post Codicem divi nominis Iustiniani promulgatae sunt; s. dazu Kaiser, Die Epitome Iuliani (o. Fn. 2), S. 175-176 (dort auch zu den Handschriftenvarianten).

Zum Studienwesen in Berytos s. jetzt L. Hall, Roman Berytus: Beirut in Late Antiquity, London u. a. 2004, S. 195-220.

Zum privaten Charakter der Novellensammlungen s. nur P. Noailles, Les collections des novelles de l'empereur Justinien, Bd. 1: Origine et formation sous Justinien, Paris 1912, S. 129.

39 S. zu den Institutionen etwa nur die Theophilusparaphrase, das einzige nahezu vollständig erhaltene griechische Unterrichtswerk aus justinianischer Zeit; s. dazu nur Scheltema, Subseciva IV: Die Institutionenparaphrase Theophili, in: Opera minora (o. Fn. 10), S. 119-121; Pieler (o. Fn. 10), S. 420, zu den Digesten den ${ }^{2} \nu d \downarrow \xi$ des Stephanos (Pieler, S. 421), zum Codex den $i \nu \delta$ i des Thalelaios (Pieler, S. 423). 
Den Index des Julian haben auch andere, namentlich nicht mehr faßbare Rechtslehrer benutzt und verändert ${ }^{40}$. Die Epitome Iuliani war zudem nicht der einzige lateinische Novellenindex. Eine - außerhalb der Novellensammlungen überlieferte lateinische Übersetzung der Novelle Justinians zum Mönchswesen vom 18. (?) März 535 dürfte ebenfalls einen ${ }^{i} \nu \partial \xi \xi$ darstellen ${ }^{41}$. Der Text teilt einige Besonderheiten mit Julian (wie etwa Rückverweise, Verwendung der ersten Person Plural - z. B. dixi$m u s$ - ohne Vorlage im Text etc.), ist aber wesentlich ausführlicher ${ }^{42}$. Wo dieser " $2 \nu$ i $\xi$ entstand, ist offen.

Neben den indices gab es als weitere Verständnishilfen für den Originaltext, das éntóv, auch Kata poda (oder Kata podas), d. h., Übersetzungen, die die Vorlage in der jeweils anderen Sprache Wort für Wort wiedergaben und wohl als Interlinearglossen in den Handschriften der Bezugstexte standen. Ein Kata poda zu den griechischen Novellen einer Sammlung von 134 Novellen Justinians ist - neben den genuin lateinischen Novellen - im sogenannten „Authenticum“ enthalten ${ }^{43}$. Verstreut sind auch außerhalb des Authenticum lateinische Kata poda griechischer Novellen überliefert ${ }^{44}$.

Als Unterrichtswerk besitzt die Epitome Iuliani naturgemäß keine normative Kraft. Sie soll die Novellen in der benutzten Sammlung nur erklären, nicht ersetzen. Dies scheint sich aber bereits in justinianischer Zeit geändert zu haben.

\section{Die Gleichstellung des $\dddot{\imath} \nu \delta_{i} \xi$ mit dem @̈ntòv}

Das derzeitige Bild des justinianischen Rechtsunterrichts ${ }^{45}$ geht davon aus, daß der antecessor zunächst vermittels eines "ivor $\xi$ in das éntòv einführte und dieses sodann

S. dazu nur die Nachweise bei Kaiser, Die Epitome Iuliani (o. Fn. 2), S. 977 (Register s. v. Epitome Iuliani/Benutzung in der Spätantike); zu den Kapitelrubriken s. bereits Biener (o. Fn. 9), S. 84.

S. dazu jetzt Kaiser, Authentizität und Geltung (o. Fn. 2), S. 371-426.

42 S. dazu demnächst W. Kaiser, in: N. Benke-St. Meissel (Hgg.), Antike-Recht-Geschichte. Symposion für Peter E. Pieler.

Zum Authenticum s. nur Scheltema, Subseciva XI. Das Authenticum, in: Opera minora (o. Fn. 10), S. 133-137; ders., L'enseignement (o. Fn. 33), S. 52-57; Pieler (o. Fn. 10), S. 425; Liebs (o. Fn. 2), S. 266-269. Die beste Beschreibung der Handschriften bietet immer noch G. E. Heimbach, Authenticum. Novellarum constitutionum Iustiniani versio vulgata, 2 Bde., Leipzig 1846-1851 (Nachdruck Aalen 1974), p. I-CXXXIII. Das Kata poda des Authenticum wurde anscheinend mit dem index des Julian zusammen verwendet. Dies legt jedenfalls ein Vorspruch zu Handschriften des Authenticum nahe, s. dazu Scheltema, Subseciva XII. Die Notiz der Codd. Vindobon. lat. iur. civ. 19 und Claustro-Neoburg. 62, in: Opera minora (o. Fn. 10), S. 138-141; ders., L'enseignement (o. Fn. 33), S. 57-60; Liebs (o. Fn. 2), S. 261262; Kaiser, Die Epitome Iuliani (o. Fn. 2), S. 308-315.

44 S. die Nachweise Kaiser, Die Epitome Iuliani (o. Fn. 2), S. 986-987 (Register s. v. Kata poda); ders. Authentizität und Geltung (o. Fn. 2), S. 539 (Register s. v. Kata poda).

45 S. dazu nur Pieler (o. Fn. 10), S. 419-426; Kaiser, Die Epitome Iuliani (o. Fn. 2), S. 182-183; Beispiele finden sich bei H. J. Scheltema, Florilegium iurisprudentiae Graeco-Romanae, Leiden 1950. 
genauer erörterte. Hierzu diktierte er Randbemerkungen (

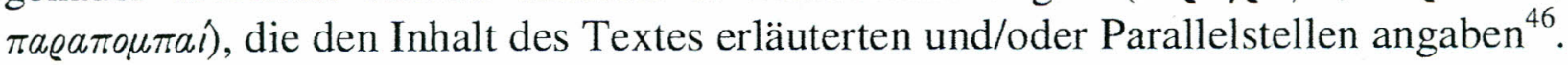
Auch im Zusammenhang mit der Epitome Iuliani sind Paragraphae überliefert, die von Julian selbst stammen dürften ${ }^{47}$. Die Überlieferung ist allerdings fragmentarisch (nur zu Ep. Iul. Constt. 15-18, 21-24, 26, 27, 32-34) ${ }^{48}$. Bezugstext dieser Paragraphae ist aber nicht, wie zu erwarten wäre, das éntòv, d. h. der griechische Novellentext, sondern die Epitome Iuliani selbst ${ }^{49}$.

Daneben haben sich weitere Randbemerkungen zur Epitome erhalten (sogenannte Paratitla $^{50}$ ), die aber nicht mehr von Julian herrühren. Sie stammen noch aus justinianischer Zeit ${ }^{51}$ und dürften im Osten entstanden $\operatorname{sein}^{52}$. Die Hs. Berlin Staatsbibl. lat. fol. 269 bewahrt noch einige Paratitla in situ ${ }^{53}$, weitere Paratitla enthalten - abgelöst vom Bezugstext - zwei Handschriften als Anhang zur Epitome (s. dazu unten S. 309). Die Paratitla behandeln die Epitome Iuliani als vollwertige Sammlung und zitieren sie gleichwertig neben Institutionen, Digesten und Codex $^{54}$.

Der Index war damit noch zu justinianischer Zeit einer genuinen Novellensammlung gleichgestellt, zumindest was die Behandlung im Unterricht betraf. Über die Gründe läßt sich nur spekulieren. Möglicherweise waren es Sprachschwierigkeiten verbunden mit der Weitschweifigkeit der Novellen, die deren Benutzung im Origi-

S. dazu nur Pieler (o. Fn. 10), S. 405

S. Kaiser, Die Epitome Iuliani (o. Fn. 2), S. 251, 257 mit weiteren Nachweisen.

Ediert bei Hänel, Iuliani epitome (o. Fn. 7), S. 178-184. Die Paragraphae stehen zu Beginn der Appendix A, s. sogleich S. 307 sowie Kaiser, Die Epitome Iuliani (o. Fn. 2), S. 250-251. Die überlieferte Textgestalt der Paragraphae besitzt frühmittelalterliche Einschübe, s. Kaiser, S. 255, 351. Die Paragraphae wurden erstmals 1561 von Miraeus unter dem Titel "Scholia in constitutiones aliquot" veröffentlicht, s. unten S. 333-336.

Dies belegt beispielsweise die Paragraphos zu Ep. Iul. Cap. 83: TEMPORIS PROLIXITAS PUBLICO NON NOCET: Nota regulam generalem, qua cavetur, ut temporis prolixitas publico non noceat. Ex hoc poteris dicere, quod fiscus pupillo similis est. Utilissimus locus est iste, et innovat omnia, quae dicuntur contra fiscum in praescriptione. Ecce enim habes in Codice in aliquibus locis, quae in hoc loco debet fisco nocere, quia per hoc etiam illud innovatum est, quae habes in secunda Institutione in titulo sexto, ubi dicit si res fisci vacantes aliquis invenerit, potes eas usucapere. Ergo dicimus, quia iam nec illo loco potest longi temporis opponi praescriptio. Ecce enim generaliter dixit, prolixitas temporis fisco non nocet (ed. Hänel, S. 182, 1-9). Das Textzitat am Ende (Ecce enim generaliter dixit prolixitas temporis fisco non nocet) stammt aus der Epitome selbst; es kommt in dieser Form in dem griechischen Novellentext nicht vor, s. hierzu die Ausführungen von Kaiser, Die Epitome Iuliani (o. Fn. 2), S. 257-266, 261.

S. dazu ausführlich Liebs (o. Fn. 2), S. 246-264 (mit Edition); Kaiser, Die Epitome Iuliani (o. Fn. 2), S. 247-259.

S. Kaiser, Die Epitome Iuliani (o. Fn. 2), S. 282, 305.

So Kaiser, Die Epitome Iuliani (o. Fn. 2), S. 306-307; anders Liebs (o. Fn. 2), S. 266 (Entstehung im Westen).

53 Ediert bei Kaiser, Die Epitome Iuliani (o. Fn. 2), S. 288-289.

S. als Beispiel nur das Paratitlon zu Ep. Iul. Cap. 114 (ed. Liebs, S. 249): Kap. CXInI innovat omnia iura, quae de legitima quarta portione posita sunt sive in secunda Institutione sub titulo De inofficioso (Inst. 2, 18) sive in II libro Codicis sub eodem titulo (C. 3, 28) sive in prima constitutione praesentium Novellarum (Ep. Iul. Const. 1). 
nal umständlicher machten als die (sekundäre) Epitome, die alles „Wesentliche“ enthielt.

\section{Anhänge zur Epitome Iuliani}

Noch in der Spätantike erhielten Handschriften der Epitome Iuliani Anhänge, die Unterrichtswerke, weitere genuin lateinische Novellen und wörtliche oder verkürzende lateinische Übersetzungen griechischer Novellen umfassen. Diese Anhänge, die wohl sukzessive entstanden, sind in unterschiedlichem Umfang in den frühmittelalterlichen Handschriften überliefer ${ }^{55}$. Man unterscheidet eine Appendix A und eine Appendix $B^{56}$. Die Appendices sind jeweils durch mehrere Handschriften bezeugt und treten in der Überlieferung getrennt auf. Zu der Appendix B sind in unterschiedlichem Umfang ebenfalls spätantike Supplemente überliefert. Die Appendix A wurde nicht mehr erweitert.

Die Appendix A umfaßt ${ }^{57}$.

(1) Paragraphae zu Ep. Iul. Capp. 52-116 in 42 fortlaufend numerierten Kapiteln (ed. Hänel, S. 178-184).

(2) Lateinische Novelle Justinians vom 21. Mai 563 über die Entführung von Jungfrauen, Witwen und Ehefrauen (Coll. CLXVIII Novv. 150; ed. Schöll - Kroll, S. 725, 23-726, 31); mit anderem Adressaten auch in der Appendix B vorhanden.

(3) Lateinische Novelle Justinians vom 13. August 554 zur Neuordnung Italiens mit 27 gezählten Kapiteln (ed. Schöll - Kroll, S. 799, 11-802, 48; ed. Hänel, S. 185-191).

(4) Lateinisches Kata poda einer Novelle Justins II. vom 14. September 566 über die Zulässigkeit der Konsensualscheidung (Coll. CLXVIII Novv. 140; ed. Schöll - Kroll, S. 701, 10 $703,21)$.

(5) Lateinische Novelle Justinians vom 7. April 540 über Fragen des Kolonats in Illyricum (ed. Schöll - Kroll, S. 796, 4-20).

(6) Lateinische Novelle Justins II. vom 1. März 570 über Fragen des Kolonats in Afrika (ed. Zachariae, S. 13-14).

(7) Lateinische Novelle Tiberius' II. vom 11. August 582 über Fragen des Kolonats in Afrika (ed. Zachariae, S. 30-31).

Dazu ausführlich Kaiser, Die Epitome Iuliani (o. Fn. 2), S. 347-354 (Appendix A), 354-374 (Appendix B); s. bereits auch Biener (o. Fn. 9), S. 240-241, 604-607. So nach der Benennung bei Hänel, Iuliani epitome (o. Fn. 7), S. 178, 192.

Die Appendix A überliefern die Hss. Paris BN lat. 4568 ff. 166r-179v (die Novelle des Tiberius befindet sich zu Beginn der Handschrift auf f. 1v-2r), Mailand Archivio storico Trivulziano 688, ff. 220v-246r, Leipzig UB Hänel 8+9 pp. 199a-225a sowie in Auszügen die Capitula legis Romanae, s. dazu Kaiser, Die Epitome Iuliani (o. Fn. 2), S. 15, 24-25, 28-29, 113, 503. Zu den Handschriften s. unten Fn. 67. 
Die Appendix B, die fünf Handschriften vollständig überliefern ${ }^{58}$, umfaßt:

(1) Lateinische Epitome der Novelle vom 1. Mai 556 über die Bestellung von Stellvertretern durch Magistrate etc. (ed. Hänel, S. 192-196).

(2) Lateinische Novelle Justinians vom 15. Juni 535 über Darlehen an Bauern (Coll. CLXVIII Novv. 34; ed. Schöll - Kroll, S. 241, 1-28).

(3) Summe der lateinischen Novelle Justinians vom 23. März 538 (Coll. CLXVIII Novv. 65) über die Veräußerungen von Vermögensgegenständen, die der Kirche Mysiens zum Gefangenenfreikauf hinterlassen wurden (ed. Hänel, S. 82 im Apparat bei Ep. Iul. Cap. 203).

(4) Lateinische Novelle Justinians vom 1. November 541 über die Unterschrift des Quästors bei kaiserlichen iussiones (Coll. CLXVIII Novv. 114; ed. Schöll - Kroll, S. 533, 1-19).

(5) Lateinische Novelle Justinians vom 21. Mai 563 über die Entführung von Jungfrauen, Witwen und Ehefrauen in der Ausfertigung an Areobindus (Coll. CLXVIII Novv. 143; ed. Schöll - Kroll, S. 707, 1-708, 19).

(6) Undatiertes lateinisches Reskript Justinians über Teilleistungen auf verzinsliche Darlehen (Coll. CLXVIII Novv. 138; ed. Schöll - Kroll, S. 700, 1-10 sowie ed. Hänel, S. 197).

(7) Lateinische Summe der Novelle vom 15. April 535 (Coll. CLXVIII Novv. 121) zur Begrenzung der Zinshöhe (ed. Hänel, S. 196-197).

In der Hs. Leipzig UB Hänel $8+9$ schließen sich hieran weitere Novellen Justinians und Exzerpte aus dem siebten Buch des Codex Iustinianus an ${ }^{59}$ :

(8) Lateinische Novelle Justinians vom 6. August 552 über den Kolonat in Afrika (ed. Schöll - Kroll S. 799, 1-9).

(9) Lateinische Novelle Justinians vom 22. September 558 über den Kolonat in Afrika (ed. Schöll - Kroll, S. 803, 25-44); wohl nur ein Ausschnitt.

(10) Lateinisches Kata poda des ersten Satzes der Praefatio sowie eines Teil von Cap. $2 \S 3$ der Novelle Justinians vom 1. Mai 538 über das Inkrafttreten kaiserlicher Konstitutionen (Coll. CLXVIII Novv. 66; ed. Conrat, BIDR 11 [1898], S. 23-24).

(11) Zwölf Konstitutionen aus den Titeln 2, 4, 7 und 10 des siebten Buches des Codex Iustinianus.

So die Hss. Berlin Staatsbibl. lat. fol. 269 ff. 149v-155v, Leipzig UB Hänel 8+9 pp. 171b183b, Vercelli Bibl. Cap. CXXII ff. 153v-159r, Leipzig UB Hänel 6 ff. 63r-65r, Wien ÖNB 2160 ff. 142r-145v, s. dazu Kaiser, Die Epitome Iuliani (o. Fn. 2), S. 16, 53-54, 109-111, 126-127, 147-148. Zu den Handschriften s. unten Fn. 67.

Hs. Leipzig, UB Hänel 8+9 pp. 183-192, s. Kaiser, Die Epitome Iuliani (o. Fn. 2), S. 17-18, 111. 
Den übrigen vier Handschriften sind folgende Erweiterungen gemeinsam ${ }^{60}$ :

(8) Domini Iuliani antecessoris dictatum de consiliariis (ed. Hänel, S. 198-201) ${ }^{61}$.

(9) Collectio domini Iuliani antecessoris (ed. Hänel, S. 201-202).

(10) Constitutio Quam iam videor (fehlt in der Hs. Berlin Staatsbibl. lat. fol. 269) und im Anschluß daran ein lateinisches Kata poda der Novelle Justinians vom 1. Mai 556 über die Bestellung von Stellvertretern durch Magistrate etc. (Coll. CLXVIII Novv. 134; ed. Schöll Kroll, S. 676, 14-689, 29).

(11) Lateinisches Kata poda von Praefatio - Caput 2 patris testimonium der Novelle Justinians vom 18. Dezember 542 über verschiedene familienrechtliche Fragen (Coll. CLXVIII Novv. 117; ed. Schöll - Kroll, S. 551, 5-553, 16).

Zwei Handschriften überliefern zudem im Anschluß ${ }^{62}$ :

(12) Paratitla zur Epitome Iuliani (ed. Hänel, S. 202-208; ed. Liebs).

(13) Unvollständig erhaltene lateinische Novelle Justinians zugunsten der Schuldner in Italien und Sizilien (ed. Schöll - Kroll, S. 803, 1-23).

Die Anhänge sind noch in der Spätantike zur Epitome hinzugekommen, zum Teil wohl noch im Osten ${ }^{63}$.

\section{Die Epitome Iuliani im Westen}

$\mathrm{Zu}$ einem nicht mehr näher bestimmbaren Zeitpunkt gelangten Handschriften der Epitome Iuliani (mit jeweils verschiedenen Anhängen) nach Italien, wohl durch

Hss. Berlin Staatsbibl. lat. fol. 269 ff. 155v/17-156r/7, 191r/17-200v/7, Vercelli Bibl. Cap. CXXII f. 159va/1-26 (nur die ersten drei Sätze des Dictatum de consiliariis), Leipzig UB Hänel 6 ff. 65r/25-67v/35, Wien ÖNB ff. 145va/24-154va/8, s. genauer Kaiser, Die Epitome Iuliani (o. Fn. 2), S. 16-17, 54-55, 148-149, 156-157. (... constitutione relatas). Hierauf folgt die Lex Dei. Der Rest des Dictatum de consiliariis sowie die darauf folgenden Stücke fehlen. Auch in der Hs. Berlin Staatsbibl. lat. fol. 269 ist die Lex Dei an dieser Stelle eingeschoben, doch sind der Rest des Dictatum sowie die übrigen Stücke nach dem Ende der Lex Dei vorhanden, s. dazu Kaiser, Die Epitome Iuliani (o. Fn. 2), S. 167-171. Hss. Leipzig UB Hänel 6, ff. 68r/1-71v/28, Wien ÖNB 2160 ff. 154va/9-162va/29, s. dazu Kaiser, Die Epitome Iuliani (o. Fn. 2), S. 17, 149, 157.

S. Kaiser, Die Epitome Iuliani (o. Fn. 2), S. 353-354 (zur Appendix A), 361 (Appendix B). Für die Erweiterungen in der Hs. Leipzig UB Hänel 8+9 ist der Entstehungsort offen, s. Kaiser, S. 374; die letzte Erweiterung der Appendix B in den Hss. Leipzig UB Hänel 6 und Wien ÖNB 2160 könnte auch erst im Westen erfolgt sein, s. Kaiser, S. 381. 
Studenten ${ }^{64}$. Eine Sammlung von Kapiteln aus der Epitome, die das Kirchenvermögensrecht betreffen (Constitutiones de rebus ecclesiasticis) dürfte noch in der Spätantike im Westen entstanden $\operatorname{sein}^{65}$. Die Vorlagen zu Capp. 5-9 der (sogenannten) Sacra privilegia concilii Vizaceni, deren neuntes Kapitel sich aus Ep. Iul. Capp. 1011 zusammensetzt, dürften aus dem spätantiken Italien stammen ${ }^{66}$.

\section{Die Epitome Iuliani im westlichen Frühmittelalter}

Die Epitome Iuliani bildete im frühen Mittelalter die maßgebliche Quelle für die Kenntnis der justinianischen Novellen, die insbesondere wegen der kirchenrechtlichen Regelungen von besonderem Interesse waren. Sie ist noch in elf Handschriften bezeugt, die vom siebten bis in das 11 . Jhd. reichen ${ }^{67}$. Handschriften der Epitome Iuliani waren in Gallien sowie in Italien verbreitet, wohl aber nicht in Rätien ${ }^{68}$.

Die normative Geltung der Sammlung stand außer Frage: Die Epitome galt als authentischer Text der Novellen Justinians. Der Name Julians war zwar in den Handschriften (jedenfalls der Textgruppe D) teilweise erhalten, jedoch wurde das Werk nicht nach dem Verfasser zitiert. Vielmehr firmierte die Epitome unter den Bezeichnungen novella ${ }^{69}$, lex Iustiniani ${ }^{70}$ oder lex Iustiniana ${ }^{71}$, liber novellarum $^{72}$,

Zur verbreiteten, aber unrichtigen Auffassung, es handle sich um eine speziell für den Westen angefertigte Übersetzung, s. unten S. 351.

S. dazu Kaiser, Die Epitome Iuliani (o. Fn. 2), S. 419-453 sowie ders., Authentizität und Geltung (o. Fn. 2), S. 456-466.

S. dazu Kaiser, Authentizität und Geltung (o. Fn. 2), S. 445.

67 S. die (chronologische) Aufstellung bei Kaiser, Die Epitome Iuliani (o. Fn. 2), S. 12-13: Hss. Skt. Gallen Stiftsbibl.1395 pp. 394-409 (Oberitalien?, s. VII-VIII), Paris BNlat. 4568 (Oberitalien, s. VIII-IX), Mailand Archivio storico civile Trivulziano 688 (Novara, s. VIII-IX), Paris BN lat. 4418 (Hofschule Ludwig des Frommen, s. IX ${ }^{1 / 4}$ ), Leipzig UB Hänel 8+9 (Verona, s. IX ${ }^{1 / 3}$ und s. IX med.), Berlin Staatsbibliothek lat. fol. 269 (Burgund, s. IX ${ }^{1 / 4}$ ), Wien ÖNB 2160 (Oberitalien, vielleicht auch Gegend von Rom; s. IX ${ }^{3 / 4}$ ), Guttaring Pfarrarchiv s. n. (Oberitalien, s. IX ${ }^{3 / 4}$ ), Vercelli Bibl. Cap. CXXII (umbro-römisch, s. Xex. vel s. XI.1), Leipzig UB Hänel 6 (Süditalien, s. XI). Hinzuzufügen ist noch die Hs. Karlsruhe Badische Landesbibl. Fragm. Aug. 145 aus dem neunten Jahrhundert, s. dazu Kaiser, Authentizität und Geltung (o. Fn. 2), S. 445 Fn. 15; zur Hs. Leipzig UB Hänel 8+9 s. Kaiser, Authentizität und Geltung (o. Fn. 2), S. 7-13; vgl. auch die Nachweise bei Radding-Ciaralli (o. Fn. 22), S. 275277 (Handschriftenregister) sowie den Nachtrag S. 353.

Zu Italien und Gallien s. die vorangehende Fn., zu Rätien Kaiser, Authentizität und Geltung (o. Fn. 2), S. 445.

69 So in dem Explicit am Ende der Hs. Mailand, Bibl. Trivulz. 688, s. Kaiser, Die Epitome Iuliani (Fn. 2), S. 29. Als novella Iustiniani bezeichnet die Epitome auch eine Vorrede zu einer apokryphen Konstitution der Kaiser Theodosius II. und Valentinian III. an den PPO Albinus, s. dazu näher Kaiser, Die Epitome Iuliani (o. Fn. 2), S. 712 sowie ders., Authentizität und Geltung (o. Fn. 2), S. 255, 270 (dort S. 201-350 zu der apokryphen Konstitution).

So in einer Seitenüberschrift der Hs. Vercelli Bibl. Cap. CXXII sowie bei den Epitomeexzerpten in der Collectio in IX libris, s. Kaiser, Die Epitome Iuliani (Fn. 2), S. 132, 620. 
liber legum novellarum ${ }^{73}$ bzw. liber novellarum legis Romanae ${ }^{74}$, novella legum Romanorum, novella Romanae legis bzw. lex novella Romanorum ${ }^{75}$.

Die frühmittelalterlichen Handschriften enthalten zumeist nur die Epitome ${ }^{76}$; eine Ausnahme bildet die Sammelhandschrift Hs. Paris BN lat. 4418, die römisches Recht (Epitome Iuliani und Epitome Aegidii) sowie verschiedene Stammesrechte vereint ${ }^{77}$.

Handschriften mit der Appendix A scheinen nicht über das Frühmittelalter bzw. frühmittelalterliche Sammlungen hinaus zu reichen ${ }^{78}$. Auf dem Konzil zu Pavia a. 1022 wurde ein Exemplar der Epitome Iuliani mit der Appendix A herangezogen, da die Konstitution Justinians an den PPO Illyriae Domnicus zitiert ist ${ }^{79}$. Der Humanist Louis Roussard besaß eine ,alte“ Handschrift der Epitome mit der Appendix A, die heute verloren is ${ }^{80}$.

Eine frühmittelalterliche Besonderheit war die Verbindung der Lex Dei mit der Epitome, die noch drei Handschriften unmittelbar bezeugen ${ }^{81}$. Die Lex Dei kam in zwei der Handschriften hinter dem dritten Satz des Dictatum de consiliariis zu stehen $^{82}$. Handschriften der Epitome dienten auch als "Auffangbecken" für weitere

71 So in den Seitenüberschriften zur Epitome Iuliani in der Hs. Paris, Bn lat. 4418 sowie bei den Exzerpten aus der Epitome in der Sammlung der Hs. Rom, Bibl. Vallic. T. XVIII, s. Kaiser, Die Epitome Iuliani (Fn. 2), S. 33, 617.

So im Explicit der Handschrift Wien ÖNB 2160, in den Capitula legis Romanae und den Regulae ecclesiasticae, s. Kaiser, Die Epitome Iuliani (Fn. 2), S. 149, 505 mit Fn. 81, 539. So in den Capitula legis Romanae und den Regulae ecclesiasticae, s. Kaiser, Die Epitome Iuliani (Fn. 2), S. S. 505 mit Fn. 81, 539. So in den Capitula legis Romanae, s. Kaiser, Die Epitome Iuliani (Fn. 2), S. 505 mit Fn. 81. So in den Capitula legis Romanae, s. Kaiser, Die Epitome Iuliani (Fn. 2), S. 505 mit Fn. 81. S. die Handschriftenbeschreibungen bei Kaiser, Die Epitome Iuliani (o. Fn. 2), S. 22-171 sowie bei Hänel, Iuliani epitome (o. Fn. 7), p. I-XII. S. die Beschreibung der Handschrift bei KAISER, Die Epitome Iuliani (o. Fn. 2), S. 31-32: Epitome Aegidii, Epitome Iuliani, Lex Ribuaria, Lex Salica, Lex Burgundionum, Lex Romana Burgundionum, Lex Visigothorum. S. die Hss. Paris BN lat. 4568, Mailand Bibl. Trivulz. 688 (jeweils oben Fn. 67). Eine Handschrift mit der Appendix A wurde für die Capitula legis Romanae verwendet, die im neunten Jahrhundert in Oberitalien entstanden sind, s. dazu Kaiser, Die Epitome Iuliani (o. Fn. 2), S. 581-588. Exzerpte aus der Appendix A begegnen auch in der Collectio Gaudenziana, s. Kaiser, S. 709-713.

S. dazu bereits F. C. von Savigny, Geschichte des römischen Rechts im Mittelalter, Bd. 2, 1. Aufl., Heidelberg 1816, S. 271, 2. Aufl., Heidelberg 1834, S. 284-286. Das Konzil ist abgedruckt bei J. D. Mansi, Sacrorum conciliorum nova collectio, Bd. 19 (1774), Sp. 343-354, zur Konstitution s. Sp. 350 D (Legant denique - et necessitatem). Dazu unten S. 324-325.

81 So die Hss. Berlin Staatsbibl. lat. fol. 269, Vercelli Bibl. Cap. CXXII sowie Wien ÖNB 2160. Auch für die Collectio in V libris wurde eine Epitomehandschrift mit Lex Dei herangezogen, s. Kaiser, Die Epitome Iuliani (o. Fn. 2), S. 102, 631 sowie den Nachtrag S. 353.

S. zu den möglichen Gründen Kaiser, Die Epitome Iuliani (o. Fn. 2), S. 170. 
Rechtstexte, die teils in den Text inseriert, teils auf freien Blättern am Ende nachgetragen wurden ${ }^{83}$. Die Appendix A wurde im Frühmittelalter bearbeitet ${ }^{84}$.

Bereits im neunten Jahrhundert setzt die Ausdünnung der Epitomehandschriften um "überflüssige" Kapitel (insbesondere diejenigen, die spätantike Verwaltungseinrichtungen betreffen) ein ${ }^{85}$. Das früheste Beispiel bilden die Korrektoren der Hs. Berlin Staatsbibl. lat. fol. $269^{86}$.

Sowohl weltliche wie kirchliche Autoritäten zogen die Epitome Iuliani heran; Exzerpte fanden vielfach in Sammlungen Eingang ${ }^{87}$. Die Provenienz der Kapitel wurde dabei teilweise angegeben ${ }^{88}$, teilweise fehlen aber auch Angaben zur Herkunft ${ }^{89}$.

\section{Konkurrenz durch das Authenticum: Die Epitome Iuliani im Hochmittelalter}

Während das Frühmittelalter die Geltung der Epitome nicht hinterfragte, geriet das Werk im Hochmittelalter ${ }^{90}$ mit der Entdeckung eines vollständigen lateinischen Novellentextes, dem Authenticum ${ }^{91}$, in eine Legitimationskrise.

\section{Zur Gestalt hochmittelalterlicher Handschriften der Epitome Iuliani}

Die hochmittelalterliche Überlieferung der Epitome ${ }^{92}$ reicht - nach den derzeitigen Datierungsvorschlägen - bis in das 14. Jahrhundert ${ }^{93}$. Auch jetzt begegnen noch

S. dazu die Übersicht bei Kaiser, Die Epitome Iuliani (o. Fn. 2), S. 18-19 sowie die Beschreibungen der Hss. Leipzig UB Hänel 8+9, Vercelli Bibl. Cap. CXXII sowie Leipzig UB Hänel 6.

S. Kaiser, Die Epitome Iuliani (o. Fn. 2), S. 351-353.

S. dazu bereits Biener (o. Fn. 9), S. 239 und unten S. 320 für das Hochmittelalter.

S. Kaiser, Die Epitome Iuliani (o. Fn. 2), S. 75-78.

Die Aufzählung würde hier den Rahmen sprengen, s. nur die umfassende Zusammenstellung bei Hänel, Iuliani epitome (o. Fn. 7), p. XLII-XLV; Hänel vermerkt im Testimonienapparat seiner Edition zu den einzelnen Kapiteln, in welchen Sammlungen sie zu finden sind. Zu den Capitula legis Romanae (Lex Romana canonice compta), den Regulae ecclesiasticae (Excerpta Bobiensia), der Collectio Anselmo dedicata, den Capitula ex lege Iustiniana sowie dem Klagenfurter Fragment und der Collectio Gaudenziana (die beiden letzten noch nicht bei Hänel verzeichnet) s. das dritte Kapitel in Kaiser, Die Epitome Iuliani (o. Fn. 2). So etwa in den Capitula legis Romanae und den Regulae ecclesiasticae, s. Kaiser, Die Epitome Iuliani (o. Fn. 2), S. 505, 539.

So etwa im Klagenfurter Fragment sowie in der Collectio Gaudenziana, s. Kaiser, Die Epitome Iuliani (o. Fn. 2), S. 652, 738.

S. dazu Hänel, Iuliani epitome (o. Fn. 7), p. XLV-XLVI; grundlegend Savigny, Geschichte, Bd. 3 (o. Fn. 9), 1. Aufl., S. 453-466 sowie 2. Aufl., S. 490-504; Biener (o. Fn. 9), S. 232242, 301-303.

Zum Authenticum s. an neuerer Literatur nur Scheltema, Subseciva XI: Das Authenticum, in: Opera minora (o. Fn. 10), S. 133-137; Liebs (o. Fn. 2), S. 266-269; H. Lange, Römisches Recht im Mittelalter, Bd. 1: Die Glossatoren, München 1997, S. 82-85 (ohne Berücksichtigung der Arbeiten Scheltemas). 
separate Handschriften der Epitome Iuliani ${ }^{94}$. Oft ist die Sammlung aber mit anderen Rechtsbüchern kombiniert. So bildet sie einen Teil des Volumen ${ }^{95}$ oder ist mit der Lombarda verbunden ${ }^{96}$. In der Hs. Köln Historisches Archiv W. 328 folgt sie auf die Institutionen ${ }^{97}$. Albericus de Rosate berichtet, sein Exemplar der Epitome Iuliani sei mit dem Authenticum verbunden ${ }^{98}$.

Spuren der Appendix A scheinen die hochmittelalterlichen Handschriften nicht mehr aufzuweisen. Hingegen hat sich die Appendix B in unterschiedlichem Umfang erhalten. Die häufigste Textfolge bildet: Summe der Novelle vom 1. Mai 556 (Coll. CLXVIII Novv. 134), Novelle vom 23. März 538 (Nov. 34), Novelle vom 21. Mai 563 (Nov. 143) ${ }^{99}$. Das Ende der Epitome mit Nov. 143 (aus der Appendix B) scheint verbreitet gewesen zu sein, denn Albericus de Rosate nennt diese Novelle ausdrück-

S. dazu die Zusammenstellung bei Hänel, Iuliani epitome (o. Fn. 7), p. XII-XVIII.

Hänel, Iuliani epitome (o. Fn. 7), p. XII-XX zählt folgende Handschriften auf (Datierung soweit nicht anders vermerkt nach G. Dolezalek-H. van der Wouw, Verzeichnis der Handschriften zum römischen Recht bis 1600, Bd. 1 und Bd. 2, Frankfurt a. M. 1972; Reihenfolge nach Hänel): Hs. Köln Historisches Archiv, W. 328 (antea W. X. 8) (s. XIex./XII); s. den Nachtrag S. 353, Paris BN lat. 4714 (s. XII), Paris BN lat. 4566 (s. XIIIex.), Oxford Oriel College 22 (antea A. 2. 7) (Volumen; s. XII), Turin Bibl. naz. J. IV. 27 (antea h. VI. 24) (s. XIVex.; 1904 verbrannt), Tours, Bibl. munic. 665 (s. XIV; 1940 verbrannt), Troyes Bibl. munic. 1171 (s. XIV/XV; aus dem Besitz von P. Pithou), Berlin Staatsbibl. lat. fol. 271 (s. XIV; aus dem Besitz von P. Pithou), Leipzig UB Hänel 7 (s. XIII), Paris BN lat. 4713 (s. XII), Madrid Bibl. nac. 629 (antea D. 23) (s. XIIIex.; aus dem Besitz von A. Agustín). - Es wäre nötig, die referierten Datierungen nach modernen Maßstäben zu überprüfen.

So die Hss. Paris BN lat. 4714, Paris BN lat. 4566, Turin Bibl. naz. J. IV. 27, Troyes Bibl. munic. 1171, Paris BN lat. 4713.

So die Hs. Oxford Oriel College 22: Die Epitome folgt auf das Authenticum, s. Hänel, Iuliani epitome (o. Fn. 7), p. XIV. Zu einem Volumen zusammengestellt wurden verschiedene Handschriften in der Hs. Berlin Staatsbibl. lat. fol. 271, s. Hänel, Iuliani epitome (o. Fn. 7), p. XVI. Die Epitome kann aber in der Vorlage mit dem Authenticum verbunden gewesen sein, s. Hänel aaO.

6 Die Lombarda folgt auf die Epitome Iuliani in den Hss. Paris BN lat. 4566 (Hänel, p. XIII), Tours Bibl. munic. 665 (vgl. Hänel, Iuliani epitome [o. Fn. 7], p. XV; die Handschrift ist 1940 verbrannt). Die Hs. Leipzig UB Hänel 7 scheint einmal eine Lombarda nebst den Konstitutionen Friedrichs II. enthalten zu haben, s. Hänel, p. XVIII.

S. Hänel, Iuliani epitome (o. Fn. 7), p. XII sowie den Nachtrag S. 353.

S. dazu sogleich S. 314. Vielleicht handelte es sich auch um ein Volumen.

S. die Hss. Köln Historisches Archiv W. 328: Summe Nov. 134 Capp. 19-21, Novv. 34, 143 (Hänel, Iuliani epitome [o. Fn. 7], p. XIII), Paris BN lat. 4714: Novv. 34, 143, 114 (Hänel, p. XIII), Paris BN lat. 4566: Summe Nov. 134, Novv. 34, 143 (Hänel, p. XIV), Oxford Oriel College 22: Summe Nov. 134, Capp. 7, 12-21, Novv. 34, 143 (Hänel, p. XIV), Turin Bibl. naz. J. IV. 27: Summe Nov. 134, Novv. 34, 143, Tours Bibl. munic. 665: Nov. 34 (HÄNEL, p. XV), Troyes Bibl. munic. 1171: Novv. 34, 143 (vor Nov. 34 aber Textausfall), Leipzig UB Hänel 7: Summe Nov. 134 Capp. 2 ff., Nov. 143 (Hänel, p. XVII; diese Handschrift endet aber mit der Const. quam iam videor, wie ansonsten nur die Handschriften mit der Appendix A), Hs. Paris BN lat. 4713: Summe Nov. 134 Capp. 3 ff., Novv. 34, 143 (Hänel, p. XVIII; auch hier endet die Epitome mit der Const. quam iam videor). - Ein Verzeichnis der Anhänge bietet bereits Biener (o. Fn. 9), S. 604-607 (zum Teil aber unrichtig, s. nur zur Hs. Paris BN lat. 4566). 
lich das Ende des liber novellarum ${ }^{100}$. Vereinzelt sind noch die Summe der Novelle vom 23. März 535 (Nov. 65) sowie die Novelle vom 1. November 541 (Nov. 114) erhalten ${ }^{101}$. Die Hs. Turin Bibl. naz. J. IV. 27 scheint von späterer Hand einen Ausschnitt aus dem Dictatum de consiliariis zu besitzen ${ }^{102}$. Eine - heute verlorene Handschrift des Alciat dürfte noch das undatierte Reskript über Teilleistungen auf Darlehen (Nov. 138) und die lateinische Summe der Novelle vom 15. April 535 (Nov. 121) enthalten haben ${ }^{103}$, eine (ebenfalls verlorene) Handschrift des Contius jedenfalls die lateinische Kurzfassung der Novelle vom 15. April 535 (Nov. 121) ${ }^{104}$.

2. Das Verhältnis der Epitome Iuliani zum Authenticum. Zugleich zur Kenntnis der Epitome Iuliani bei den Glossatoren

Mit der Heranziehung des Authenticum stellte sich die Frage nach dem Verhältnis der beiden Novellensammlungen. Konnte die Epitome Iuliani neben dem "Volltext" der Novellen überhaupt noch Geltung beanspruchen? Und wenn ja, in welchem Verhältnis stehen die beiden Texte zueinander? Die erste Frage diskutiert ausführlich Albericus de Rosate $\left(*\right.$ ca. $1290, \dagger 1360^{105}$ ) bei Const. Cordi $\S 4^{106}$. Albericus erörtert, ob das Authenticum wirklich von Justinian herrührt ${ }^{107}$ und kommt danach zu der Frage, ob der liber novellarum, d. h., die Epitome Iuliani, überhaupt zum ius civile $\mathrm{zu}$ rechnen ist ${ }^{108}$ :

S. Albericus, Commentarii in primam Codicis partem, zu C. 1, 14, 12 (am Ende): ... pro hac opinione Io. optime facit in novellis de rap. mulie. in prin. qui est ultimus titulus novellarum, \& in Auth. eo. tit. in prin. \& de adop. l. impuberum in ff. ... Benutzt wurde die Ausgabe: Albericus de Rosate, Commentarii in Codicis primam partem, Venedig 1586 (Nachdruck: Bologna 1979); dort f. 54ra/28.

S. die Hs. Madrid Bibl. nac. 629: Summa Nov. 134, Novv. 34, 65, 143 (Hänel, p. XVIII); Hs. Paris BN lat. 4417: Summe Nov. 134, Novv. 34, 114 (s. Paris 4417 f. 58r/27-v/12: Nostre serenitatis sollicitudo - faciat pervenire notitiam; die Mitteilung von G. Heimbach, die Hänel, Iuliani epitome [o. Fn. 7], p. XIII referiert, trifft also zu). Nov. 114 steht in der Appendix B an sich vor Nov. 143. So jedenfalls Hänel, Iuliani epitome (o. Fn. 7), p. XV. Dies legt das Vorhandensein beider Texte in der Edition der Epitome durch A. Agustín (a. 1567) nahe, s. dazu unten S. 321. Dies zeigt ein Verweis des Contius auf eine eigene Handschrift bei Nov. 121 in einem erstmals 1571 erschienenen Novellenindex, s. dazu unten S. 324. Zur Person s. nur F. C. von Savigny, Geschichte des römischen Rechts im Mittelalter, Bd. 6, 2. Aufl., Heidelberg 1850, S. 126-136.

S. Commentarii in Codicis primam partem (o. Fn. 100), f. 6rb-vb.

S. die Zusammenstellung der einschlägigen Stellen bei Biener (o. Fn. 9), S. 607-610.

S. Commentarii in Codicis primam partem (o. Fn. 100), f. 6va (gegen Ende). Auf die Stelle scheint erstmals Philipp Friedrich Weis, Historiae novellarum literariae particula prima periodum antehaloandrinam complexa, Marburg 1800, S. 38 (non vidi) aufmerksam zu machen, s. Biener (o. Fn. 9), S. 303 Fn. 42 (mit Wiederabdruck nach Karl Friedrich Wenck, Magister Vacarius primus iuris Romani in Anglia professor, Leipzig 1820, S. 132). Den Beleg erwähnt 
Sed de libro novellarum magis dubitatur, utrum sit liber iuris civilis, et quidam habent coniunctum cum Authentico, et ita ego habeo, communiter tamen non bene reperitur. Et quod sit liber $<$ non $>109$ approbatus, nec allegandus in causis, tenet patenter $<\mathrm{R}>$ of (fredus) ${ }^{110}$ in libello de bono. posses. contra tabu. quae datur patri, avo, seu proavo, secunda colum., versicul. septimo. cuius contrarium videtur Azo sentire in princip. summae Authen. et Ac(cursius) multoties in gl(osis) suis ipsum librum novellarum allegat. Item quaedam contenta in ipso libro novellarum sunt canonizata in decretis, ut patet 2 q. 7 c. si hereticus XXX quaestione ultima si quis alias est $\S$ sub c(anone) nec illud. Dominus etiam Odof(redus) hic tenet, quod sit liber approbatus. Sed esto, quod sit liber approbatus, adhuc dubium est, utrum fuerit compositum post librum Authe(nticorum) aut ante. Odofredus hic videtur tenere, quod factus fuerit post Aut(henticum) et quod praefationes positae in libro Authen(ticorum) decise sunt in libro novellarum. Idem videtur sentire Azo in dicto principio summae Authent(ici) et ita vidi teneri communiter. In quibusdam tamen scripturis antiquorum doctorum, inveni quod liber novellarum primo compositus fuit, et postea fuit correctus per librum Authenticorum, et ideo fuit appellatus lib(er) Aut(henticorum) quia magis Authenticus quam ille, et magis completus, et hoc satis videtur posse colligi ex isto, $\S$ dum dicit, quod si contingat eum facere librum novum, quod appellabit eum librum novellarum, ideo videtur liber novellarum primo compositus.

Nach Albericus war umstritten, ob die Epitome normative Kraft besaß oder nicht (magis dubitatur). Roffredus Beneventanus, ein Zeitgenosse des Azo ${ }^{111}$, hält sie für nicht allegierbar. In seinem Libellus de bonorum possessione contra tabulas, quae patri, avo et proavo datur ${ }^{112}$ bezeichnet Roffredus die novellae (Epitome Iuliani) als liber non authenticus und mißt deren Verständnis der Novelle vom 1. März 536 (Auth. 18) keine Bedeutung bei ${ }^{113}$. Als gegenteilige Meinung referiert Albericus die Summa Authentici des Azo (* vor 1190, $† 1220)^{114}$. Die Summa wurde im Hochmittelalter Azo zugeschrieben und firmiert in Handschriften und Drucken unter seinem Namen $^{115}$, dürfte aber in Wahrheit von Johannes Bassianus ${ }^{116}$ stammen. Sie ist zu-

auch Hänel, Iuliani epitome (o. Fn. 7), p. XIX Fn. 6; s. dazu auch Kaiser, Die Epitome Iuliani (o. Fn. 2), S. 310.

$\mathrm{Da}$ hier im Druck (oder bereits in dessen handschriftlicher Vorlage) ein non ausgefallen ist, ergibt sich aus dem folgenden nec.

Die Ausgabe Venedig 1586 (o. Fn. 100) besitzt unrichtig Gof(redus).

Zu ihm s. Lange (o. Fn. 91), S. 314-323.

Abgedruckt in: Roffredi Beneventani libelli iuris civilis, libelli iuris canonici, quaestiones Sabbatinae, Nachdruck der Ausgabe Avignon 1500 (Corpus glossatorum iuris civilis 6), Turin 1968 , f. 127vb-128va (S. 254-256).

S. Roffredi Beneventani libelli iuris civilis (wie Fn. 112), f. 128rb, Zeile 6-12: ... hodie intellegas de tertia: quia sicut augmentata est tertia in persona filii que olim fuit quarta ita et in persona patris ut in aut(entico) de triente et se(misse) coll(atione) III in fine I columne licet quidam glosent ibi quod illud quod ibi dicitur hoc observando in omnibus personis qui de inofficioso testamento. restringant tamen ad filios nepotes et pronepotes: non ad fratres nec ad parentes sicut habetur in novellis in e(odem) t(itulo) qui liber autenticus non est. unde durum est...

S. zu Azo nur Lange (o. Fn. 91), S. 255-271.

Benutzt wurde hier der Nachdruck der Ausgabe Pavia 1506: Azonis summa super Codicem. Instituta extraordinaria (Corpus Glossatorum iuris civilis 11), Turin 1966. Die Summa Authentici befindet sich dort auf den S. 455-481 (Seitenzählung nicht in der Ausgabe 1506). 
dem anscheinend nur in einer Bearbeitung des Accursius erhalten ${ }^{117}$. Albericus drückt sich hier vorsichtig aus: Azo scheine anderer Ansicht zu sein ... cuius contrarium videtur Azo sentire in princip(io) summae Authen(tici). Die Summa Authentici erwähnt zu Beginn ein weiteres Rechtsbuch, das ebenfalls liber novellarum geheiBen habe, weshalb man die zweite Novellensammlung in "Authenticum" umbenannt habe $^{118}$. Die Summa selbst zitiert die Epitome jedoch öfter" ${ }^{119}$.

Auch andere (voraccursische) Glossatoren wußten um die Epitome Iuliani. Irnerius dürfte die Epitome gekannt haben, ihre Heranziehung bei der Abfassung der Authentiken ist aber unwahrscheinlich ${ }^{120}$. Placentinus $(\dagger 1192)$ erörtert zwar in der Summa Codicis das Verhältnis von liber novellarum und Authenticum bei der Const. Cordi nicht ${ }^{121}$, er zitiert aber die Epitome Iuliani gelegentlich ${ }^{122}$. Hugolinus ${ }^{123}$ benutzte wohl die Epitome für seine Vorlesungen über den Codex ${ }^{124}$. Azo spricht in der Summa Codicis bei der Const. Cordi von einem liber novellarum, den Justinian geschaffen habe, freilich ohne dessen Verhältnis zum Authenticum zu problematisieren $^{125}$. Zu C. 1,5 allegiert er die Epitome, allerdings kann er hier aus Placentin

Geburts- und Sterbejahr sind nicht bekannt; Johannes Bassianus lebte in der zweiten Hälfte des 12. Jhds., s. nur Lange (o. Fn. 91), S. 215-226.

S. dazu Lange (o. Fn. 91), S. 264-265, 220-221, 342.

S. die Summa Authentici (o. Fn. 115), S. 455-465: Liber iste quem domino donante lecturi sumus dudum liber novellarum dicebatur eo quod in eo comprehenditur omne id novum quod varia rerum natura creavit et nova negotia que ante huius librum confectionem minime fuerant laqueis iuris innodata in huius libri corpore clauduntur [es folgen Allegationen]. Verum tamen quia et alius liber est hoc nomine vocatus qui tractat similem expositionem huius postea placuit ut ad eius differentiam huius libri nomen mutaretur ut autenticum vel autent(?) seu liber autenticorum nominaretur eo quod pre ceteris legum libris auctorizabilis habeatur ...

S. die Nachweise bei Hänel, Iuliani epitome (o. Fn. 7), p. XLV Fn. 127; hieraus als Beispiel zu Novelle 4 (De monachis) (im Nachdruck der Ausgabe Pavia 1506 [o. Fn. 115], S. 459b, Z. 37): ... et semper interrogatur ab abbate et monachis ut dicitur in novellis, que cause impulerunt eum ad hanc compunctionem ... (Ep. Iul. Cap. 19).

S. dazu Hänel, Iuliani epitome (o. Fn. 7), p. XLVI Fn. 130 (Mitte; gegen die These von Biener).

S. das Prooemium zur Summa Codicis, in: Placentini Summa Codicis, accessit Proemium quod in Moguntia editione desiderabatur, Turin 1962, p. XV (Nachdruck der Ausgabe Mainz 1536).

S. Hänel, Iuliani epitome (o. Fn. 7), p. XLV Fn. 127 sowie S. 71 zu Ep. Iul. Cap. 173; s. Summa Codicis (o. Fn. 115) zu C. 1, 5 (S. 11): ... sed forte hodie (sicut in novellis legitur) nullus haereticus in nullo casu: nisi ubi curialis revocatur, contra catholicum admittitur (Ep. Iul. Cap. 173).

Zu ihm s. nur Lange (o. Fn. 91), S. 271-273.

Dies ergibt sich aus einem Bericht des Odofredus zur Authentike Nisi rogati nach C. 6, 49, 6 (ad SC Trebellianum) in seiner Lectura super Codice II (f. 79ra/24): Or signori, dominus Hug(olinus) extraxit etiam prolixius: quia ivit ad librum novellarum et sicut ibi invenit, ita scribsit etiam hic; vgl. Hänel, Iuliani epitome (o. Fn. 7), p. XLII. Die Erläuterungen des Hugolinus zum Codex sind anscheinend noch nicht erschlossen, s. Lange (o. Fn. 91), S. 275.

S. Summa super Codicem (o. Fn. 115), S. 2 zur Const. Cordi (am Ende): Si autem aliquid fuerit necessarium scribi in speciali libro novellarum nomine assignabitur. Welche Novellensammlung hiermit gemeint ist, bleibt offen. 
schöpfen ${ }^{126}$. Voraccursische Glossen zum Authenticum ziehen die Epitome Iuliani heran $^{127}$.

Nach Albericus führt Accursius $\left(\dagger 1263^{128}\right.$ ) den liber novellarum multoties an. Dies trifft auch zu: So hat Biener in der Glossa ordinaria 54 Allegate der Epitome gezählt, die sich zum Codex und zum Authenticum finden ${ }^{129}$.

Die Epitome fand zwar keinen Eingang in das Bologneser Lehrprogramm ${ }^{130}$, glossierte Handschriften der Epitome sind jedoch vorhanden ${ }^{131}$. Die Statuten der Universität von Bologna überliefern eine Taxliste für juristische Bücher, die aus dem Jahre 1326 stammen dürfte ${ }^{132}$. Dort ist auch die Epitome Iuliani zu finden, s. [Nr. 65] Liber novellarum in textu ..., [77] Apparatus super libro novellarum ... Mit dem Liber novellarum ist die Epitome Iuliani gemeint ${ }^{133}$.

Das Verhältnis von Epitome und Authenticum - sofern man die Epitome überhaupt als zitierfähig ansah - zeigt die Lectura super Codicem des Odofredus $(\dagger$ $1265)^{134}$, auf die Albericus im Fortgang verweist: Odofredus geht bei der Besprechung der Const. Cordi von einem Nebeneinander von Authenticum und liber novellarum aus, die sich gegenseitig ergänzen. Odofredus wendet sich gegen die anfäng-

S. Summa super Codicem (o. Fn. 115) zu C. 1, 5 (S. 6b, 2. Zeile von unten): Quidam tamen dicunt in novellis haberi quod non licet heretico ferre testimonium contra orthodoxum nisi ubi curialis revocetur ad curiam (Ep. Iul. Cap. 173); zur Benutzung von Placentinus für den Codexkommentar des Azo s. Lange (o. Fn. 91), S. 265.

So etwa in der Hs. Paris BN lat. 4429, einem Volumen (nach Dolezalek-van der Wouw [o. Fn. 93]: s. XIII). Allegate der Epitome teilt hieraus bereits Savigny mit, s. Geschichte, Bd. 3 (o. Fn. 9), 1. Aufl., S. 460 Fn. 1, 2. Aufl., S. 498 Fn. e); zu der Handschrift s. Heimbach, Authenticum (o. Fn. 43), p. XLII-XLVI (zu den Glossen p. XLV-XLVI).

Zu seinem Leben s. Lange (o. Fn. 91), S. 335-342.

S. Biener (o. Fn. 9), S. 301 Fn. 35; Biener weist allerdings die Belege nicht nach; viele Beispiele aber bei Hänel, Iuliani epitome (o. Fn. 7), p. XLV Fn. 128.

S. bereits Savigny, Geschichte (o. Fn. 9), Bd. 3, 2. Aufl., S. 495; Biener (o. Fn. 9), S. 291.

Einige Glossen hat Hänel bekanntgemacht, s. Hänel, Iuliani epitome (o. Fn. 7), S. 219-225 (aus den Hss. Paris BN lat. 4566, Leipzig UB Hänel 7, Madrid Bibl. nac. 629).

S. zu dieser Taxliste, ihrer Überlieferung und Datierung ausführlich P. Soetermeer, Utrumque ius in peciis: Die Produktion juristischer Bücher an italienischen und französischen Universitäten des 13. und 14. Jahrhunderts. Aus dem Niederländischen übersetzt von G. Hillner, Frankfurt am Main 2002, S. 393-434 mit Neuedition S. 398-403 (hiernach wird zitiert). Die Taxliste ist bereits publiziert durch Savigny, Geschichte, Bd. 3 (o. Fn. 9), 1. Aufl., S. 600606, 2. Aufl., S. 649-654.

S. bereits Savigny, Geschichte, Bd. 3 (o. Fn. 9), 1. Aufl., S. 457-458, 2. Aufl., S. 495-496; Hänel, Iuliani epitome (o. Fn. 7), p. XLVI; Soetermeer (o. Fn. 132), S. 416, 417 (der Glossenapparat ist sonst nicht weiter bekannt).

Hier wurde benutzt: Odofredi iuris utriusque peritissimi dicaearchi, in primam Codicis partem ... sowie Odofredi iuris utriusque peritissimi dicaearchi, in secundam Codicis partem ..., jeweils Lyon 1552 in dem Nachdruck: D. Maffei-E. Cortese-G. Rossi (Hgg.), Opera iuridica rariora 5, 1: Odofredus, Lectura super Codice I und 5, 2: Odofredus, Lectura super Codice II, Bologna 1968. 
liche Meinung des Irnerius, das Authenticum sei kein justinianischer Rechtstext ${ }^{135}$ und fährt fort:

... hic dixit Iustinianus quod si que questiones supervenirent faciet librum Aut(henticorum) sive novellarum. unde apparet, quod liber Aut(henticorum) est authenticus liber et a Justiniano factus quia hic Iustinianus fecit mentionem de libro Aut(henticorum) sive novellarum. et nota quod liber Authenticorum et novellarum sunt idem quo ad quid: quia tota medulla est in utroque sed differunt quia arenge et praefationes que posite sunt in Aut(hentico) sunt decise per librum novellarum. unde si aliquis vult scire librum Aut(henticorum) debet habere librum novellarum, et in eo studere quia eundem textum ponit, sicut Aut(henticum) et ideo potius legimus Aut(henticum) quia quicquid est in libro novellarum, est in libro Aut(henticorum). sed in Aut(hentico) sunt multa alia notabilia et multa pulchra verba, que non sunt in libro novellarum: quia ibi ponuntur solum modo decisiones. Nec obstat quod liber Aut(henticorum) non habet similem modum seu stilum ut alii libri legales quia Iustinianus imperator bene potest tenere unum modum in uno libro et alium modum in alio libro ...

Dementsprechend legt Odofredus den liber novellarum zum besseren Verständnis der Authentike sed et si quis zu C. 5, 9, 3 zugrunde zug $^{136}$.

Auch der handschriftliche Befund zeigt die enge Verbindung von Epitome und Authenticum. So besitzen manche der hochmittelalterlichen Handschriften der Epitome die Kollationenzählung des Authenticum ${ }^{137}$. Umgekehrt sind in einigen Handschriften des Authenticum die Rubriken der Epitome beigeschrieben ${ }^{138}$.

Auch die Kanonisten waren hinsichtlich der Allegierbarkeit der Epitome unterschiedlicher Meinung. Während Huguccio $(* 1140, \dagger 1210)$ die Epitome für nicht zitierfähig hält ${ }^{139}$, reiht sie Hostiensis (* ca. 1194, † 1271) ohne Weiteres unter die Quellen des römischen Rechts ein ${ }^{140}$. Das Vorhandensein von Epitomekapiteln in kanonistischen Werken hebt bereits Albericus hervor: Quaedam sunt canonizata in decretis ... Albericus nennt als Beispiel Decretum Gratiani C. 30, qu. 5, can. 8. Hier

S. Odofredus, Lectura super Codice I (o. Fn. 134) zur Const. Cordi, f. 4vb (ca. Mitte). Eine Zusammenstellung einschlägiger Bemerkungen der Glossatoren zu dieser Frage bietet Biener (o. Fn. 9), S. 607-610.

S. Odofredus, Lectura super Codice I (o. Fn. 134), f. 270rb: SED ET SI QUIS Hec auth(entica) habet plures lecturas, que potius sunt abusiones: tamen premittam vobis veriorem lecturam, que colligitur in libro novellarum: et s(ecundum) ea exponam litteram ... Gemeint ist Ep. Iul. Cap. 142.

So die Hss. Oxford Oriel College 22 und Paris BN lat. 4566, s. Hänel, Iuliani epitome (o. Fn. 7), p. XIV (zu beiden Hss.), XLVI.

S. die Angaben bei Hänel, Iuliani epitome (o. Fn. 7), p. XLVI Fn. 130, mit einem Verzeichnis von Marginalrubriken in Handschriften des Authenticum auf der Grundlage von Heimbach, Authenticum (o. Fn. 43), p. DIII-DXVIII.

139 S. dazu unten S. 319.

140 S. Summa Domini Henrici Cardinalis Hostiensis, Lyon 1537 (Nachdruck Aalen 1962), f. $2 \mathrm{vb} / 7$ : Et ut breviter comprehendam in quinquaginta libris pandectarum. III institutionum: duodecim codicis: novem collationibus authenticorum: novella lombarda: et consti(tutionibus) feu(dorum) constitit legalis sapientia. - Die Summa des Hostiensis entstand um die Mitte des 13. Jhds.; zur Summe s. nur F. Soetermeer, Summa archiepiscopi alias Summa copiosa ..., in: A Ennio Cortese, Bd. 3, Rom 2001, S. 280-298. 
wird bei der Problematik der matrimonia clandestina ein Kapitel der Epitome Iuliani zitiert (Ep. Iul. Cap. 244), nach dem der Ehewille für eine gültige Ehe ausreicht. Auch an anderen Stellen begegnet die Epitome Iuliani im Dekret ${ }^{141}$.

Schon Albericus bemerkt, daß die Epitome nicht leicht zu finden ist ${ }^{142}$. Die Auffassung, daß die Epitome gegenüber dem Authenticum zurückzutreten hat und nicht zitierfähig ist, hat sich anscheinend im vierzehnten Jahrhundert durchgesetzt. Die Postglossatoren scheinen sie nur dem Namen nach zu kennen ${ }^{143}$.

\section{Zitierweise und Wissen um den Verfasser}

Die hochmittelalterlichen Handschriften der Epitome Iuliani bewahren teilweise noch das Incipit, das Julian als Verfasser der Sammlung angibt ${ }^{144}$, teilweise fehlt es $\operatorname{aber}^{145}$. Die Glossatoren allegieren - entsprechend der frühmittelalterlichen Tradition - die Epitome als liber novellarum oder als novellae. Namentlich erwähnt Julian anscheinend nur der Kanonist Huguccio $\left(* 1140, \uparrow 1210^{146}\right)$, der bei Decretum Gratiani, C. 11, qu. 1, can. 38 zu den Worten Novellarum (ed. Friedberg, Sp. 63) bemerkt ${ }^{147}$ : id est Autenticorum. Novella dicitur quoddam opus, quod dicitur esse factum a Juliano apostata et monacho, et non est autenticatum: de hac novella non dicitur hic. Der Benennung als apostata et monachus zeigt die Gleichsetzung Julians mit dem Kaiser Julian. So bezeichnet etwa die Legenda aurea (ca. 1263-1269) Kaiser Julian als monachus und apostata ${ }^{148}$.

141

142

143

144

Zusammenstellungen finden sich bereits bei den Humanisten, so etwa Agustín (unten Fn. $345)$.

S. oben S. 315: ... communiter tamen non bene reperitur. Allerdings scheinen noch einige Handschriften der Epitome dem 14. Jhd. anzugehören, s. oben Fn. 93.

S. Savigny, Geschichte, Bd. 3 (o. Fn. 9), 2. Aufl., S. 496; Biener (o. Fn. 9), S. 303. - Die Frage wäre erneut zu untersuchen.

So die Hss. Troyes Bibl. munic. 1171 (Hänel, Iuliani epitome [o. Fn. 7], p. XV), Leipzig UB Hänel 6 (Hänel, p. XVII; hier wird Iulian als censor civitatis Constantinopolitanae bezeichnet), Hs. Madrid Bibl. nac. 629 (Hänel, p. XVIII). In der Hs. Paris BN lat. 4713 erscheint das Incipit als „Explicit“, s. Hänel, p. XVIII.

S. Hänel, Iuliani epitome (o. Fn. 7), p. XII zur Hs. Köln Historisches Archiv W. 328, p. XIII zur Hs. Paris BN lat. 4714, p. XIV zur Hs. Paris BN lat. 4566, p. XIV zur Hs. Oxford Oriel College 22, p. XIV zur Hs. Turin Bibl. naz. J. IV. 27, p. XV zur Hs. Tours Bibl. munic. 665, wohl auch in der Hs. Berlin Staatsbibl. lat. fol. 271, vgl. Hänel, p. XVI, p. XVIII zur Hs. Paris BN lat. 4713.

Zu ihm s. W. Müller, Huguccio. The Life, Works and Thought of a Twelfth-Century Jurist (Studies in Medieval and Early Modern Canon Law, 3), Washington D. C. 1994.

Die Angabe basiert auf Savigny, Geschichte, Bd. 3 (o. Fn. 9), 2. Aufl., S. 496 Fn. e); danach auch Hänel, Iuliani epitome (o. Fn. 7), p. XLI.

S. nur Legenda aurea, Cap. 30: ... Fuit et alius Iulianus, non quidem sanctus, sed sceleratissimus, scilicet Iulianus apostata. Hic Iulianus prius fuit monachus, et magnae religionis simulator, hier zitiert nach J. Larmat, Julien dans les textes du moyen âge, in: R. Braun-J. Richer (Hgg.), L'empereur Julien, Bd. 1: De l'histoire à la légende (331-1715), Paris 1978, S. 268-294, 287. 
Accursius zitiert die Kapitel der Epitome als tituli ${ }^{149}$, wie dies bereits im Frühmittelalter und auch später gelegentlich der Fall ist ${ }^{150}$. Noch die Edition der Epitome Iuliani durch die Gebrüder Senneton a. 1550 nennt die Kapitel tituli (s. dazu unten S. 341).

Die hochmittelalterlichen Handschriften der Epitome verfügen nicht mehr über den ursprünglichen Kapitelbestand, "überflüssige" Kapitel fehlen ${ }^{151}$. Der Ausfall zahlreicher Kapitel hatte anscheinend das Verschwinden der Konstitutionen- und Kapitelzählung zur Folge. Auch den Kapitelrubriken scheint keine besondere Bedeutung mehr beigemessen worden zu sein: Sie fehlen häufig. Subskriptionen werden - wie beim Codex Iustinianus - nicht mehr abgeschrieben ${ }^{152}$. Den geschilderten Befund spiegeln noch die frühen Drucke der Epitome wider ${ }^{153}$.

IV. Die Wiedergewinnung des Textes und das neue Verständnis der Epitome im 16. Jhd.

Das Interesse der Humanisten an den justinianischen Novellen erstreckte sich auch auf die Epitome Iuliani, deren "elegantes" Latein man dem "barbarischen" des Authenticum gegenüberstellte. Die Beschäftigung mit den griechischen Novellen ${ }^{154}$ führte zu der Erkenntnis, daß es sich bei der Epitome Iuliani um eine Übersetzung handelt. In den Jahren 1538 bis 1576 wurde der Text vollständig zurückgewonnen und ein Wissensstand über das Werk und seinen Verfasser erreicht, der bis zum Beginn des 19. Jhd. maßgeblich blieb.

S. nur die Beispiele bei Hänel, Iuliani epitome (o. Fn. 7), p. XLV Fn. 128.

So zitieren die Regulae ecclesisticae (Excerpta Bobiensia), die im neunten Jahrhundert wohl in der Lombardei entstanden, die Kapitel als tituli, ebenso auch ein Teil der Epitomeexzerpte in der Collectio in V libris, s. dazu Kaiser, Die Epitome Iuliani (o. Fn. 2), S. 539, 635.

S. dazu bereits oben S. 310 zum Frühmittelalter. Hänel, Iuliani epitome (o. Fn. 7), p. XIIXVIII verzeichnet bei den Codices tertiae classis jeweils die fehlenden Kapitel; zudem gibt er eine Überblick zu den Capita omissa auf S. 266*-268* seiner Edition; eine entsprechende Übersicht findet sich auch bei C. G. Mor, Una forma ,abbreviata“ dell'Epitome Juliani, in: Scritti di storia giuridica altomedievale, Pisa 1977, S. 241-267.

Vgl. jeweils die Bemerkungen bei Hänel, Iuliani epitome (o. Fn. 7), p. XII-XX zu den einzelnen Handschriften.

S. dazu unten S. 340-341.

S. zu der Auseinandersetzung der Humanisten mit dem Codex und den Novellen nur die Darstellung bei H. Troje, Graeca leguntur. Die Aneignung des byzantinischen Rechts und die Entstehung eines humanistischen Corpus iuris civilis in der Jurisprudenz des 16. Jahrhunderts, Köln - Wien 1971, S. 50-73 sowie ders., Die Literatur des gemeinen Rechts unter dem Einfluß des Humanismus, in: H. Coing (Hg.), Handbuch der Quellen und Literatur der neueren europäischen Privatrechtsgeschichte, Bd. 2, 1. Teilband, München 1977, S. 615-795, 645-656. 


\section{Handschriften der Humanisten}

Viele Humanisten verfügten über Handschriften der Epitome Iuliani. Die meisten dieser Manuskripte sind heute verloren, gelegentlich läßt sich aber ihr Aussehen in Umrissen aus den Angaben in Vorreden von Editionen oder aus Briefen rekonstruieren.

Bereits Andrea Alciati (Andreas Alciatus; * 1492, † 1550) besaß eine Handschrift der Epitome. Das Manuskript ist heute verloren, jedoch erlaubt die Korrespondenz von Antonio Agustín (Antonius Augustinus; $* 1517,+1586^{155}$ ), der eine Abschrift erhalten hatte ${ }^{156}$, Rückschlüsse auf ihr Aussehen. So liefert Jean Matal (Johannes Metellus; * ca. 1517, $† 1597)^{157}$ in einem Brief an Agustín vom 25. 121543 (aus Ferrara $)^{158}$ eine knappe Beschreibung der Handschrift, zudem berichtet Agustín in einem Brief an Don Diego Hurtado de Mendoza ${ }^{159}$ vom 1. August 1544 (aus Bologna) über sie ${ }^{160}$. Die Handschrift (in littera Longobardica) war in zwei Bücher geteilt, besaß ein vollständiges Incipit, war aber am Ende wegen Blattausfalls unvollständig (in welchem Umfang, ist unbekannt) ${ }^{161}$. Anscheinend war aber die Appendix B (teilweise?) vorhanden, denn Agustín bietet in seiner Ausgabe erstmalig das undatierte Reskript Justinians über Teilleistungen auf verzinsliche Darlehen (Nov. 138) sowie die lateinische Kurzfassung der Novelle vom 15. April 535 (Nov. 121) ${ }^{162}$. Kapitelzählung sowie Kapitelrubriken waren vorhanden ${ }^{163}$. Agustín bezeichnet die

Zu ihm s. nur F. Maassen, Geschichte der Quellen und der Litteratur des canonischen Rechts im Abendlande, Bd. 1, Graz 1870 (Nachdruck Graz 1956), p. XIX-XXXIV; J. F. von Schulte, Die Geschichte der Quellen und Literatur des canonischen Rechts, Bd. 3, 1: Von der Mitte des 16. Jahrhunderts bis zur Gegenwart, Stuttgart 1875 (Nachdruck Graz 1956), S. 723-728 sowie P. Landau, Art. Antonio Agustín, in: M. Stolleis (Hg.): Juristen: Ein biographisches Lexikon; von der Antike bis zum 20. Jahrhundert, 2. Aufl., München 2001, S. 21-23. S. dazu unten S. 326. $\mathrm{Zu}$ ihm s. nur P. Heuser, Jean Matal: Humanistischer Jurist und europäischer Friedensdenker (um 1517-1597), Köln-Weimar-Wien 2003.

S. zu dem Brief bereits Haubold (o. Fn. 9), S. 149 Fn. 14. Der Brief ist abgedruckt bei Juan Andrés (Johannes Andresius), Antonii Augustini Epistolae Latine et Italicae, nunc primo editae, Parma, 1804, Nr. 87 (S. 180-182) sowie bei C. Flores Sellés, Epistolario de Antonio Agustín, Salamanca 1980, Nr. 131 (S. 177-178).

Fn. 157), S. 71-72.

Ediert bei Andrés (o. Fn. 158), Nr. 7 (S. 11-26), Flores Sellés (o. Fn. 158), Nr. 137 (S. 184192). Den Brief erwähnt bereits Haubold (o. Fn. 9), S. 149 Fn. 14.

S. aus dem Brief Matals an Agustín (o. Fn. 158), ed Andrés (o. Fn. 158), S. 180-181, ed. Flores Sellés (o. Fn. 158), S. 177: Novellarum Iustiniani compendium ostendit [Alciati] mihi manu Longobardica ante multos annos descriptum, edito, si ei credis, longe locupletius. Desunt in extremo aliquot pagellae, vel potius, ut mihi videtur, multi codicilli. Nam primum etsi liber est integer, secundus, non enim plures in hoc leguntur, paucioribus paginis constat, quarum postrema sententiam non absolvit. Inscriptio eadem libri cum ea quam tu a me habes, nisi qui illic auctor deest, hic Juliano adscribitur, quamvis attrita fere \& minio scripta. S. dazu Biener (o. Fn. 9), S. 392.

163 S. aus dem Brief Agustíns an Mendoza (o. Fn. 160), ed. Andrés (o. Fn. 158), S. 22, ed. Flores Sellés (o. Fn. 158), S. 189: ... cum vero illis deficimur, Juliani Epitomen, quam ex Alciati nostri libro habuimus, in qua non solum singula capita separantur, sed \& tituli quidam breves 
Handschrift als einen pervetus liber ${ }^{164}$. Alciati benutzte die Handschrift anscheinend auch selbst: So bemerkt Agustín in seinen Paratitla zur Epitome Iuliani ${ }^{165}$, Alciati habe das Zitat von Ep. Iul. Capp. 488-489 im Decretum Gratiani für unrichtig gehalten, da in seiner Handschrift diese und weitere Kapitel fehlten ${ }^{166}$.

Aus dem Besitz von Aymar de Ranconet (Aemilius Ranconetus; * 1498, † $1559^{167}$ ) stammt die Hs. Paris BN lat. 4568 (Oberitalien, s. VIIIex.), die Louis Le Mire seiner Edition 1561 zugrundelegte ${ }^{168}$. Die Identifizierung dieser Handschrift gelang F. C. von Savigny ${ }^{169}$. Ranconet scheint die Handschrift nicht verwertet zu haben. Nach seinem Tod gelangte die Handschrift in die königliche Bibliothek, dort hatte P. Pithou Zugang zu ihr ${ }^{170}$.

Jacques Cujas (Jacobus Cuiacius; $* 1522, \dagger 1586)^{171}$ gehörten zwei Handschriften der Epitome, beide sind anscheinend verloren ${ }^{172}$. Rückschlüsse auf ihr Aussehen erlaubt die Vorrede von Louis Le Mire zu seiner Ausgabe der Epitome (a. 1561).

ipsis partibus inscripti sunt, quos nos non praetermisimus. Et sane a Graecis ita hae Constitutiones referri solent, ut Novellae \& capitis numeris significetur, quod ut a nobis usurpetur, vehementer probaverim ...

S. die Vorrede: Ad nostras manus venerunt ... And. Alciati pervetus liber, et alter Pallantinae ecclesiae Hispaniensis minus vetustus ... Zu der Edition s. unten S. 336-337.

S. zu den Paratitla unten S. 336 mit Fn. 281.

S. das Paratitlon zu Nov. 123: c. 59 \& 60) Refert Grat. d. quaest. 3 cap. ult. [Decr. Grat. Causa 19, quaest. 3, cap. 10] In libro veteri Iuliani And. Alciati haec capita deerant, sed non sola. Id occasionem ei dedit negandi, Iustinianum ea conscripsisse, quae Gratianus affirmaverat; vgl. Hänel, Iuliani epitome (o. Fn. 7), p. XIX. Ep. Iul. Capp. 488-489 entsprechen Coll. CLXVIII Novv. 123, 41.

S. zu ihm nur A. Tardif, Histoire des sources du droit français. Origines romaines, Paris 1890 (Nachdruck Aalen 1974), S. 474.

S. dazu unten S. 333.

S. die Mitteilung von Savignys bei Haubold (o. Fn. 9), S. 138 Fn. 11.

Vgl. Hänel, Iuliani epitome (o. Fn. 7), p. II. Dies zeigt die Bemerkung Pithous in der Hs. Berlin Staatsbibl. lat. fol. 269 f. 149v am unteren Rand, die sich auf Ep. Iul. Cap. 564, das letzte Kapitel der Epitome, bezieht: In Vet(eri) Cod(ice) qui fuit Aymari Ranconeti nu(nc) est regis, sequitur Const. CXXVII. Quam iam videor conscripisisse in regia civitate in eadem constitutione finiunt Novellae constitutiones quae post Codicem divini nominis Iustiniani promulgatae sunt Expliciunt constitutiones secundum capitula superius designata; sodann in einer neuen Zeile: Vicarius Asianae Frigia in duas dividitur provincias. Es handelt sich um das Ende der Epitome und den Beginn der Paragraphae in der Hs. Paris BN lat. $4568 \mathrm{ff}$. 165v/20-166r/1. - Aus der Edition von Le Mire (a. 1561; unten Fn. 259) konnte Pithou die Angaben in dieser Form nicht schöpfen, da Miraeus das Explicit (in eadem constitutione designata) nicht abdruckt, s. Hänel, Iuliani epitome (o. Fn. 7), p. XXIV.

S. zu ihm nur E. Spangenberg, Jakob Cujas und seine Zeitgenossen, Leipzig 1822 (Nachdruck Frankfurt a. M. 1967) sowie die Nachweise bei K. Stapelfeldt, Art. Cujas, in: G. Kleinheyer J. Schröder, Europäische Juristen, 4. Aufl., Heidelberg 1996, S. 102-105.

S. Haubold (o. Fn. 9), S. 150-151; Hänel, Iuliani epitome (o. Fn. 7), p. XIX. Die Vermutung von Biener (o. Fn. 9), S. 386, die Hs. Paris BN lat. 4566 könnte das Exemplar des Cujas gewesen sein, basiert auf unrichtigen Voraussetzungen. Biener geht davon aus, daß in der Handschrift die Kurzfassung der Novelle vom 23. März 538 (Appendix B; Coll. CLXVIII Novv. 65) vorhanden ist, was jedoch nicht zutrifft, s. Hänel, Iuliani epitome (o. Fn. 7), p. XIV. 
Cujas hatte Le Mire die beiden Manuskripte geliehen ${ }^{173}$. Die Handschriften verfügten nicht über eine Appendix A; eine von beiden (oder beide?) jedoch über eine Appendix B, die noch bis zur Novelle vom 1. Mai 563 (Coll. CLXVIII Novv. 143) reichte ${ }^{174}$. Eines der beiden Julianmanuskripte hatte Cujas bereits früher Antoine Le Conte überlassen ${ }^{175}$. Cujas erhielt auch Zugang zu Handschriften anderer Humanisten. So gab er im Jahre 1559 erstmals die Konstitution Justins II. vom 1. März 570 über die Ehen von Freien und Kolonen in Nordafrika heraus ${ }^{176}$, die (nur) die Appendix A zur Epitome Iuliani überliefert ${ }^{177}$. Zudem erwähnt er die Konstitution Justinians vom 7. April 540 an den PPO Illyrici Domnicus, die auch nur dort erhalten ist. Deren Text könne er aber nicht mitteilen, da er unvollständig und zudem korrumpiert sei ${ }^{178}$. Den Fundort nennt er nicht. Da seine beiden Handschriften ausscheiden, könnte als Quelle die Handschrift Roussards in Betracht kommen ${ }^{179}$. Zudem konnte Cujas die Hs. Berlin Staatsbibl. lat. fol. 269, die Pierre Pithou gehörte ${ }^{180}$, benutzen. Denn Cujas ergänzte in der zweiten Auflage der Expositio novellarum (Lyon, a. 1577) zu vier Novellen weiteren Text, der in der ersten Ausgabe der Expositio (Lyon, a. 1570) noch fehlt. Die Ergänzungen sind nur noch in der Hs. Berlin Staatsbibl. lat. fol. 269 erhalten $^{181}$.

Miraeus führt zunächst aus, daß auch das Exemplar Ranconets verschiedene Lücken und Korruptelen aufweise, und fährt fort: Quos [die Fehler] cùm Iacobo Cuiacio antiquitatis felicissimo restauratore indicasssem, is lubenter mihi pro sua singulari, quam in me gerit, benevolentia, multos restituit. Quin \& duo vetusta Iuliani exemplaria manu scripta summa cum alacritate exhibuit ...

Vgl. die Bemerkungen von Le Mire in der Vorrede (unten Fn. 195). Hiernach besaß (nur) die Handschrift Roussards dieselben Anhänge wie die Ranconets; vgl. die Übersicht zu seiner Edition unten S. 334-336. Le Conte dankt Cujas hierfür in der Vorrede zu seiner Ausgabe des Volumen (a. 1559), s. dazu unten Fn. 185.

176 S. Hänel, Iuliani epitome (o. Fn. 7), p. XXV.

177 S. Observationes IV Cap. 28. Die Überschrift lautet: Prolata Iustiniani \& Iustini Constitutiones quendam de condicione eorum, qui ex adscripticio et libera muliere nascuntur: s. sodann im Text: ... Et hoc de re [Status von Kindern aus Ehen Kolonen - Freie] Latinam Iustiniani Constitutionem apud me habeo ad Dominicum praef. praet. Illyrici (ad quam illa quoque posterior Novella) scriptam: quam ut non obtinuisse existimem haec, cuius verba subijicam, Iustini Constitutio facit, qua is quasi in Illyrico adhuc obtinente Novella Iustiniani conscripta anno XIII idem ut in Africa observetur constituit. Verba Constitutionis haec sunt: IMP. CAES. FL. IUSTINUS fidelis in Christo - es folgt die Titulatur - Theodoro Die noctuque es folgt der Text der Konstitution - observare procurent. DAT. KAL. MAI. - weitere Datierung - INDICTIONE TERTIA.

S. Observationes IV Cap. 28 im Anschluß an den Text der vorangehenden Fn.: Apposuissem et ultime Iustiniani constitutionis verba, qua ius antiquum restituit, si proinde atque huius integra \& incorrupta habuissem. Verum eius est sententia manifesta, verba eius mirum in modum corrupta ... Immerhin vermittelte Cujas diese Handschrift an Le Mire, s. dazu unten S. 334.

S. dazu unten S. 326.

S. dazu bereits Biener (o. Fn. 9), S. 409-410, F. Blume, Lex Dei sive Mosaicarum et Romanarum legum collatio, Bonn 1823, p. XVIII-XIX und ausführlich Kaiser, Authentizität und Geltung (o. Fn. 2), S. 22-23. 
Antoine Le Conte (Antonius Contius; $* 1517, \dagger 1586)^{182}$ teilt in der Vorrede zu seiner Ausgabe des Volumens (a. 1559) ${ }^{183}$ mit, daß er eine collatio decima zum Authenticum zusammengestellt habe, die Novellen enthält, die im Authenticum nicht $\mathrm{zu}$ finden sind. Hierunter finden sich auch Konstitutionen aus der Epitome Iuliani ${ }^{184}$, die Le Conte aus einer der Handschriften des Cujas schöpfte, die dieser ihm geliehen hatte ${ }^{185}$. Es handelt sich um Ep. Iul. Const. 26 (Coll. CLXVIII Novv. 35 ) und Const. 56 (Nov. 62) ${ }^{186}$. Anscheinend verfügte Contius später über eine eigene Handschrift des Julian (wohl verloren), die er in der Vorrede zu seiner Ausgabe des Codex aus dem Jahre 1562 erwähnt ${ }^{187}$. Zudem rekurriert er auf sie in den Randbemerkungen zu einem Novellenindex, der erstmals in seiner Corpus iuris-Ausgabe des Jahres 1571 begegnet ${ }^{188}$. Es handelte sich um eine Handschrift mit der Appendix B, die außer der Novelle vom 21. Mai 563 (Coll. CLXVIII Novv. 143) auch noch die Novelle vom 15. April 535 (Coll. CLXVIII Novv. 121) enthielt ${ }^{189}$.

Eine weitere Handschrift der Epitome besaß Louis Roussard (Ludovicus Russardus; $\dagger 1567)^{190}$. Das Manuskript, das er von Jean de Grenet (Iohannes Grenetius), einem regius consiliarius aus Chartres erhalten hatte ${ }^{191}$, ist anscheinend verloren ${ }^{192}$.

S. zu ihm nur Tardif (o. Fn. 167), S. 479 sowie die Nachweise bei Kühlmann-Hartmann-El Kholi (unten Fn. 335), S. 86.

S. dazu ausführlich Biener (o. Fn. 9), S. 373-376; zur Ausgabe (non vidi) s. E. Spangenberg, Einleitung in das roemisch-justinianeische Rechtsbuch oder Corpus Iuris civilis Romani, Hannover 1817 (Nachdruck Aalen 1970), S. 804. Die Vorrede ist hier benutzt nach dem Nachdruck in: Volumen legum, quod parvum vocant ..., Lyon, bei P. Landry, 1612.

S. gegen Ende der Vorrede: ... Quod autem ille Iacobus [de Bellovisu] Extravagantes apellabat, omnes partim ex Haloandro, partim ex Scrimgerio, partim ex Iuliano manuscripto, partim ex meis manuscriptis in Decimam Collationem coacervavi ...

S. die Vorrede des Contius: Iisdem autem temporibus, quibus illa tralatio [das Authenticum] facta est, prodiit et harum constitutionum epitome à Iuliano quodam viro eloquentissimo, antecessore Constantinopolitanae civitatis: Sic enim apellatur in veteri quadam eius epitome manuscripta, quam mihi communicavit aliquando doctissimus antecessor Iacobus Cuiacius. Quae quidem epitome longè purioribus verbis, \& elegantioribus conscripta est quam vetus illa tralatio; vgl. bereits Haubold (o. Fn. 9), S. 150. Auf die Handschrift des Cujas nimmt Le Conte auch in der Decima collatio bei Nov. 62 Bezug, s. Biener (o. Fn. 9), S. 374.

S. Biener (o. Fn. 9), S. 375. Zudem publizierte Le Conte in der Collatio decima erstmalig die Novelle Justinians vom 14. April 535 (Coll. CLXVIII Novv. 11), s. Biener, aaO.

S. Biener (o. Fn. 9), S. 605; zu der Ausgabe (non vidi) Spangenberg, Einleitung (o. Fn. 183), S. 813.

S. Haubold (o. Fn. 9), S. 152; zu der Ausgabe (non vidi) Spangenberg, Einleitung (o. Fn. 183), S. 824. Der Index ist hier benutzt nach dem wortgetreuen Abdruck in: L. Charondas, Authenticae seu Novellae Constitutiones DN. Iustiniani Sacratiss. Principis, Cum veteri tralatione, Graecis nunc primùm Ant. Contij I. C. opera apposita ..., Antwerpen 1575, S. 4-6.

S. die Bemerkung von Le Conte zu Coll. CLXVIII Novv. 143: Epitome Hal. edidit. Extat \& in fine epitomes Iuliani, quam habeo manuscriptam sowie zu Nov. 121: Nam epitomen Iuliani habet editio Augustini, quam in meis libris invenire non potui.

S. zu ihm Tardif (o. Fn. 167), S. 475-476.

S. die Vorrede Roussards zur Collatio decima in seiner Ausgabe der Novellen a. 1561 (unten Fn. 196) nach Haubold (o. Fn. 9), S. 151 Fn. 25: Nactus quoque sum nuper opera Ioannis Grenetii, Carnuntensis Regii Consiliarii, viri docti et insigniter eruditi, librum pervetustum 
Sein Aussehen kann aber aus den Angaben bei Le Mire, dem es für die Edition zur Verfügung stand, erschlossen werden. Die Handschrift, die sowohl er selbst als auch Miraeus als "alt" bezeichnen ${ }^{193}$, verfügte über eine Appendix $\mathrm{A}^{194}$, denn sie glich in den Anhängen der Hs. Paris BN lat. 4568. Außerdem fehlte dort wie in der Hs. Paris BN lat. 4568 ein Incipit zur Epitome ${ }^{195}$. Sie stammte daher vielleicht noch aus dem Frühmittelalter. Roussard benutzte seine Julianhandschrift auch selbst, um in einer Ausgabe der Novellen, die er im Jahre 1561 veranstaltete ${ }^{196}$, fehlende Konstitutionen zu ergänzen ${ }^{197}$.

Möglicherweise war Jean de Tillet (Johannes Tilius; $\dagger 1570)^{198}$ im Besitze einer Handschrift der Epitome Iuliani, denn er verfügte - wie P. Pithou mitteilt - über Bruchstücke der Lex Dei, die bislang nur in Überlieferungseinheit mit der Epitome Iuliani bekannt ist ${ }^{199}$.

Pierre Pithou (Petrus Pithoeus; * 1539, †1596) ${ }^{200}$ gehörten mehrere Handschriften der Epitome Iuliani, die noch erhalten sind: Hss. Berlin Staatsbibl. 1at. fol. 269, Troyes, Bibl. munic. 1171, Berlin Staatsbibl. lat. fol. $271^{201}$. P. Pithou war zudem die Handschrift Ranconets zugänglich ${ }^{202}$. Von besonderer Bedeutung ist die Hs.

Novellarum Iuliani Patritii, ex quo Epitomen nonnullarum Novellarum adhuc desideratarum, subiciendum curavi.

S. Haubold (o. Fn. 9), S. 150-151; Hänel, Iuliani epitome (o. Fn. 7), p. XIX.

S. zu Roussard soeben Fn. 191, s. zu Miraeus die Vorrede der ed. 1561 (unten Fn. 261): nec satis illi [Cujas] fuit sua commodasse, ni etiam apud Ludovicum Russardum virum, ut audio, restituendis bonis auctoribus impense deditum, aliud antiquum impetrandi gratia pararium se mihi praestitisset.

S. bereits Hänel, Iuliani epitome (o. Fn. 7), p. XIX.

S. aus der Vorrede des Miraeus: ... Scholia porro illa, quae proximè sequuntur Iulianum haud omnino aspernanda, ex Ranconeti \& Russardi libris sumpta sunt ... Quae vero deinceps subsequuntur aliquorum Impp. Constitutiones, eas partim in Cuacij, partim in Ranconeti \& Russardi libris reperimus ... Exemplaria verò Ranconeti \& Russardi àveníreàa prorsus erant, neque ullam auctoris nomenclaturam prae se ferebant.

S. den Titel der Ausgabe nach Spangenberg, Einleitung (o. Fn. 183), S. 811 (Nr. 242): Justiniani principis Novellae constitutiones ex Gregorii Haloandri et Henrici Agylaei interpretatione, ad Graecum Scrimgeri exemplar nunc primum editae. Quibus suis locis interseritur, quicquid vetus versio amplius habet, atque proximis editionibus, ex vetustis libris ac Juliani epitome adspersum est ..., Basel 1561; s. ausführlich zu der Ausgabe Biener (o. Fn. 9), S. 376-378.

Es handelt sich nach Biener (o. Fn. 9), S. 378 um Ep. Iul. Const. 56 (Nov. 62), Const. 47 (Nov. 53), Const. 59 (Nov. 65). Zudem begegnet Ep. Iul. Const. 26 (Nov. 35), deren Text aber nach Biener, aaO., unverändert aus Contius übernommen ist.

S. zu ihm Tardif (o. Fn. 167), S. 474-475; D. R. Kelley, Jean du Tillet, Archivist and Antiquary, in: The Journal of Modern History 38 (1966), S. 337-354.

S. dazu Kaiser, Die Epitome Iuliani (o. Fn. 2), S. 96, 101.

S. zu ihm etwa R. Naz, Art. Pithou, Pierre, in: Dictionnaire de droit canonique 6 (1957), Sp. 1505 - 1506; D. R. Kelley, Foundations of Modern Historical Scholarship, New York - London 1970, S. 241-270.

S. Hänel, Iuliani epitome (o. Fn. 7), p. II, XV, XVI. Zu den Handschriften s. oben Fn. 67, 93.

S. oben Fn. 170. 
Berlin Staatsbibl. lat. fol. 269 (Südostfrankreich; s. IXin.) ${ }^{203}$. Aus dieser Handschrift gab P. Pithou 1573 erstmals die Lex Dei ${ }^{204}$ sowie verschiedene weitere Inedita aus den Anhängen zur Epitome Iuliani heraus ${ }^{205}$. Sein Bruder François konnte die Handschrift für die Ausgabe der Epitome Iuliani (a. 1576) benutzen ${ }^{206}$. Auch Cujas konnte die Handschrift konsultieren ${ }^{207}$.

Als letzter Humanist ist Antonio Agustín zu nennen. Im Jahre 1543 stieß Agustín in Venedig in der Bibliothek von Ottonellus Discalcius, einem berühmten Paduaner Rechtsgelehrten $(\dagger 1607)^{208}$, auf eine Handschrift der Epitome Iuliani, die aber nach seinem Urteil stark verderbt war. Er ließ von dem Manuskript eine Abschrift anfertigen (und bot zudem Lelio Torelli eine solche an) ${ }^{209}$. Auch Jean Matal erhielt eine Kopie, für die er sich am 6. Februar 1544 von Ferrara aus bei Agustín bedankte ${ }^{210}$. Diese Abschrift liegt anscheinend noch in der Hs. Escorial d.-II.-3 (ff. 346, 349-

Aus dem Nachlaß Pithous kam die Handschrift in die Bibliothek des Marquis Louis Le Peletier de Rosanbo, aus der sie die Herzogin von Berry nebst anderen Handschriften erwarb. Bei der Versteigerung der Bibliothek der Herzogin von Berry (sogenannte Bibliothèque de Rosny) in Paris konnte G. Hänel im Jahre 1837 unter anderem auch diese Handschrift für die königliche Bibliothek zu Berlin ankaufen. In der Wissenschaft galt die Handschrift lange Zeit als verschollen, s. dazu näher Kaiser, Die Epitome Iuliani (o. Fn. 2), S. 40-41.

Fragmenta quaedam Papiniani, Pauli, Ulpiani, Gaii, Modestini, aliorumque veterum iuris auctorum ex integris ipsorum libris ante Iustiniani imp. tempora collecta et cum Moysis legibus collata ... ex bibliotheca P. Pithoei Jc. cuius etiam notae adiectae sunt, Paris 1573.

S. Fragmenta quaedam Papiniani (o. Fn. 204), S. 55: Undatiertes lateinisches Reskript über die Zinshöhe bei Darlehen (Coll. CLXVIII Novv. 138), S. 56: Lateinische Kurzfassung der Novelle vom 16. April 535 (Coll. CLXVIII Novv. 121), S. 59-63: Dictatum de consiliariis, S. 63-65: Collectio domini Iuliani antecessoris. Die Novv. 138, 121 hatte bereits Agustín veröffentlicht, was P. Pithou aber anscheinend nicht bekannt war (vgl. das Frontispiz der Ausgabe der Lex Dei: ... Omnia nunc primum in lucem edita). Die Stücke druckte F. Pithou in seiner Edition der Epitome (a. 1576) wieder ab.

S. dazu unten S. 338.

S. oben Fn. 181.

S. zu ihm den Art. Discalcius, Ottonellus, in: J. H. Zedler, Grosses vollständiges Universallexikon, Bd. 7 (1734), Sp. 1042.

S. den Brief an Lelio Torelli vom 20. Oktober 1543 (Bologna), ed. Andrés (o. Fn. 158), Nr. 73 (S. 145-148, 147), Flores Sellés (o. Fn. 158), Nr. 129 (S. 174-176, 175): Inventus etiam a nobis est vetus ille Novellarum liber latinus, quem Iulianum patritium(!) scripsisse Alciatus noster auctor est, apud doctum virum Ottonellum Venetiis, quem nunc describendum curamus. Is nisi mendosus maxime esset, non mediocriter ius civile iuvaret. est enim earum legum epitome non inelegans, cuius si cupis, exemplum ad te mittam, quamquam eum librum, cum ceteris quae Haloandro desunt et nostra interpretatione, curabo ut multis exemplis scribantur ... Den Brief erwähnen auch Haubold (o. Fn. 9), S. 151 und Hänel, Iuliani epitome (o. Fn. 7), p. XIX, die aber den Adressaten unrichtig angeben (Matal) und den Fundort nicht nachweisen.

S. den Brief bei Andrés (o. Fn. 158), Nr. 88 (S. 182-183, 182), Flores Sellés (o. Fn. 158), Nr. 132 (S. 178-179, 178): Librum Iuliani Bizantini una cum suavissimis litteris tuis accepi a Petro Torrone Barchinonense: qui liber mihi fuit valde gratus, quod privata studia nostra potest adiuvare; nam ut publica, nisi ad veterem eruditionem nonnihil accedat et industriae et diligentiae, nimium foede corruptus est ... 
383) vor $^{211}$, die wohl auch die Druckvorlage für die Ausgabe der Epitome durch Agustín im Jahre 1567 war. Am 25. Dezember 1543 teilt Matal Agustín das Aussehen der Handschrift Alciats mit ${ }^{212}$. Matal bezieht sich dabei auf das Incipit zu Julian, das Agustín aus einer früheren Mitteilung Matals anscheinend schon anderweitig kannte $^{213}$. In einem Brief vom 1. August 1544 an Jacopo Mendoza ${ }^{214}$ erwähnt Agustín erneut die Handschrift Alciats, von der er nunmehr eine Abschrift (exemplum veteris libri Alciati) besaß, die Matal ihm geschenkt hatte ${ }^{215}$. Unklar ist, ob Agustín in den Besitz der Handschrift Alciats selbst gelangte. In der Vorrede zu seiner Edition gibt er an, zwei Handschriften der Epitome Iuliani herangezogen zu haben, und zwar eine Handschrift Alciats sowie ein Manuskript der ecclesia Pallantina (dazu s. sogleich): Ad nostras manus venerunt praeter hos [die Lyonneser Editionen der Epitome] And. Alciati pervetus liber, et alter Pallantinae ecclesiae codex Hispanensis minus vetustus. Agustín müßte sich die Handschrift nach dem Tod Alciats besorgt haben. Im Fortgang des Briefes schreibt Agustín jedoch: ... Iuliani epitomen, quam ex Alciati nostri liber habuimus ... Die Formulierung ... quam ex ... habuimus ... deutet eher auf eine Abschrift. Auch das Paratitlon Agustíns zu Nov. 123 scheint besser zu einer Abschrift zu passen: Refert Grat. d. quaest. 3 cap. ult. In libro veteri Iuliani And. Alciati haec capita deerant, sed non sola..${ }^{216}$. Immerhin verwendet Agustín hier für einen Textbefund in der Handschrift des Alciat die Vergangenheit (deerant), nicht das Präsens ("desunt"), was nahegelegen hätte, wenn er die Handschrift selbst besaß. Die offene Formulierung ad manus ... venerunt in der Vorrede ließe sich auch so verstehen, daß Agustín die Handschrift Alciats nur via Abschrift zur Verfügung stand. Doch muß es hier bei Vermutungen bleiben.

Weiter bezieht sich Agustín auf eine Handschrift der Kirche von Palencia (ecclesia Pallantina). Von dieser Handschrift hatte Juan de Arze Agustín in einem Brief vom 20. Mai 1546 (aus Palencia) Mitteilung gemacht ${ }^{217}$ : Es handelte sich um ein

S. J.-L. Ferrary, Correspondance de Lelio Torelli avec Antonio Agustín et Jean Matal (1542 1553), Como 1992, S. 35-36, zum Inhalt der Handschrift ebenda S. 253 Fn. 11. Die Hs. El Escorial d-II-3 wurde zweimal kollationiert, einmal nach einer Handschrift Alciats, sowie nach einer Handschrift aus Palencia, s. Ferrary, S. 33-34. Auch Flores Sellés (o. Fn. 158), S. 179 Anm. 2 hält die Identität zumindest für möglich. Nach Hänel, Nachtrag (o. Fn. 9), S. 359 steht in der Handschrift der Apparat Agustíns für seine Ausgabe (nebst einer Abschrift der Hs. Madrid Bibl. nac. 629). S. zu dem Brief oben Fn. 161. Hierauf deutet die Formulierung in dem Brief an Agustín (o. Fn. 161): Inscriptio eadem libri cum ea quam tu a me habes...

S. ed. Andrès (o. Fn. 158), Nr. 7 (S. 11-26), ed. Flores Sellés (o. Fn. 158), Nr. 137 (S. 184191).

215 S. den Brief (o. Fn. 214) ed. Andrés (o. Fn. 158), S. 13, ed. Flores Sellés (o. Fn. 158), S. 185): Per te [Mendoza] etiam isthic Iuliani Epitomen a docto quodam viro optimo causarum patrono, Lugduni conscriptam [ed. Bohier a. 1512] consecuti sumus; quam postea ex Andreae Alciati praeceptoris, veteris libri exemplo (quo nos Jo. Metellus noster donavit) permultis mendis expurgavimus. Vgl. das Wort exemplum oben bei Fn. 209. S. dazu bereits oben Fn. 166.

217 Abdruck des Briefes bei Flores Sellés (o. Fn. 158), Nr. 147 (S. 205-211, 207): ... Adhuc Institutiones D. Iust. Adhuc liber autenticorum: occupatis nobis circa totius reip. curas lib. 
Volumen ${ }^{218}$. Agustín erwartete bereits im Oktober 1546 die Übersendung dieser Handschrift aus Spanien nach Rom ${ }^{219}$.

Agustín besaß zudem noch eine weitere Handschrift der Epitome Iuliani, die Hs. Madrid Bibl. nac. $629^{220}$, die wohl nicht mit der Handschrift aus Palencia identisch ist $^{221}$. In dem frühesten Katalog der Bibliothek von Agustín, der 1586 erschien $^{222}$, ist keine Handschrift der Epitome nachgewiesen ${ }^{223}$.

\section{Editionen der Epitome}

Die früheste Druckausgabe ${ }^{224}$ der Epitome Iuliani besorgte Nicolas Bohier (Nicolaus Boerius/Boherius, * 1469, $† 1539^{225}$ ) im Jahre 1512 in Lyon $^{226}$. Bohier edierte die

XII. Adhuc de iure fisci. Liber feudor. Constitutiones novellae de graeco in latinum versae per Iulianum virum eloquentissimum qui sic incipit: in digestis et in Constitutionibus didicimus etc....

S. den Fortgang des Briefes: Ai otros algunos mas. El principal es aquel del Cardenal [eine Handschrift der Digesten und des Codex, die dem Kardinal Pedro Gonzalez de Mendoza gehörte] y este de las novellas; y si no los ubiesen hurtado y <estu>viesen enprestados creo abria algunos...

S. den Brief vom 9. Oktober 1546 (Rom) an Torelli, Ferrary (o. Fn. 211), S. 197-198 (Nr. 77), 197: ... item Juliani Antecessoris librum, quem iterum Metellus noster hic contulit, et propediem ex Hispania aliud exemplum expecto ...

220 So Hänel, Iuliani epitome (o. Fn. 7), p. XVIII.

221 S. Ferrary (o. Fn. 211), S. 36 Fn. 62: Die Handschrift besitzt nach Ferrary keine handschriftlichen Annotationen Agustíns. Hänel, Iuliani epitome (o. Fn. 7), p. XVIII hält eine Identifizierung mit der Hs. Madrid, Bibl. nac. 629 für möglich. Dagegen spricht aber auch, daß es sich bei der Handschrift aus Palencia um ein Volumen handelt (s. oben Fn. 217), während die Hs. Madrid Bibl. nac. 629 die Epitome Iuliani allein überliefert (aus der Beschreibung bei Hänel geht auch nicht hervor, daß diese Handschrift einmal Bestandteil eines Volumen gewesen sein könnte).

222 Zur Bibliothek Agustíns s. M. Mayer, Towards a History of the Library of Antonio Agustín, in: Journal of the Warburg and Courtauld Institutes 60 (1997), S. 261-272, zum Katalog S. 262. Möglicherweise geht der Katalog noch auf Agustín selbst zurück, s. Mayer, aaO. Der Katalog wurde hier benutzt nach: Antonii Agustini archiepiscopi Tarraconensis opera omnia ..., Bd. 7, Lucca 1772, S. 30-118.

Die pars Latina des Katalogs enthält in dem Abschnitt Ius Caesareum (S. 102-105) justinianisches Recht sowie Werke mittelalterlicher Juristen. Dort sind unter Nr. 369 und 370 zwei Handschriften des Volumen nachgewiesen, unter Nr. 379 eine Handschrift (nur) des Authenticum. Die Epitome ist nirgends gesondert erwähnt.

Zu den Druckausgaben s. Spangenberg, Einleitung (o. Fn. 183), S. 592-594; Haubold (o. Fn. 9), S. 154-185; Biener (o. Fn. 9), S. 317-431 passim und zuletzt Hänel, Iuliani epitome, p. XX-XXXIV. - Die Wiedergabe von Titeln und Überschriften in den Drucken erfolgt hier nicht werkgetreu (buchstabengetreue Werktitel finden sich bei Hänel). Falls ganze Zeilen in Großbuchstaben (meist wiederum der Größe nach abgestuft) gedruckt sind, wird dies hier durch große Anfangsbuchstaben der einzelnen Worte wiedergegeben. Nicht beibehalten ist auch die Schreibweise $v$ für $u$. 
Epitome im Anschluß an die Lombarda. Da diese Verbindung auch in verschiedenen hochmittelalterlichen Handschriften bezeugt ist, wenngleich in umgekehrter Reihenfolge ${ }^{227}$, dürfte die - ungewöhnliche - Kombination auf Bohiers handschriftliche Vorlage zurückgehen. Bohier legte eine - heute verlorene ${ }^{228}$ - hoch- oder spätmittelalterliche Handschrift zugrunde ${ }^{229}$. Die Epitome endet mit Cap. 493 (fisci rationibus compellatur; ed. Hänel, S. 163, 8), daher war die Handschrift (bzw. deren Vorlage) am Ende verstümmelt. Die Edition weist viele Kapitel der Epitome gar nicht auf; auch Umstellungen sind häufig ${ }^{230}$.

Erst 38 Jahre nach Bohier - im Jahre 1550 - erschien eine weitere Ausgabe der Epitome Iuliani bei den Brüdern Jean und Jacques Senneton ${ }^{231}$ in Lyon. Die Epitome ist im Rahmen einer Gesamtausgabe des Corpus iuris ${ }^{232}$ in das Volumen integriert $^{233}$, besitzt aber eine eigene Vorrede ${ }^{234}$. Die Gebrüder Senneton kannten die

225 S. zu Leben und Werk von Bohier nur Tardif (o. Fn. 167), S. 470-471; Schulte (o. Fn. 155), S. 553-554; R. Orestano, Art. Bohier, Nicolaus, in: Novissimo Digesto italiano, 3. Aufl., Bd. 2, Turin 1957, S. 440 s.v.

Leges Longobardorum seu Capitulare divi Carolimagni(!) imperatoris: et francie regis ac novelle constitutiones domini Iustiniani imperatoris cum prefaciuncula et annotationibus in ipsas leges et constitutiones novellas per clarissimum et spectabilem virum dominum Nicolaum boherii I. U. interpretem. sacri regalis constistorii ordinarium consiliarium (videlicet an sint allegabiles ad causarum decisionem et ligent omnes aut solum lombardos) editis nusquam impresse (ohne Druckort und Erscheinungsjahr). Die Epitome Iuliani steht auf den ff. 101160. Zu der Ausgabe s. Haubold (o. Fn. 9), S. 154-155; Hänel, Iuliani epitome (o. Fn. 7), p. XX-XXI sowie kurz Spangenberg, Einleitung (o. Fn. 183), S. 592-593. Hänel druckt die editio princeps als Anhang zu seiner Edition ab (S. $3 *-50 *$; ohne Auszüge aus der Vorrede) und vermerkt jeweils die ,,moderne“ Zählung der dort vorhandenen Kapitel der Epitome. - Benutzte Ausgabe: UB Tübingen, Ha III 215.

S. dazu oben Fn. 96.

228 S. Haubold (o. Fn. 9), S. 149; Hänel, Iuliani epitome (o. Fn. 7), p. XIX.

229 So die Vermutung bei Hänel, Iuliani epitome (o. Fn. 7), p. XXI aufgrund der Abkürzungen in der Edition. Die Glossen, die Bohier mitdruckt, dürften ebenfalls aus der Handschrift stammen, s. Hänel, p. XXI Fn. 14 (mit Wiedergabe der Glossen).

S. zu den fehlenden Kapiteln Haubold (o. Fn. 9), Übersicht nach S. 188 sowie Hänel, Iuliani epitome (o. Fn. 7), p. XXI, zu den Umstellungen ebenda p. XXI Fn. 22.

$\mathrm{Zu}$ Jean und Jacques Senneton s. J. Baudrier, Bibliographie lyonnaise: recherches sur les imprimeurs, libraires, relieurs et fondeurs de lettres de Lyon au seizième siècle, Bd. 7, Lyon 1908, S. 367-448 (S. 367-397 zu den Lebensumständen) sowie die Nachträge bei S. von Gültlingen, Bibliographie des livres imprimés à Lyon au seizième siècle, Bd. 8, Baden - Baden u. a. 2002, S. 180-209.

$232 \mathrm{Zu}$ dieser Corpus iuris-Ausgabe der Gebrüder Senneton s. Spangenberg, Einleitung (o. Fn. 183), S. 786-788.

Avthentica: D. Ivstiniani Imp. Aug. Novellarum Volumen eruditis animadversionibus, adscriptionibusque prętextum: a falsis, ad veras allegationes reductum. non prętermissa lectionum legi dignarum varietate. Denique graphica argumenti effigie in singulis librorum prototitlis, per imaginis emblema, oculis subiecta fidelibus. Adiectus est nunc primum libellus Novellarum D. Iust: è graeca epitome, in latinum compendium uersus. Et partim ex Iámolim excuso, sed imperfecto atque informi: partim ex manu scripto exquisito, eleganti, et copioso exemplari concinnatus, Lyon 1550. Spangenberg, Einleitung (o. Fn. 183), S. 788 gibt als Erscheinungsjahr des Volumen 1549 an. Zu der Ausgabe s. Haubold (o. Fn. 9), S. 155-158; Biener (o. Fn. 9), S. 362-363; Hänel, Iuliani epitome (o. Fn. 7), p. XXII. Die Vorrede teilt 
Edition Bohiers ${ }^{235}$, zogen aber noch zusätzlich eine weitere (wohl ebenfalls spätmittelalterliche) Handschrift heran ${ }^{236}$. In der Handschrift (bzw. deren Vorlage) war das

Haubold (o. Fn. 9), S. 156-158 auszugsweise mit (vollständig unten Fn. 234). Hänel druckt den Text der Gebrüder Senneton (ohne die Vorrede) als Anhang zur Epitome Iuliani ab (S. *51-*100), wiederum unter Bezifferung der Epitomekapitel nach der heutigen Zählung. Benutzte Ausgabe: UB Tübingen, Ha I 19.

S. die Vorrede auf der Rückseite des Frontispizes (unter dem Privilegium regis vom 12. September 1548): In Authentica, Et Novellas Proparalexis. Authenticas Constitutiones, Quae ab Augustiss. ipsius imperatoris principali autoritate denominationem sumpserunt: ut quas ipse sola tituli inscriptione per indubitatam assertionem, maximè ratas esse voluit: ex suisque

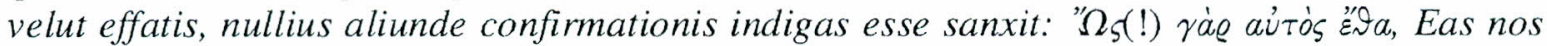

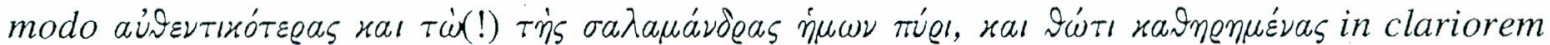
solis, hominum, oculorum, animorum, ac iudiciorum lucem emittimus. Tum etiam illis tanquam eodem argumento conformes NOVELLAS D. Iust. Imp. Constitutiones, pro corollario curavimus adijciendas. quas ex Graeca oratione, in latinum sermonem Iámolim verterat Constantiensis quidam haud ineruditus, sed nominis sui dissimulans, interpres. Verum adeo truncas, \& imperfectas, ut earum bona pars multis locis à veteribus allegata Doctoribus desideratur. Nos igitur non lacerum \& mancum, sed integrum, membrisque omnibus absolutum iuris corpus proferre conati: diligentissima undecumque investigatione tandem perfecimus, ut Novellarum vetustissimum exemplar in pergamena membranarum charta manu conscriptum invenerimus: inventum contulerimus cum vulgato, \& excuso: sed longe imperfectissimo libello. Atque ita unius lacunas, ex alterius plenitudine explevimus: \& in altero luculentam, nec satis propriam dictionis formam, pura ex altero elegantia eluimus: adeoque perfectum opus concinnasse videmur: \& supremo iuridici corporis vertici, perinde ac columnae firmiter constitutae epistylium, non temere, nec sine ratione superimposuisse. Praesertim cùm Imperator ipse Iustinianus in praefatione tituli tertij C. libro primo ad Senatum urbis Constantinopolitanae, conqueratur, \& non ferat Novellas constitutiones à corpore sui Codicis avulsas divulgari. Quamquam (ni nos iudicii fallit) videtur libellus hic, nihil aliud esse quam Epitome Authenticorum, à Graecis primum in Compendium coacta, \& et mox à cive quodam Constantiensi latinè transcripta. Adeo plaerique loci, tituli, argumenta, ordo, \& collationum numerus pariter conveniunt, paucis mutatis, superfluis resectis, nonnullis etiam fortasse omissis, quae ut aliquando inventum iri non desperamus, ita in illis conquirendis quod nostra, nostrorumque diligentia perficere potuit, certè praestitimus. Porro nè quis parvam esse Novellarum autoritatem putet: is intelligat ex iuris peritissimo Haloandro eas ab ipso Imperatore confirmatas fuisse in futurum in tertia constitutione, quae praefationis loco, repetitae Codicis praelectioni praescripta est. Item Azonem testimonia producere ex Novellis in collationes collectis. ipsaque Novellas in usu habitas fuisse ante annos plus tercentum, ut si non omnes: attamen plaerasque. Item Accursium Collationes illas Authenticorum multis in locis perobscuras, ex Novellarum contextu illustrare solitum, easque passim á Doctoribus adduci in testimonium. Ex quarum inopia nonnulli foede sunt lapsi. Ut qui in l. non plures. \& l. qui sub praetextu. C. de sacrosanctis ecclesiis. interpretantur Decanos pro Clericis. Ex quibus (inquit ille) tametsi plaeraeque generales non sunt: tamen eas propter cognitionem rerum, \& exemplum, omissas non oportuit. Quibus nos adducti rationibus eas toti iuris corpori, tamquam coronae apicem superimponendas censuimus. Nostris autem laboribus publica fruatur utilitas.

S. aus der Vorrede (o. Fn. 234): diligentissima undecumque investigatione tandem perfecimus, ut Novellarum vetustissimum exemplar in pergamena membranarum charta manu conscriptum invenerimus: inventum contulerimus cum vulgato, \& excuso: sed longe imperfectissimo libello. Atque ita unius lacunas, ex alterius plenitudine explevimus: \& in altero luculentam, nec satis propriam dictionis formam, pura ex altero elegantia eluimus: adeoque perfectum opus concinnasse videmur... 
Ende der Epitome nebst dem Beginn der Appendix B ausgefallen. An Ep. Iul. Cap. 512 (Nemo oratorium - civiles magistratus) schließen sich die Kapitel 18-21 der lateinischen Summe der Novelle vom 1. Mai 556 (Coll. CLXVIII Novv. 134) sowie die Novelle vom 15. Juni 535 (Coll. CLXVIII Novv. 34; ab rem duram) an ${ }^{237}$. Trotz ihrer Behauptung, die Ausgabe sei umfangreicher als die frühere Edition, fehlen dort Kapitel, die bei Bohier zu finden sind ${ }^{238}$. Allerdings sind auch zahlreiche zusätzliche Kapitel vorhanden ${ }^{239}$.

Auf dem Text der Gebrüder Senneton basiert die Ausgabe der Epitome Iuliani, die im Jahre 1553 - ebenfalls integriert in einen Band des Volumen ${ }^{240}$ - Hugo a Porta $^{241}$ herausbrachte ${ }^{242}$. Die Epitome steht am Ende des Bandes. Die Ausgabe besitzt keine Vorrede ${ }^{243}$; neue Handschriften sind nicht herangezogen ${ }^{244}$.

Im Jahre 1558, also acht Jahre nach der Ausgabe der Gebrüder Senneton, edierte L. Pesnot ${ }^{245}$ die Epitome Iuliani erneut in Lyon ${ }^{246}$. Pesnot legt die Edition der Ge-

236 Sie scheint verloren, s. Haubold (o. Fn. 9), S. 150; Hänel, Iuliani epitome (o. Fn. 7), p. XIX.

237 S. ed. Senneton, Sp. 73: titulus CXXXV: De ędificatione venerabilium locorum, Sp. 74: Nemo oratorium aedificare - \& civiles magistratus [Ep. Iul. Cap. 512]. § Si monachus condemnationem effugiens - subijciendus est. $\S$ Nulli iudici liceat - morti damnare. $\S$ Fures autem dicimus - autem usque ad tertium gradum vocantur [Novelle vom 1. Mai 556, Capp. 18-21; ed. Hänel, S. 196]. § Nam duram atque inhumanam - in suis pecuniis patientem iacturam [ed. Schöll-Kroll, Novellae, S. 241]. Finis Novellarum.

S. nur das Verzeichnis der fehlenden Kapitel bei Bohier und Senneton bei Haubold (o. Fn. 9), Übersicht nach S. 188 sowie Hänel, Iuliani epitome (o. Fn. 7), p. XXI (Bohier) und XXIII (Senneton).

So Ep. Iul. Capp. 69, 81, 424, 434, 438, 441, 452, 457, 461-472, 474, 476-483, 494-512.

Zur Gesamtausgabe des Corpus iuris s. Spangenberg, Einleitung (o. Fn. 183), S. 793-794.

S. zu Hugues de la Porte Baudrier, Bibliographie lyonnaise (o. Fn. 231), Bd. 8, Lyon 1908, S. 262-342 (262-300 zur Person) sowie die Ergänzungen bei von Gültingen, Bibliographie (o. Fn. 231), Bd. 6, Baden - Baden u.a. 1999, S. 180-204.

242 Volumen. Hoc complectitur (sice enim peculiari vocabulo vocant) Novellas Constitutiones Iustiniani Principis Post Repetitam Codicis Praelectionem Aeditas: Authentica vulgo appellant: Tres item posteriores libros Codicis: Feudorum seu Beneficiorum duos: Constitutiones Friderichi Secundi Imperatoris: Extravagantes duas Henrici Septimi Imperatoris et tractatum de pace Constantiae. Omnia ad vetustissimorum simul et emendatissimorum Exemplarium fidem recognita, emendata. Accesserunt nunc primum, et nusquam antehac aediti Iustiniani Novellarum Constitutionum libri duo cum multis Annotationibus ex doctissimorum hominum Commentariis, quae non parum lucis ac dignitatis huic Volumini afferunt, Lyon 1553. Zu der Ausgabe s. Haubold (o. Fn. 9), S. 158-160; Hänel, Iuliani epitome (o. Fn. 7), p. XXIII. - Benutzte Ausgabe: UB Tübingen, Ha I 5.

Nur das Kapitel aus den Parerga Alciats ist hinter dem Inhaltsverzeichnis zum Volumen abgedruckt (wie bei Senneton).

Zu Übereinstimmungen mit der ed. Senneton a. 1550 s. nur Hänel, Iuliani epitome (o. Fn. 7), p. XXIII.

245 S. zu den Aktivitäten von Louis Pesnot Baudrier, Bibliographie lyonnaise (o. Fn. 231), Bd. 3, Lyon 1897, S. 166-170 sowie die Nachträge bei von Gültingen, Bibliographie (o. Fn. 231), Bd. 8, Baden-Baden 2002, S. 157-159.

246 Novellarum Constitutionum Domini Iustiniani Sacratissimi principis \& Imperatoris Libri duo, Epitomis, praeter veterum exemplarium et collationem et emendationem, novè illustrati, Lyon 1558. S. zu der Ausgabe Haubold (o. Fn. 9), S. 160-164; Hänel, Iuliani epitome (o. Fn. 7), p. 
brüder Senneton zugrunde: So entspricht etwa das Ende der Epitome exakt demjenigen bei den Gebrüdern Senneton ${ }^{247}$. Auch die Äußerlichkeiten stimmen mit der Ausgabe der Gebrüder Senneton überein, wenngleich Pesnot auch Veränderungen vornahm ${ }^{248}$. Zahlreiche Kapitel fehlen ${ }^{249}$, allerdings hat Pesnot Kapitel, die in der ed. Senneton nicht vorhanden sind, zum Teil aus der ed. Bohier übernommen ${ }^{250}$. Eine Vorrede besitzt die Ausgabe nicht. Pesnot erwähnt aber im Titel den Vergleich mit "alten" Exemplaren ${ }^{251}$. In der Tat muß Pesnot eine Handschrift zugänglich gewesen sein, denn Ep. Iul. Cap. 442, das sowohl in der ed. Bohier als auch in der ed. Senneton fehlt ${ }^{252}$, ist bei ihm vorhanden ${ }^{253}$. Zudem gibt Pesnot bei einigen Kapiteln der Epitome am Rande variierende Lesarten $a^{254}$, die sich zwar zum Teil in der ed. Bohier finden ${ }^{255}$, ansonsten aber aus einer Handschrift herrühren müssen ${ }^{256}$. Die äußere Gestalt der Handschrift ist nicht mehr bestimmbar ${ }^{257}$.

XXIII-XXIV (mit Berichtigungen gegenüber Haubold). Hänel druckt die Edition Pesnots ebenfalls im Anhang zur Epitome Iuliani ab (S. 100*-160*). - Benutzte Ausgabe: UB Tübingen, Hc 218.

S. ed. a. 1558 (am Ende): Titulus LVII: De aedificatione venerabilium locorum. Nemo oratorium aedificare - \& et civiles magistratus. Titulus LVIII: de poenis. Si moechus condemnationem effugiens - ad tertium gradum vocantur. Titulus LVIII (!). De usuris ab agricolis creditoribus praestandis. Nulli liceat mutuanti - accipiat. Rem duram atque inhumanam-in suis pecuniis patientem iacturam. S. dazu unten S. 341.

S. Haubold (o. Fn. 9), Übersicht nach S. 188; Hänel, Iuliani epitome (o. Fn. 7), p. XXIV Fn. 10 .

$\mathrm{Zu}$ aus der ed. Bohier hinzugefügten Kapiteln s. bereits Hänel, Iuliani epitome (o. Fn. 7), p. XXIII Fn. 6 (vgl. z. B. Ep. Iul. Capp. 54, 56-58, 60 etc.).

251 S. oben Fn. 246; Hänel, Iuliani epitome (o. Fn. 7), p. XXIV erwägt, ob damit nicht nur die früheren Editionen gemeint sind.

252 S. ed. Senneton a. 1550, Sp. 65: ... ut quod iniuste fecit, ipse patiatur [Ep. Iul. Cap. 441 fin.]. Titulus CV. De episopis sua manu cedentibus [Cap. 442 rubr.]. Nulli alium clericum [Cap. 444 init.] (ed. Hänel, S. 93*).

S. ed. Pesnot a. 1558: ... ut quod iniuste fecit, ipse patiatur [Ende Ep. Iul. Cap. 441], § Non liceat episcopo manibus suis aliquem caedere. Hoc enim alienum est a sacerdote [Cap. 442]. Quales esse debent, qui divino ministerio praeficiendi sunt. Nulli alium clericum ... [Beginn Cap. 444] (ed. Hänel, S. 155*-156*). S. zu den Kapiteln nur Hänel, Iuliani epitome (o. Fn. 7), p. XXIV.

Aus Bohier können folgende Variantenangaben stammen: Pesnot lib. 2 tit. 17 (bei Ep. Iul. Cap. 310): ... si quidem habeat curiales..., am Rand: *curialis, Bohier: ... habeat curialis; bei Senneton fehlt das Kapitel; lib. 2 tit. 29 (Cap. 370):... sive referendariorum depositiones*..., am Rand: *alias dispositiones, Bohier: ... sive referendariorum dispositiones, Senneton: ... sive referendariorum depositiones; lib. 2 tit. 45 (bei Cap. 412): ... si quis autem creditor* ..., am Rand: *alias conductor, Bohier: si quis autem conductor, Senneton: si quis autem creditor; lib. 2 tit. 50 (bei Cap. 487): ... hoc ipsum* matrimonium ..., am Rand: *alias ipso, Bohier: hoc ipso matrimonium, Senneton: hoc ipsum matrimonium; lib. 2 tit. 50 (bei Cap. 493): ... monasterio cautioni* tradatur ..., am Rand: *alias cautiori, Bohier: monasterio cautiori tradatur, Senneton: in monasterio cautioni tradatur.

Pesnot lib. 1 tit. 2 (Ep. Iul. Cap. 2): Quod si omnes* praesto non sint ..., am Rand: alias, omnino (so auch ed. Hänel, S. 22, 8), Bohier und Senneton: Quod si omnes praesto non sint; lib. 1 tit. 2 (Cap. 2): ... locum habebit* ..., am Rand: *habeat, Bohier und Senneton: locum habebit (so auch ed. Hänel, S. 23, 10); lib. 2 tit. 17 (Cap. 313): ... ab Imperiali nomine* ..., 
Den entscheidenden Fortschritt für die Wiedergewinnung der Epitome Iuliani brachte die Ausgabe, die Louis Le Mire (Ludovicus Miraeus ${ }^{258}$ ) im Jahre 1561 in Lyon veranstaltete $^{259}$. Wie Miraeus in seiner Vorrede bemerkt ${ }^{260}$, standen ihm mehrere Handschriften zur Verfügung, aufgrund derer er erstmals die Epitome vollständig edieren konnte. Er nennt den Codex des Aymar de Ranconet (jetzt Hs. Paris BN lat. 4568), zwei Handschriften, die ihm Jacques Cujas aus eigenen Beständen geliehen und eine Handschrift des Louis Roussard, deren Ausleihe Cujas vermittelt hat-

am Rand: *numine (so auch ed. Hänel, S. 107, 20), Bohier: ab Imperiali nomine, bei Senneton fehlt das Kapitel; lib. 2 tit. 20 (Cap. 334): ... eo tempore antequam* donatio facta sit..., am Rand: *alias quo, Bohier: ... eo tempore accipere antequam donatio facta sit ..., Senneton: ... eo tempore antequam donatio facta sit ..., ed. Hänel, S. 112, 29: eo tempore acciperent, antequam donatio facta sit; lib. 2 tit. 23 (Cap. 349): ... sed in scriptis. quos* iudicio instruatur. Oportet enim mulierem certiorare: alioquin si eam non certioraverit vel parentem suum: nihil videbitur maritus egisse, am Rand: *alias quod si in iudicio instruatur, oportet omnimodo mulierem certiorari: alioqui si ea non certioretur vel pater, nihil videtur maritus egisse, Bohier: ... sed in scriptis. Quod si in iudicio instruatur oportet omnimodo mulierem ceriorari alioquin si eam non certioraverit vel patrem nihil videtur maritus egisse, Senneton: ... sed in scriptis quos iudicio instruatur. Oportet enim mulierem certiorare: alioquin si eam non certioraverit vel parentem suum: nihil videbitur maritus egisse, ed. Hänel, S. 117, 11: sed in scriptis. Quod si in iudicio instruatur, oportet omni modo mulierem certiorari; alioquin si eam non certioraverit vel parentem ipsius, nihil videbitur maritus egisse; lib. 2 tit. 36 (Cap. 392): ... post tres contestationes * ..., am Rand: *denuntiationes, Bohier: ... post tres contestationes (so auch ed. Hänel, S. 134, 14), bei Senneton fehlt das Kapitel; lib. 2 tit. 51 (Cap. 496): ... Christiani ultores* ..., am Rand: *alias ulteriores (so auch ed. Hänel, S. 163, 27), bei Bohier fehlt das Kapitel, Senneton: ... Christiani ultores ...; Pesnot lib. 2 tit. 52 (Capp. 500-505): ... Areopagitis ... Areopagitae ... Areopagita ... Areopagita ... Areopagita, am Rand: Argyropretis ... Argyropretae ... Argyropreta ... Argyropreta ... Argyropreta (so auch ed. Hänel, S. 164-165 mit der Schreibweise argyropratis etc.) Bohier: Kapitel fehlt, Senneton: Areopagitis ... Areopagitae ... Areopagita ... Areopagita ... Areopagita. - Manche der Varianten bei Pesnot lassen sich - ausweislich des kritischen Apparats der ed. Hänel - nicht in anderen Handschriften nachweisen.

S. bereits Hänel, Iuliani epitome (o. Fn. 7), p. XXIV. In der ed. Bohier a. 1512 fehlen Ep. Iul. Capp. 437-443.

Miraeus hatte bereits in den Jahren 1548-1550 eine glossierte Ausgabe des Corpus iuris und in den Jahren 1552-1553 eine unglossierte Ausgabe besorgt, s. dazu Spangenberg, Einleitung (o. Fn. 183), S. 784-786, 794-796. Im Jahre 1580 veranstaltete er eine Edition der Theophilusparaphrase der Institutionen Justinians: Institutiones iuris civilis per Theophilum antecessorem in Graecam linguam trad. ac fusius explicatae. Cura ac studio Viglii Zuichemi primum in lucem ed., nunc vero à Ludovico Miraeo emendatiores redd., add. Latina interpretatione Jac. Curtii ..., Lyon 1580. Über sein Leben ist anscheinend nichts Näheres bekannt.

Imp. Iustiniani novellae constitutiones, Interprete Iuliano Patricio ac Antecessore urbis Constantinopolitanae, hactenus desideratae, inter quas extant multae, quae in Graeco archetypo non habentur. Quibus accesserunt scholia seu notae incerti auctoris in aliquot Constitutiones. His subiunximus ipsius etiam Justiniani, Justini iunioris, Tiberij Constitutiones nonnullas antehac typis non excusas, Lyon 1561. S. zu der Ausgabe Haubold (o. Fn. 9), S. 164-167; Hänel, Iuliani epitome (o. Fn. 7), p. XXIV-XXV. - Benutzte Ausgabe: UB Tübingen, Ha I 64. Die Vorrede ist auch abgedruckt in der ed. Pithou a. 1576 (unten Fn. 286). 
$\mathrm{te}^{261}$. Die Handschrift Roussards gehörte zur Textgruppe A (mit Appendix A) ${ }^{262}$. Als Grundlage für die Edition diente Miraeus die Handschrift Ranconets ${ }^{263}$. Die Epitome umfaßt nunmehr alle Kapitel und endet - wie in den Handschriften der Textgruppe A - mit der sogenannten Const. Quam iam videor ${ }^{264}$. Den Titel der Epitome sowie einen Teil des Anhangs schöpfte Miraeus aus den beiden Handschriften des $\mathrm{Cu}$ $\mathrm{jas}^{265}$. Le Mire ediert als erster die (spätantiken) Anhänge zur Epitome Iuliani in größerem Umfang, die Appendix A sogar vollständig ${ }^{266}$. Für die Novellen, die auch das Authenticum überliefert, verweist Le Mire auf die Edition durch Haloander. Im Einzelnen ergibt sich folgende Bild (die Epitome endet auf S. 176 mit der Const. Quam iam videor, gezählt als Const. 125$)^{267}$ :

Seite Gegenstand

S. 176-180: Paragraphae zu Ep. Iul. Capp. 52-116 ${ }^{268}$
Herkunft

Appendix A

S. aus der Vorrede des Miraeus: nam is [Ranconet] praeter admirabilem \& stupendam disciplinarum omnium, iuris potissimum civilis, ac utriusque litterature cognitionem, non vulgari etiam librorum veterum supellectile instructissimus erat. inter quos fortè delitescebat harum Iuliani Novellarum exemplar vetustissimum ac integerrimum omnium, quae mihi videre contigit. quòd cum ab eo statim, ut erat in me iuvando proclivis, impetrassem: coepi quamprimum cum impressis conferre. In quibus, Deum immortalem, quot hiatus, quot lacunas, quot versus omissos, quot denique constitutiones deesse reperi, ne dicam interim operis rudem indigestamque molem, \& ineptam in duos libros divisionem, cum debeat in constitutiones, ut in illo vetusto exemplari, \& ratio operis postulat, distingui. Miraeus führt aus, daß das Exemplar Ranconets aber auch verschiedene Lücken und Korruptelen aufweist, und fährt fort: Quos [die Fehler] cùm Iacobo Cuiacio antiquitatis felicissimo restauratore indicasssem, is lubenter mihi pro sua singulari, quam in me gerit, benevolentia, multos restituit. Quin \& duo vetusta Iuliani exemplaria manu scripta summa cum alacritate exhibuit: nec satis illi fuit sua commodasse, ni etiam apud Ludovicum Russardum virum, ut audio, restituendis bonis auctoribus impense deditum, aliud antiquum impetrandi gratia pararium se mihi praestitisset. Ex quorum omnium collatione primùm quae deerant in illo Ranconeti vetusto supplevi ... - Zur Benutzung der Handschriften Ranconets und Russards s. auch die Angaben bei Hänel, Iuliani epitome (o. Fn. 7), XXV Fn. 16.

S. dazu oben S. 325.

S. aus der Vorrede: ... Hoc tamen exemplar etsi cetera integritate \& scripturae vetustate (erant enim ... vidi) \& ordinis concinnitate superare videretur ... Ex quorum omnium [die übrigen Hss.] collatione primùm quae deerant in illo Ranconeti vestusto supplevi.

So auch noch die Edition von Hänel.

S. dazu unten Fn. 329; der Titel entspricht dem Incipit der Textgruppe D (oben Fn. 34).

Zur vorgängien Publikation der Novelle Justins II. vom 1. März 570 durch Cujas im Jahre 1559 s. oben Fn. 177.

Vgl. auch Hänel, Iuliani epitome (o. Fn. 7), p. XXIV-XXV.

Für die Paragraphae zweifelte Le Mire, ob sich deren Edition lohnte, doch half hier das Zureden von Cujas, s. aus der Vorrede des Miraeus: Scholia porro illa, quae proximè sequuntur Iulianum haud omnino aspernanda, ex Ranconeti \& Russardi libris sumpta sunt: sed ea auctoris nomine in utroque exemplari carebant: neque in totum corpus Novellarum scripta, sed in constitutiones tantum XV. XVI. XVII. XVIII. XXI. XXIII. XXIIII. XXVI. XXVII. XXXII. XXXIII. XXXIII nec ultra progrediuntur. Eaque adeò corrupta erant, ut prorsus illa edendi aninum saepius desponderim, ni monitore Cuiacio, eiusque discipulo Petro Pithoeo, adulescente tum probo, tum docto (quem [es folgt ein Lob P. Pithous] editurus) quatenus fieri potuit emendavissem. 
(2) S. 181-183: Lateinische Epitome der Novelle vom 1. Mai 556 (Coll. CLXVIII Novv. 134), als Const. CXXV gezählt.

(3) S. 183: Novelle Justinians vom 15. Juni 535 (Coll. CLXVIII Novv. 34) ohne Zählung, aber mit eigener Überschrift (Ut nulli liceat - accipiant). Nur der Beginn des Textes ist abgedruckt (Rem duram), für den Rest ist auf Haloander verwiesen (in editione Haloand. numero 34).

(4) S. 183: Summe der lateinischen Novelle Justinians vom 23. März 538 (Coll. CLXVIII Novv. 65), ohne Zählung und Überschrift.

(5) S. 183:

Novelle Justinians vom 21. Mai 563 (Coll. CLXVIII Novv. 143) ohne Zählung, aber mit eigener Überschrift (De raptu mulierum). Nur der Beginn des Textes ist abgedruckt (Legis interpretationem), für den Rest ist auf Haloander verwiesen (quae habetur in editione Haloand. numero 143).

\section{- Querbalken -}

(6) S. 183-189: Lateinische Novelle Justinians vom 13. August 554 (mit der Überschrift: Pragmatica sanctio Iustiniani imp. complectens varia capitula).

S. 189: Expliciunt Iustiniani imperatoris constitutiones.
(7) S. 190-191: Lateinisches Kata poda der Novelle Justins II. vom 14. September 566 (Coll. CLXVIII Novv. 140).

(8) S. 191-192: Novelle Justinians vom 7. April 540.

(9) S. 192-193: Novelle Justins II. vom 1. März 570.
Appendix B

Appendix B

Appendix B

Appendix B ${ }^{269}$

Appendix A

Appendix A

Appendix A

Appendix A

269 Die Novelle ist ebenfalls in der Appendix A überliefert (Coll. CLXVIII Novv. 150). Darauf, daß Le Mire hier auf die Fassung der Appendix B verweist, deutet die Rubrik (De raptu mulierum), die entsprechend in der Appendix B wiederkehrt (s. dazu Kaiser, Die Epitome Iuliani [o. Fn. 2], S. 358), während sie für die Novelle in Appendix A lautet: De raptu virginum, viduarum et matrimonialium (s. Kaiser, S. 348). 
(10) S. 193-194: Sanctio pragmatica Tiberius' II. vom 11. Appendix A August 582.

Hierauf ediert Miraeus noch die Novelle Justinians vom 14. April 535 an den Erzbischof von Prima Iustiniana (Coll. CLXVIII Novv. 11; S. 194-195) ${ }^{270}$, auf die ein Kapitelverzeichnis zur Epitome Iuliani folgt, das bereits die verstümmelten Paratitla, die die Handschriften der Textklasse A überliefern, enthält ${ }^{271}$. Die Edition des Miraeus druckte Hubert Goltz (Hubertus Goltzius; * 1526, † 1583) in den Jahren 1565 und 1570 in Brügge/Flandern nach ${ }^{272}$.

Eine Ausgabe des Volumen, die 1562, 1567, 1575, 1580 und 1585 in Lyon bei den Gebrüdern Gabiano erschien ${ }^{273}$, enthält auch die Epitome Iuliani. Sie steht im Anschluß an das Authenticum auf Sp. 521-626 (Ende: Const. Quam iam videor) ${ }^{274}$, die Anhänge umfassen Sp. 626-635. Die Ausgabe entspricht äußerlich der ed. Miraeus (so zählt sie nach Konstitutionen und Kapiteln), ist aber im Text ein Konglomerat früherer Ausgaben und der ed. Miraeus ${ }^{275}$. Die Scholien (Paragraphae) sind weggelassen ${ }^{276}$. Die Edition scheint noch zweimal in Venedig $(1592,1598)$ nachgedruckt worden zu sein ${ }^{277}$.

Im Jahre 1567, nur sechs Jahre nach Miraeus, veröffentlichte Agustín in Lérida eine Edition der Epitome Iuliani. Die Ausgabe folgt auf eine Edition der griechischen Konstitutionen des Codex Iustinianus ${ }^{278}$ und besitzt eine ausführliche Vorre-

S. ed. Miraeus, S. 194-195: De Privilegio Archiepiscopi primae Iustiniane No. X quae in aliis exemplaribus deest, ex vetere libro Idem A. Catelliano viro beatissimo - perducere non differat. - Die Novelle machte erstmals Contius bekannt, s. oben Fn. 186.

S. dazu nur Kaiser, Die Epitome Iuliani (o. Fn. 2), S. 299-300.

S. zu den Ausgaben Hänel, Iuliani epitome (o. Fn. 7), p. XXV-XXVI (a. 1565), XXXIII (a. 1570).

Volumen locupletius quam antehac. Continet enim praeter posteriores tres libros Codicis, Novellas \& Feuda, multa alia pagina sequenti declarata, Lyon 1562. S. zu den Ausgaben Spangenberg, Einleitung (o. Fn. 183), S. 813 - 814 (a. 1562; ohne Nennung des Julian), 819 (a. 1567), 827-828 (a. 1575), 833 (a. 1580), 846 (a. 1585); Biener (o. Fn. 9), S. 387-388 (a. 1562), 391 (a. 1567), 403 (a. 1575), 411 (a. 1580), 415 (a. 1585); zur Epitome Iuliani s. Haubold (o. Fn. 9), S. 178-179; Biener (o. Fn. 9), S. 387-388, Hänel, Iuliani epitome (o. Fn. 7), p. XXVIII-XXIX. - Benutzte Ausgabe: UB Tübingen, Ha I 17 (a. 1580).

Die Überschrift lautet (Sp. 521): Iuliani patritij antecessoris Constantinopolitanae civitatis in Iustiniani novellas constitutiones epitomata.

S. nur den Beginn der Epitome (Sp. 521): Constitutio prima. Primum quidem \& in digestis ... Der Beginn des ersten Kapitels ist gemischt aus den früheren Editionen (Primum quidem; vgl. nur die ed. Senneton a. 1550) und Miraeus (et in Digestis). S. dazu auch Hänel, Iuliani epitome (o. Fn. 7), p. XXVIII.

S. bereits Biener (o. Fn. 9), S. 388; Hänel, Iuliani epitome (o. Fn. 7), p. XXIX.

S. dazu Hänel, Iuliani epitome (o. Fn. 7), p. XXXIII.

Ant. Augustini Episcopi. Ilerdensis Constitutionum Graecarum Codicis Iustiniani Imp. collectio, et interpretatio - Iuliani antecessoris. Constantinopolitani Novellarum eiusd. Imp. epitome. additis Latinis quibusdam Novellis Constitutionibus eiusdem: - Cum Paratitlis, sive 
$\mathrm{de}^{279}$. Die Ausgabe des Miraeus kannte Agustín wohl nicht ${ }^{280}$. Jedoch bietet Agustín verschiedene eigene Erläuterungen (Erklärungen ungewöhnlicher Wörter, Hinweise auf weitere Quellenstellen ${ }^{281}$ ), die sich bei Späteren großer Beliebtheit erfreuten. Agustín gibt im Vorwort an, daß seine Edition auf der Handschrift des Alciat und einem Manuskript aus der Kirche von Palencia basiert ${ }^{282}$. Die Ausgabe Augustíns ist nachgedruckt in: Antonii Augustini archiepiscopi Tarraconensis opera omnia, Bd. 2, Lucca 1766, S. 255-384 ${ }^{283}$. Dort ist die Edition durch F. Pithou (s. sogleich) berücksichtigt und das äußere Erscheinungsbild gegenüber der Erstausgabe verändert ${ }^{284}$.

Die für die nächsten 300 Jahre maßgebliche Edition der Epitome veranstaltete Francois Pithou $\left(* 1543, \dagger 1621^{285}\right.$ ). Sie erschien im Jahre 1576 in Basel ${ }^{286}$. F. Pithou kannte die Ausgaben von Le Mire und Agustín ${ }^{287}$, insbesondere konnte er die

Scholijs, Lérida 1567 (non vidi). - Zu der Ausgabe s. Haubold (o. Fn. 9), S. 169-173, Hänel, Iuliani epitome (o: Fn. 7), p. XXVI-XXVIII.

279 Auch abgedruckt in der ed. Pithou (a. 1576).

280 S. dazu Hänel, Iuliani epitome (o. Fn. 7), p. XXVII-XXVIII.

281 S. ed. Agustín a. 1567 ff. 4a/10-22a/12: Paratitla sive Scholia, ff. 90-102a/13: Verborum quorundam Iuliani interpretatio. F. Pithou druckt in seiner Edition a. 1576 sowohl die Verborum quorundam Iuliani interpretatio (S. 273-281) als auch die Paratitla (S. 282-298). Auch die deutsche Übersetzung durch Justin Gobler druckt die Paratitla ab, s. dazu nur Hänel, Iuliani epitome (o. Fn. 7), p. XXXIII-XXXVI. In neuerer Zeit finden sie sich etwa bei P. Fiorelli-A. M. Bartoletti Colombo, Iuliani Epitome Latina Novellarum secondo l'edizione die Gustavo Hänel e col glossario d'Antonio Agustín. Testo, indici, concordanze, Florenz 1996, S. 423-447.

282 S. oben S. 326.

283 Hier lautet der Titel: Juliani Antecessoris Constantinopolitani Novellarum Justiniani imperatoris epitome. Antonius Augustinus archiepiscopus Tarraconensis emendavit, et auxit. Additis latinis quibusdam Novellis Constitutionibus eiusdem Imperatoris cum Paratitlis, sive Scholiis, \& Variis Lectionibus, ac Verborum quorundam Juliani interpretatione. Accedunt nonnulla ex Novellarum earundem Libro, a Pithoeis Fratribus olim edito. - S. zu der Ausgabe Haubold (o. Fn. 9), S. 171, 184; Hänel, Iuliani epitome (o. Fn. 7), p. XXXI-XXXII.

284 S. Haubold (o. Fn. 9), S. 184; Hänel, Iuliani epitome (o. Fn. 7), p. XXXII.

285 Zu ihm vgl. etwa R. Naz, Pithou (François), DDC 6, Paris 1957, Sp. 1504-1505.

286 Imp. Iustiniani Novellae Constitutiones, Per Iulianum Antecessorem Constantinopolit. De Graeco Translatae. Nunc primum restitutae, emendatae \& auctae, quibus adiecta sunt eiusdem Iustiniani \& Iustini Impp. constitutiones aliquot numquam antea editae. Ex Bibliotheca Petri Pithoei IC. Accessere praeterea paratitla sive scholia \& verborum quorundam Iuliani interpretatio auctore Antonio Augustino Episcopo Ilerdensi, ut de caeteris taceam quae versa pagina indicabit, Basel 1576. S. zu der Ausgabe Haubold (o. Fn. 9), S. 180-184, Biener, Geschichte der Novellen, S. 407-409, Hänel, Iuliani epitome (o. Fn. 7), p. XXIX-XXX sowie Kaiser, Authentizität und Geltung (o. Fn. 2), S. 21-28. - Kopie im Institut für Rechtsgeschichte, Freiburg.

287 S. aus der Vorrede: Omnia omnium praeconia et auctoritates superat [die Epitome Iuliani], magnum studium, multaque opera in hoc antea edendo repurgandoque à praestantiss. viris posita. Ne quid de aliis dicam, unus mihi instar est omnium Iacobus Cuiacius utriusque nostrum magister; quo adiutore pereleganter illius editionem, atque ceteris pleniorem procuravit Ludovicus Miraeus ab hinc annis aliquot. De qua aliquid inaudisse magnum Hispaniarum ornamentum Antonium Augustinum pervelim. Accessissent quidem satis multa ad tantam diligentiam, quam in eodem limando eridutissimum adhibuisse virum indicant quae adiecit para- 
bis dato noch nicht berücksichtigte Handschrift seines Bruders Pierre heranziehen (Hs. Berlin, Staatsbibl. 1at. fol. 269) ${ }^{288}$. Zudem konnte er Bibliotheken in Venedig und Augsburg konsultieren. Unterstützung erhielt er weiterhin durch Gian Vincenzo Pinelli (Ioannes Vincentius Pinellus; * 1535, $\uparrow 1601$ ) aus Padua, dem Inhaber einer der reichhaltigsten Bibliotheken des 16. Jhds. ${ }^{289}$, sowie durch Bonifatius Amerbach $\left(* 1495, \dagger 1562^{290}\right)^{291}$. Dic Ausgabe von F. Pithou basiert grundsätzlich auf der ed. Miraeus $^{292}$, jedoch ergänzt Pithou diese um Lesungen und Besonderheiten der Berliner Handschrift ${ }^{293}$. So fügt er etwa (erstmals) die Konstitutionenrubriken hinzu, die die Berliner Handschrift überliefert (ab Ep. Iul. Const. $38^{294}$ ). Die ed. Pithou enthält die gesamte Appendix A (aus Miraeus) und die Appendix B, zumeist nach der Ausgabe durch P. Pithou in der Lex Dei. F. Pithou überarbeitete jedoch gelegentlich den Text $^{295}$. Die sonstigen Anhänge bieten verschiedene Inedita, deren konkrete handschriftliche Vorlage sich nicht mehr bestimmen läß ${ }^{296}$, s. die Übersicht:

titla, indices, variae lectiones, obscurorum verborum significationes. Nec tamen omnia sine mendis, quae qui Miraeo tribuit, fidem religionemque in corrigendis libris evertit.

Die Handschrift bezeichnen noch Haubold (o. Fn. 9), S. 152; Blume (o. Fn. 181), p. XIX als verloren, s. zu ihrem Schicksal oben Fn. 203.

S. zu ihm und seiner Bibliothek M. Grendler, A Greek Collection in Padua: The Library of Gian Vincenzo Pinelli (1535-1601), in: Renaissance Quarterly 33 (1980), S. 386-416.

Kurzbiographie bei H. Hagemann, Die Rechtsgutachten des Basilius Amerbach, Basel 2001, S. 11-16; s. dazu auch Kaiser, Authentizität und Geltung (o. Fn. 2), S. 27 Fn. 32.

S. aus der Vorrede: ... Quantulumcunque est quod in eo praestiti, hoc me acceptum referre par est viris amplissimis et ornatissimis, quorum benignitate ad librorum sacraria, Venetiis et Augustae Vindelicorum patuit mihi aliquotiens introitus. Sed \& permulta debeo V.C. \& numquam laudato satis, Ioanni Vincentio Pinello: ex cuius unica bibliotheca plura mihi de Iustiniano didicisse contingit, quam ex caeteris omnibus. Ingratissimus etiam sim si non in ista editione magnis me agnoscam effectum beneficijs ab amantissimo utriusque nostrum Basilio Amberbachio I.C. doctiss. \& prudentiss. Ut plane in toto isto opere meum nihil proprie sit. Quid enim mihi constitutiones aliquot vindicem quae accessionis vice caeteris cedunt? Sed aut tua sunt omnia: aut amicorum: nisi si quae peccata sunt, ut erunt fortasse permulta.

S. bereits Biener (o. Fn. 9), S. 409.

293 S. nur die Vorrede: Quas ubique tanti ego feci, ut vix ac ne vix quidem ab exemplaris tui $[\mathrm{P}$. Pithou] scriptura discesserim, variis caeterorum lectionibus in cumulum Augustinianarum rejectis. Superstitio est ista, inquies. Atqui codicis vetustas et bonitas hoc postulabat. In quo etsi aliquid desiderari credam, et indicio sit Novella ultima, cujus inscriptio ex notatione mea nescio quomodo irrepsit: permulta tamen ex eo nunc primum restituta, emendata, aucta dari ingenue polliceri possum. Quantum profecerim, aliorum, praesertim vero Jureconsultorum esto judicium.

S. ed. Pithou a. 1576, S. 60: CONSTITUTIO XXXVIII De officio quaestoris exercitus \& designatis quinque provintijs ei subiectis. CLXVI De quaestoribus, id est praefectis insularum. Die Konstitutionenrubriken (s. dazu oben bei Fn. 26) enden bei Ep. Iul. Const. CXV.

S. zu Beispielen für die Überarbeitung Kaiser, Authentizität und Geltung (o. Fn. 2), S. 23 Fn. 9 (Summe der Novelle vom 1. Mai 556; Coll. CLXVIII Novv. 134), 24 Fn. 18 (Dictatum de consiliariis).

296 Dies gilt für das Edictum Iustiniani de fide, die drei Kapitel aus den "Sacra privilegia" sowie die drei Novellen aus dem Authenticum, s. genauer Kaiser, Authentizität und Geltung (o. Fn. 2), S. 25, 26, 27. 
(2) S. 198

Undatiertes lateinisches Reskript Justi-

Appendix B nians (Coll. CLXVIII Novv. 138); als Const. 126 der Epitome gezählt.

(3) S. 199

Lateinische Summe der Novelle vom 15.

(P. Pithou 1573) April 535 (Coll. CLXVIII Novv. 121), als

Appendix B Const. 127 der Epitome gezählt.

(4) S. 199 Const. quam iam videor; als Const. 128 der Epitome gezählt ${ }^{297}$.

(5) S. 200-205 Scholia in constitutiones aliquot ${ }^{298}$.

(P. Pithou 1573)

Miraeus 1561

Appendix A

(Miraeus 1561)

(6) S. 205-207 Dictatum de consiliariis.

Appendix B

(P. Pithou 1573)

(7) S. 207-208 Collectio de tutoribus.

Appendix B

(P. Pithou 1573)

(8) S. 208-229 Edictum piissimi imperatoris Iustiniani

"Erstedition" 299

(9) S. 229-236 fidei confessionem continens ...

(10) S. 236-237

Novelle Justinians vom 13. August 554

Appendix A zur Neuordnung Italiens (,Sanctio prag(Miraeus 1561) matica pro petitione Vigilii").

(11) S. 237

Novelle Justininians vom 7. April 540

Appendix A über den Kolonat in Illyricum.

(Miraeus 1561)

Novelle Justinians vom 6. Oktober 541 Erstedition

für die nordafrikanische Provinz Byzacium.

(12) S. $237-238$

Novelle Justinians vom 29. Oktober 542 für die Diözese Africa.

(14) S. 240 Novelle Justins II. für die nordafrikanische Provinz Byzacium vom 1. Mai 568.

(15) S. $240-241$

(16) S. 242

Novelle Justins II. vom 1. März 570 über den Kolonat in Afrika.

Novelle Tiberius' II. vom 11. August 582

Erstedition

Erstedition

Appendix A

(Miraeus 1561)

Appendix A

297 Zu der unrichtigen Überschrift zur Constitutio quam iam videor s. Kaiser, Authentizität und Geltung (o. Fn. 2), S. 24 Fn. 13.

298 Zu Veränderungen gegenüber Miraeus s. Kaiser, Authentizität und Geltung (o. Fn. 2), S. 24.

299 Pithou gibt an, er habe den Text: ex libro manuscripto, womit er gewöhnlich Erstveröffentlichungen anzeigt. Allerdings ist das Edikt bereits früher veröffentlicht worden in: P. Crabbe, Concilia omnia tam generalia, quam particularia, Bd. 1, 2. Aufl., Köln 1551, Sp. 1061 b (Edictum piissimi imperatoris Iustiniani ... Scientes quod nihil aliud sic potest ...) - 1073a (... et salvatore nostro Iesu Christo in die iudicij), vgl. Haubold (o. Fn. 9), S. 176; zu ergänzen bei Kaiser, Authentizität und Geltung (o. Fn. 2), S. 24 mit Fn. 19. - Pithou scheint aber die frühere Ausgabe durch Crabbe nicht gekannt zu haben. 

S. $243-245$
Auth. 38 (Coll. CLXVIII Novv. 36) ${ }^{300}$.
Auth. 39 (Coll. CLXVIII Novv. 37).
S. $246-248$
Auth. 37 (Coll. CLXVIII Novv. 35).

über den Kolonat in Afrika.

(18) S. 245-246

(Miraeus)

Erstedition

Erstedition

Erstedition

Die Ausgabe blieb bis zur kritischen Edition Hänels maßgebend ${ }^{301}$. Sie wird im Jahre 1689 noch einmal im Rahmen der Werke der Gebrüder Pithou zu Codex und Novellen von François Desmarés herausgegeben ${ }^{302}$. Am Rande stehen einige Varianten, die in der Ausgabe des Jahres 1576 noch nicht vorhanden waren und die Desmarés wohl aus einem Handexemplar der Gebrüder Pithou schöpfte ${ }^{303}$.

Noch im 16. Jhd. erschien auch eine deutsche Übersetzung der Epitome Iuliani, die Justin Gobler herausbrachte ${ }^{304}$.

\section{Das äußere Erscheinungsbild der Editionen}

In der ältesten Ausgabe durch Bohier war die Epitome noch - analog zum Authenticum - in neun Kollationen eingeteitt ${ }^{305}$. Die Ausgaben Lyon 1550 (Senneton), 1553 (Hugo a Porta), 1558 (Pesnot) und 1562 ff. (Volumen locupletius quam antehac) teilen die Epitome in zwei libri bzw. partes ${ }^{306}$. Miraeus gibt - nach dem Vorbild der Hs. Paris BN lat. 4568 - die Zweiteilung auf, die er für unpassend hält ${ }^{307}$. Agustín und Pithou übernehmen hingegen die Zweiteilung ${ }^{308}$.

Pithou benutzte für diese und die beiden folgenden lateinischen Novellen eine Vulgathandschrift des Authenticum, s. Kaiser, Authentizität und Geltung (o. Fn. 2), S. 26.

S. nur Haubold (o. Fn. 9), S. 173: ,... daher man ohne Bedenken jetzt die Pithoeische Ausgabe für die beste hält und gewöhnlich nach ihr citiert"; ebenso auch S. 185.

Petri et Francisci Pithoei jurisconsultorum observationes ad codicem et novellas Justiniani imperatoris per Julianum translatas. Accedit Legum Romanarum et Mosaicarum collatio notis illustrata, Ex bibliotheca illustrissimi D.D. Claudii Le Peletier Regni Administri Regii Aerarii Praefecti, \& Supremi Galliarum Senatus Praesidis infulati. Cura Francisci Desmarés, Domini de Palis, et de Luyéres in Curia Patroni, et Facultatis Jurium in Universitate Parisiensi Doctoris Honorarii, Paris 1689. Zu der Ausgabe s. Haubold (o. Fn. 9), S. 180-185; Hänel, Iuliani epitome (o. Fn. 7), p. XXX-XXXI; Kaiser, Authentizität und Geltung (o. Fn. 2), S. 28.

Beispiele zu Verbesserungen in den drei ersten Kapiteln der Sacra privilegia bei Kaiser, Authentizität und Geltung (o. Fn. 2), S. 29.

S. dazu Hänel, Iuliani epitome (o. Fn. 7), p. XXXIII-XXXIV; zu Justin Gobler s. nur H. Troje, Art. Justin Gobler, in: Handwörterbuch zur deutschen Rechtsgeschichte 1 (1971), Sp. $1726-1729$.

S. dazu Haubold (o. Fn. 9), S. 155; Hänel, Iuliani epitome (o. Fn. 7), p. XXI.

S. nur die Angabe bei Hänel, Iuliani epitome (o. Fn. 7), p. XXII, XXIII, XXVIII.

S. aus der Vorrede (o. Fn. 261): ... \& ineptam in duos libros divisionem, cum debeat in constitutiones, ut in illo vetusto exemplari [die Hs. Ranconets], \& ratio operis postulat, distingui.

S. zu Agustín nur Hänel, Iuliani epitome (o. Fn. 7), p. XXVI, zu Pithou s. nur die ed. 1576, S. 80: Incipit pars secunda novellarum. 
Die Edition Bohiers zählt die Kapitel der Epitome gar nicht ${ }^{309}$. Die Ausgabe der Gebrüder Senneton gliedert die Epitome in tituli, die auch mehrere Kapitel umfassen können, und zählt diese durchgängig von 1-135 (so auch Hugo a Porta a. 1553); eine Konstitutionen- und Kapitelzählung fehlt ${ }^{310}$. Pesnot (a. 1558) behält die tituli bei, jedoch numeriert er sie nicht fortlaufend, sondern nach Büchern ${ }^{311}$. Le Mire führt die Konstitutionen- und Kapitelzählung ein und versieht die Konstitutionen mit Subskriptionen.

Agustín hielt sich bei seiner Edition nicht an die Legalfolge der Epitome, sondern glich die Reihenfolge der Konstitutionen derjenigen in der Coll. CLXVIII Novv. $\mathrm{an}^{312}$. Auch ansonsten veränderte er den Textbestand, insbesondere ließ er die Konstitutionen- und Kapitelzählung weg und präsentierte nur wenige Subskriptionen.

Die Bezeichnung des Novellenindex als "Epitome" war um die Mitte des 16. Jhds. allgemein geläufig ${ }^{313}$.

\section{Die Person Julians und der Zweck der Epitome}

Bohier setzt sich in seiner Vorrede hauptsächlich mit den Leges Langobardorum auseinander $^{314}$. Soweit die Vorrede auf die Epitome eingeht ${ }^{315}$, handelt sie - ganz in mittelalterlicher Tradition - von deren Allegierbarkeit ${ }^{316}$ sowie den Allegaten bei Accursius und anderen mittelalterlichen Juristen ${ }^{317}$. Die Handschrift Bohiers besaß

309

310

311

312

S. nur Hänel, Iuliani epitome (o. Fn. 7), p. XXI.

So dann auch die Ausgabe a. 1553 (Hugo a Porta) sowie a. 1558 (Pesnot).

S. nur Haubold (o. Fn. 9), S. 161.

S. die Vorrede: Ordinem libri aliquot locis mutavimus, ut facilius Novellarum libros subsequeretur. Latinas constitutiones suo quamque loco inseruimus: ut \& magis Iuliani labor eluceret comparatione Latinarum Legum; \& ut minus in Graecis laboremus, quae de eadem re scripta sunt.

S. etwa den Brief Agustíns an Mendoza vom 1. August 1544 (o. Fn. 215): Per te [Mendoza] etiam isthic Iuliani Epitomen ..., die Vorrede des Contius zu den Novellen (a. 1559; o. Fn. 185): ... harum constitutionum epitome à Iuliano ... Agustín nimmt die Bezeichnung sogar in den Titel seiner Ausgabe auf (s. oben Fn. 286): Iuliani antecessoris Constantinopolitani Novellarum eiusd. Imp. epitome ...; ähnlich auch der Titel im Volumen locupletius quam antehac (1562 ff.; o. Fn. 274): Iuliani patritij ... in Iustiniani novellas constitutiones epitomata. Vgl.

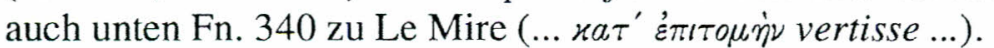

Die Epitome Iuliani behandelt Bohier auf f. 6rb-vb. Einen Auszug aus der Vorrede mit den wesentlichen Ausführungen Bohiers zur Epitome druckt F. Pithou (a. 1576); der Ausschnitt bei Pithou umfaßt f. 6va/10-vb/30 (Et sic Novellae constitutiones - causa brevitatis omitto).

S. ed. Bohier (o. Fn. 226), ff. 2va-8vb; die Überschrift lautet (f. 2va): Praefaciuncula in leges longobardorum et novellas constitutiones domini iustiniani ...

S. ed. Bohier (o. Fn. 226), Praefaciuncula, f. 6rb/17-va/10. Bohier legt dar, daß nicht nur die Quellen Geltung beanspruchen könnten, die das traditionelle sechsbändige Corpus des römischen Rechts vereint, sondern auch Texte außerhalb desselben. Daher gelten auch die Novellen, die er nach den Leges Langobardorum abdruckt.

Bohier konnte aber wegen der Unvollständigkeit seiner Handschrift der Epitome nicht mehr alle Allegationen verifizieren, vgl. etwa aus seiner praefaciuncula (f. 6va/10-vb/30): Ad idem 
ein (wenn auch korrumpiertes) Incipit, aus dem hervorging, daß es sich um eine Übersetzung aus dem Griechischen in das Lateinische handelte, die ein illuster [für Iulianus] vir eloquentissimus, civis Constant() veranstaltet hat ${ }^{318}$. Bohier zieht aber hieraus keine Folgerungen.

Julian als Verfasser der Novellenübersetzung kommt anscheinend erstmalig bei Andrea Alciati im Jahre 1538 in einem Kapitel der Parerga vor ${ }^{319}$. Alciati nennt Julian beim Namen und ordnet die Epitome erstmals explizit als Übersetzung griechischer Novellen ein ${ }^{320}$. Alciati tituliert Julian als patricius und exconsul; diese Titel sind handschriftlich nicht bezeugt. Bereits Agustín bemerkte, daß Alciati den antecessor Julian zu Unrecht mit dem consul und patricius Julian gleichsetzt, dem Priscianus seine Institutio grammatica widmet ${ }^{321}$; dennoch konnte sich die unrichtige

gloss(a) in l. fin. in verba tam eas $C$. de agricolis et censitis lib. XI et l. nemini in verbum dignitatem $C$. de consulibus liber XII, ubi alleg(at) tit(ulum) de ordi(ne) sedendi (Ep. Iul. Cap. 200), quem non inveni integraliter. Nec tit(ulum) Ut ecclesia sanctae resurrectionis quem allegat Alber(icus) de rosa(te) inditio(?) in verbum ecclesia in II ad hoc quod dicitur ecclesia Hierosolymitana in qua mundi creator dignatus est constitui in humana generatione ut in Novellis (Ep. Iul. Cap. 195). An der ersten Stelle verweist die Glosse auf Ep. Iul. Cap. 200, Albericus de Rosate allegiert Ep. Iul. Cap. 195; Ep. Iul. Capp. 200, 195 fehlen in der Ausgabe Bohiers, vgl. nur die Konkordanz bei Haubold (o. Fn. 9), nach S. 188 sowie Hänel, Iuliani epitome (o. Fn. 7), p. XXI.

318 S. die Überschrift zur ed. Bohier (o. Fn. 226) f. 101r (vgl. auch Hänel, S. $3^{*}$ ): In nomine domini incipit liber iustiniani novellarum imperatoris translatus de greco in latinum per illustrem virum eloquentissimum constant 3 civitatis civem. - Der Name Julians verbirgt sich hinter illuster, er ist nicht ausgefallen, wie Biener (o. Fn. 9), S. 72 meint. Andreae Alciati Iurisconsulti Mediolanensis Parergon Iuris Libri III, Basel 1538, Lib. II, Cap. 46, S. 64.

S. Alciati, Parerga (o. Fn. 319), Lib. II. Cap. 46: Quum interrogatus quandoque essem, unde fieret, ut Constitutionum Iustiniani volumen, Authentici nomine citaremus, quum tamen nusquam appareat hunc ei titulum ab ipso legislatore praefixum esse: sic respondendum duxi. Editum esse eum ibrum graeco sermone, \& Constitutiones eas graece vea@às appellatas fuisse. Verum cum Asiatica quadam luxuria diffusus prolixitateque nimia scriptus liber esset, translatum latine a Iuliano Patricio \& exconsule fuiße: sed compendiosius, \& stylo, ut tum tempora ferebant, non inelegante. qui liber adhuc extat, \& Novellae titulo circumfertur, dubio procul legitimus Iustiniani ipsius partus, quem tamen doctores nostri ut spurium reiecerunt: maluitque Accursius barbaram \& Bulgari tempore factam translationem interpretari, quod uberior ei videretur: ideoque Authenticam appellavit, quoniam ex ipso graeco originali ad litteram traducta esset. Sanè authenticon pro re certae fidei poni constat, non solum apud Iulianum, Paulumque Iuriscons. sed etiam apud Ciceronem epist. ad Attic. lib. IX \& X. Tamen si Gaza libellus de mensibus, hanc vocem apud veteres hoc sensu non reperiri scribat: sed

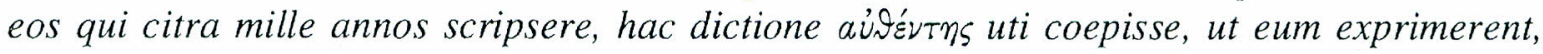
quam Latini authorem dicunt. Olim enim id significat, quod aúóxele, id est, propria manu aliquid patrans.

321 S. die Vorrede Agustíns (o. Fn. 278): Existimo eum putasse eundem fuisse Iulianum illum, quem eisdem titulis Priscianus ornavit. A qua opinione discedo, propterea quod Prisciani libri extant Mavortio Consule scripti a discipulis Prisciani. Illius autem consulis annus collectionem Novellarum, quae post mortem Iustiniani facta est, quinquaginta amplius annos excedit. Alius eodem nomine fuit Praefectus Praetorio, ad quem extant aliquot Graecae constitutiones datae Lampadio, et Oreste consulibus. Sed hunc etiam alium esse existimamus, tum propter rationem temporum, tum propterea, quod hunc videmus in veteribus libris, nec Patri- 
Auffassung von Julian als patricius bis in neueste Zeit halten ${ }^{322}$. Grund für die Übersetzung ist nach Alciati die Prolixität der griechischen Originale. Zeitlich ordnet Alciati die Epitome zutreffend ein: Sie sei noch unter Justinian entstanden. Da Justinian die Übersetzung selbst veranlaßt habe, hätten die mittelalterlichen Doktoren sie zu Unrecht nicht als Rechtsquelle anerkannt. Dem Authenticum, das er als Werk des Bulgarus ansieht, sei sie allemal vorzuziehen. Zum Ort der Abfassung äußert sich Alciati nicht. Das Kapitel aus den Parerga wird späteren Ausgaben der Epitome häufig beigefügt ${ }^{323}$.

Die Handschrift, die die Gebrüder Senneton heranzogen, lieferte augenscheinlich keine Informationen über den Verfasser des Werks ${ }^{324}$. Die Vorrede übernimmt für die Epitome weitgehend die Angaben der ed. Bohier ${ }^{325}$. Die Ausführungen Alciats in den Parerga sind nicht eingearbeitet, obgleich sie im Wortlaut abgedruckt werden ${ }^{326}$. Nach der Vorrede ist die Epitome eine lateinische Übersetzung einer vorgängigen griechischen Kurzfassung der Novellen ${ }^{327}$. Die Gebrüder Senneton betonen ebenfalls - unter Bezugnahme auf Const. Cordi $\S 4$ - daß die novellae (d. h., die Epitome Iuliani) von Justinian autorisiert sind ${ }^{328}$.

Über Alciati gelangte erst Le Mire hinaus. Er teilt zunächst die richtige Überschrift zur Epitome Iuliani mit, die eines der beiden Exemplare des Cujas aufwies ${ }^{329}$.

cium se, nec Consularem, aut Praefectorium appellasse, aut, ut tunc usurpabant, Exconsule, vel Expraefecto; sed tantum Antecessorem CP; vgl. Priscianus, Institutionum grammaticarum libri XVIII, ed. M. Hertzius, in: H. Keil, Grammatici Latini, Bd. 2, Leipzig 1855 (Nachdruck Hildesheim 1961), S. 1: Priscianus Caesariensis grammaticus Iuliano consuli ac patricio ...; zu diesem Julian s. J. R. Martindale, The Prosopography of the Later Roman Empire, Bd. 2 (A. D. 395-527), Cambrigde u. a. 1980, S. 641 (Iulianus 26). So noch J. R. Martindale, The Prosopography of the Later Roman Empire, Bd. 3a, Cambridge 1992, S. 733.

So etwa in der ed. Senneton (a. 1550; o. Fn. 233), der ed. Pesnot (a. 1558; o. Fn. 246) sowie den Ausgaben des Volumen locupletius quam antehac (a. 1562 ff.; o. Fn. 273). Auch die ed. Pithou (a. 1576; o. Fn. 286) druckt es ab, allerdings nicht mehr vollständig: Das Ende (Sane authenticom(!) pro re certae fidei-aliquid patrans) fehlt.

S. ed. Senneton, Sp. 1: NOVELLARUM CONSTITUTIONUM DOMINI IUSTINIAni Sacratissimi principis, incipit liber primus.

S. die Vorrede (o. Fn. 234): Tum etiam illis tanquam eodem argumento conformes NOVELLAS D. Iust. Imp. Constitutiones, pro corollario curavimus adijciendas. quas ex Graeca oratione, in latinum sermonem Iámolim verterat Constantiensis quidam haud ineruditus, sed nominis sui dissimulans, interpres. Die Fehlauflösung der Abkürzung Constant 3 bei Bohier zu Constantiensis bemerkt schon Agustín, s. unten S. 345.

So etwa wird Julian nicht genannt; das Kapitel aus Alciat findet sich hinter dem Inhaltsverzeichnis zum Volumen.

S. aus der Vorrede (o. Fn. 234): Quamquam (ni nos iudicii fallit) videtur libellus hic, nihil aliud esse quam Epitome Authenticorum, à Graecis primum in Compendium coacta, \& et mox à cive quodam Constantiensi latinè transcripta.

S. aus der Vorrede (o. Fn. 234): Porro nè quis parvam esse Novellarum autoritatem putet: is intelligat ex iuris peritissimo Haloandro eas ab ipso Imperatore confirmatas fuisse in futurum in tertia constitutione, quae praefationis loco, repetitae Codicis praelectioni praescripta est. S. ed. Miraeus, S, 1: In Nomine Domini. Incipiunt Constitutiones Novellae Iustiniani Imperatoris, de Graeco in Latinum translatae per Iulianum eloquentissimum Antecessorem Constan- 
Hieraus leitet Le Mire ab: Julian war antecessor in Konstantinopel und übersetzte die Novellen Justinians aus dem Griechischen in das Lateinische. Das Wort antecessor erklärt er unter Zuhilfenahme der Const. Omnem ${ }^{330}$. Le Mire ist zudem der erste, der die Gedichte in der Anthologia Graeca mit Julian in Zusammenhang bringt, wenngleich er zögert, den dort genannten Julian mit dem Verfasser der Epitome Iuliani gleichzusetzen ${ }^{331}$. Die Angabe Alciatis, Julian sei patricius und exconsul gewesen, referiert $\mathrm{er}^{332}$; den Titel patricius führt Julian auch im Werktitel ${ }^{333}$. Le Mire setzt das Wirken Julians in die Regierungszeit der Kaiser Justin II., Tiberius II. und Mauricius ${ }^{334}$, wozu ihn wohl die verschiedenen Konstitutionen Justins II. in der Appendix A und der Appendix B sowie die Konstitution Tiberius' II. in der Appendix A veranlaßten. Die Datierung greift Marquard Freher $\left(* 1565, \dagger 1614^{335}\right)$ auf, der die Ausgabe des ius Graeco-romanum des Johannes Löwenklau (Leunclavius; 1533-1593) besorgte ${ }^{336}$ und dieser eine Chronologia imperii utriusque, sive Graecorum sive Germanorum ${ }^{337}$ voranstellte ${ }^{338}$. Sie hält sich bis in das beginnende 19.

tinopolitanae civitatis. Constitutio I. Et in Digestis ...; vgl. die Vorrede: Iam verò quis fuerit hic Iulianus, \& quo tempore vixerit, haud compertum habeo, nisi quòd Antecessorem eum Constantinopoleos fuisse indicat titulus alterius exemplaris Cuiacij.

S. die Vorrede (im Anschluß an Fn. 329): quae dignitas erat iuris ac legum professio, ut coniectari licet ex constitutione praefixa Digestis quae incipit, Omnem, statim in initio.

S. die Vorrede: Atque haud scio an epigrammata quae in Anthologia epigrammatum libro

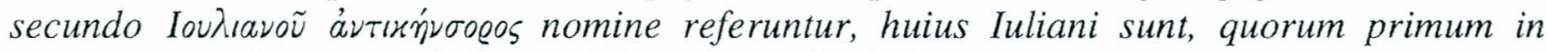
quendam pumilionem sic habet; es folgen Anth. Gr. 367-369.

S. die Vorrede (im Anschluß an die Gedichte aus der Anthologia Graeca): Alciatus eum Patricium \& Exconsule fuisse scribit.

333 S. oben Fn. 259.

334 S. die Vorrede: Verùm ex catalogis consulum, qui hodie circumferuntur, quoniam ad eius usque consulatum non extenduntur, exactè qua aetate vixerit cognosci non potest, nisi quòd summa mihi coniectura est eum circa tempora saltem Iustini iunioris, Tiberij, \& Mauricij floruisse.

335 S. zu ihm W. Kühlmann-V. Hartmann-S. El Kholi, Marquard Freher (Die deutschen Humanisten, Abt. 1, Bd. 1, 1), Turnhout, 2005; Kurzbiographie dort auf S. 1.

336 Iuris Graeco-romani tam canonici quam civilsis Tomi duo. Iohannis Leunclavii Amelburni, V. Cl. studio ex variis Europae Asiaeque Bibliothecis eruti, Latineque redditi: nunc primum editi curâ Marquardi Freheri I.C. cum eiusdem auctario, Chronologia iurs ab excessu Iustiniani ad amissam Constantinopolim, et Prefatione ad Imp. Caes. Rudolphum II. P. F. PP. A. ..., Frankfurt 1596. S. zu der Ausgabe Kühlmann-Hartmann-El Kholi (o. Fn. 335), S. 50-144.

Chronologia imperii utriusque, Orientis et Occidentis, sive Graecorum et Germanorum; et iuris tam Canonici quam Civilis in utroque conditi: ab excessu Iustiniani Aug. Imp. (in quo Freymonius, Contius, Gifanus, alliique desinunt) usque ad excidium urbis Constantinopolis, \& imperii Orientalis finem: ad Iuris pariter \& Historiarum cognitionem apprime utilis; hierzu s. Kühlmann-Hartmann-El Kholi (o. Fn. 335), S. 140. Die Chronologia Freheriana wurde auch anderen Werken hinzugefügt, so etwa frühen Corpus iuris-Ausgaben des D. Gothofredus, vgl. D. Kornexl, Studien zu Marquard Freher (1565-1614). Leben, Werk und geschichtliche Bedeutung, Bamberg 1967, S. 111-112 (Nr. 10).

338 S. Chronologia zum Jahre 570: Gregorius Monachus, Episcopus Antiochenus 63. Iulianus, antecessor Constantinop. hoc tempore vivit: cuius extat versio Novellarum Iustiniani, dictatum de tutoribus, \& alis. 
Jhd. ${ }^{339}$. Le Mire schildert die Kürzungen Julians ${ }^{340}$ und setzt sich für dessen Stil ein. Miraeus vergleicht zudem als erster die Abfolge der Konstitutionen mit dem archetypus Graecus, womit wohl die Sammlung der 168 Novellen gemeint ist ${ }^{341}$. Er erkennt, daß vielfach Abweichungen vorliegen und merkt in seiner Edition jeweils die griechischen Parallelstellen an. Über den Zweck der Epitome äußert er sich nur insoweit, als daß sie den griechischen Novellentext lateinischsprachigen Personen bekannt machen sollte.

Agustín skizziert in seiner Vorrede Julian als antecessor in Konstantinopel, der sowohl des Griechischen wie des Lateinischen mächtig war und die Novellen ins Lateinische übersetzt hat, unter Weglassung der Einleitungen ${ }^{32}$. Agustín geht sodann auf die These von Alciat ein, Julian sei patricius und exconsul gewesen. Er vermutet, daß Alciat Julian mit einem Konsul Julian gleichsetzt, den Priscianus nennt. Agustín will Julian auch nicht mit dem PPO Iulianus gleichsetzen, an den einige Novellen gerichtet sind. Er weist die Auffassung zurück, Julian sei ein Constantiensis gewesen ${ }^{343}$ und habe zur Zeit des Irnerius gelebt. Sodann gibt Agustín die erste Wirkungs- und Editionsgeschichte des Julian ${ }^{344}$, die er zudem noch um eine

S. dazu unten S. 351.

S. aus der Vorrede: Quantum verò ad harum Novellarum translationem attinet, palam est eum vвa@às Graecas non integras, sed amputatis longissimis praefationibus \& hyperbatis,

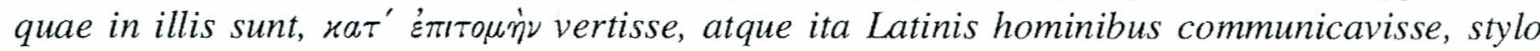
magis ut illis temporibus simplici \& fideli quam elaborato ...

S. aus der Vorrede (gegen Ende): Porrò ut in promptu sit cuivis conferendi, sicubi fortè haerat, Iuliani versionem cum archetypo Graeco: \& Novellarum Graecarum numerum qui saepissime à Iuliano ordine discrepat, in margine adposuimus ...

S. aus der Vorrede: Hic [Iulianus] Antecessor Constantinopolitanus, hoc est iuris praeceptor, utriusque linguae peritus fuit, Graecas Novellas constitutiones Latinas fecit \&prooemijs, ac perorationibus sublatis singulorum capitum sententiam paucis verbis dilucide explicat. Hunc Alciatus meus Consularem virum, \& patricium appellat in parergis. Existimo eum putasse eundem fuisse Iulianum illum, quem eisdem titulis Priscianus ornavit. A qua opinione discedo, propterea quod Prisciani libri extant Mavortio Consule scripti a discipulis Prisciani. Illius autem consulis annus collectionem Novellarum, quae post mortem Iustiniani facta est, quinquaginta amplius annos excedit. Alius eodem nomine fuit Praefectus Praetorio, ad quem extant aliquot Graecae constitutiones datae Lampadio, et Oreste consulibus. Sed hunc etiam alium esse existimamus, tum propter rationem temporum, tum propterea, quod hunc videmus in veteribus libris, nec Patricium se, nec Consularem, aut Praefectorium appellasse, aut, ut tunc usurpabant, Exconsule, vel Expraefecto; sed tantum Antecessorem CP. Neque illi audiendi sunt, qui Constantiensem fuisse dixerunt, \& temporibus Irnerij conscripsisse: quos \& veteres libri, \& et plurima antiquorum scriptorum testimonia, quae in Paratitlis retulimus, aliter rem se habere docebunt.

So erscheint er in der Vorrede der ed. Senneton (a. 1550), s. oben Fn. 234.

S. aus der Vorrede (im Anschluß an Fn. 342): Usum fuisse hoc libro Irnerium, Bulgarum, Azonem, Ioannem, Accursium, et ceteros interpretes non Iuliani nomine, sed Novellae, certis-

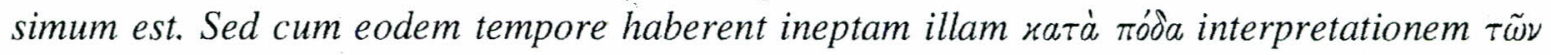

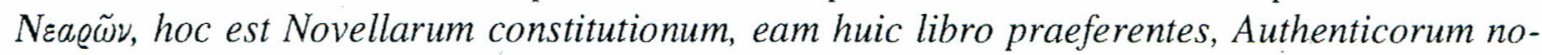
mine exornarunt. Es folgen Ausführungen zum Authenticum sowie zu Editionen des griechischen Novellentextes und den lateinischen Übersetzungen desselben, sodann heißt es: Primus Nicolaus Boerius legib. Longobardorum Iuliani libellum coniunxit, scholijs ornavit, \& in 
Beigabe mit Stellen aus dem kanonischen Recht, in denen Julian zitiert wird, erweitert $^{345}$. Über die Entstehungszeit der Epitome äußert er sich nicht explizit ${ }^{346}$. Agustín scheint als erster das Bedürfnis empfunden zu haben, die Edition des Julian zu rechtfertigen und deren Nützlichkeit zu begründen ${ }^{347}$.

Die Ausgabe von F. Pithou (a. 1576) bringt keine neuen Erkenntnisse mehr über Person und Werk des Julian. F. Pithou verweist dementsprechend auch auf den erreichten Kenntnisstand ${ }^{348}$.

\section{Ausblick: Die Epitome Iuliani im Usus modernus}

Das Wissen über Julian vermehrte sich im Usus modernus nicht ${ }^{349}$. Die unrichtige Betitelung als patricius und exconsul wurde vielfach wiederholt ${ }^{350}$, ebenso die Datierung der Epitome um das Jahr $570^{351}$. Heineccius hält beispielsweise fest, daß von dem patricius und antecessor Iulianus eine elegantere Novellenübersetzung exis-

publicum proposuit. Hunc secuti sunt Lugdunenses librarij, qui minus mendosos libros habuerunt.

S. die Edition Agustíns a. 1567 f. 25b: Iuris Pontificii capita ex Novellis.

Am Ende seiner Vorrede bemerkt er, daß die Coll. CLXVIII Novv. auch Novellen von Justin II. und Tiberius sowie drei Edikte an die Prätorianerpräfekten aufgewiesen habe; es sei unklar, ob Julian diese gekannt habe.

S. aus der Vorrede: Dicet aliquis, quid mihi cum Iuliano? qui aut eadem dicit, quae ceteri interpretes, \& et supervacaneum laborem sustinebo; aut alia quae neque in Graecis, neque in Latinis legibus continentur; \& cum probationem res desideret, aliunde mihi quaerenda auctoritas, \& probationis genus est?

S. den Beginn der Vorrede: Iulianum antecessorem Constantinopolitanum quanti facias [P. Pithou], non ignoro. Mihi quidem sic videtur, Novellarum epitomen non potuisse latinè elegantius ab alio fieri. Sermo illi est tersus \& elegans, Iustinianeorum temporum redolens antiquitatem, quibus propterea quoque proximum fuisse est verisimile. Non repetam quae alij de eo scripsere, quod illa huis editioni inserenda iustis de causis duxerim.

S. nur beispielshalber J. Gothofredus, Manuale juris seu parva iuris mysteria, Genf 1632 (benutzt in der 10. Aufl., Genf 1695), Cap. VI, Nrn. IX-XI (S. 66); J. G. Heineccius, Antiquitatum Romanarum iurisprudentiam illustrantium Syntagma, Bd. 1, Halle 1719 (benutzt: 3. Aufl., Straßburg 1755), Prooemium, Cap. 32 (S. 24); J. S. Brunquellus, Historia iuris Romano-Germanici, Jena 1727 (hier benutzt nach der dritten Auflage, Amsterdam 1740), Pars II, Cap. 12, §§ 1-3 (S. 279-281); Ch. G. Hoffmann, Historiae juris Romano-Iustinianei, Bd. 1, Leipzig 1734, Lib. II, cap. 2, § 15 (S. 612-615); J. A. Bach, Historia iurisprudentiae Romanae quattuor libris comprehensae, Leipzig 1754 (hier benutzt in der sechsten, von A. C. Stockmann besorgten Ausgabe Leipzig 1796), Lib. IV, Cap. 1, sect. 3, § 19 (S. 633-634).

S. nur Heineccius (o. Fn. 349), Cap. 32: ... Exstant et versiones latinae cultiore stilo [als das Authenticum] adornatae partim a Iuliano, Patricio et Antecessore Constantinopolitano, partim a Greg. Haloandro, quarum haec cum corpore iuris Haloandrino, illa e bibliotheca Pithoeorum prodiit Bas. 1576 et Paris. 1689, vgl. auch Brunquell (o. Fn. 349), S. 279: patricius und exconsul; richtig aber Bach (o. Fn. 349), S. 633.

S. etwa Gothofredus (o. Fn. 349), S. 66: Iuliana (!) Atecessoris (!) Constantinopolitani Novellarum liber sequitur, circa A. 570. confectus, ... So auch Brunquell (o. Fn. 349), S. 279, Hoffmann (o. Fn. 349), S. 612, Bach (o. Fn. 349), S. 633. 
tiert, als sie das Authenticum bietet ${ }^{352}$. Die Epitome selbst wurde nur noch als Übersetzung betrachtet.

Die erstmalige "Entdeckung" des (verlorenen?) Julian wurde unrichtig Ambrosius Traversarius $^{353}$ zugeschrieben $^{354}$. Erstmals behauptete dies anscheinend Joseph Maria Suarèz ${ }^{355}$ im Jahre $1638^{356}$.

Eine Novellenausgabe, die Conrad Rittershausen (Rittershusius; * 1560, † $1613)^{357}$ um das Jahr 1609 plante, kam nicht zur Ausführung ${ }^{358}$. Rittershausen wollte eine synoptische Edition der Novellen bieten. Die griechischen Novellen sollten beidseitig von lateinischen Übersetzungen umgeben sein, nämlich dem Authenticum und der Übersetzung Haloanders. Voranstehen sollte die Eptiome Iuliani ${ }^{359}$.

352 Wie oben Fn. 349.

353 Ambrogio Traversari (Ambrosius Traversarius, 1386-1439) war ein bekannter Gräzist und Ordensgeneral der Camaldulenser, s. zu ihm etwa nur die Beiträge in: G. C. Garfagnini (Hg.), Ambrogio Traversari nel VI centenario della nascita: convegno internazionale di studi (Camaldoli-Firenze, 15-18 settembre 1986), Florenz 1988.

354 S. dazu die Ausführungen von Haubold (o. Fn. 9), S. 134-137. Übernommen hat die Behauptung von Suarèz beispielsweise Brunquell (o. Fn. 349), S. 281.

355 Suarèz war von 1633-1666 Bischof von Vaison (la Romaine).

356 Benutzt wurde Iosephi Mariae Suaresii Episcopi Vasionensis Notitia Basilicorum, recensuit et observationibus auxit Christianus Fridericus Pohlius, Leipzig 1804 (die Erstauflage erschien 1638 in Rom), S. 85, § 21: Haec Epitome Novellarum ab Ambrosio Camaldulensi Mantuae reperta, sub titulo Ioannis consulis, De variis quaestionibus, ut ipse Ambrosius testatur in Epistolis, quae manuscriptae visuntur in Vaticanae Codice MDCCXCIII et refert Augustinus Monachus in vita eiusdem Ambrosii, edita fuit cum legibus Langobardorum a Nicolao Boerio ... Abgedruckt auch bei Haubold (o. Fn. 9), S. 136.

357 S. zu ihm nur A. Eisenhart, Art. Rittershausen, Konrad, in: Allgemeine deutsche Biographie, Bd. 28 (1889), S. 698-701 sowie Th. Duve, Art. Rittershausen (Rittershusius), Conrad, in: Neue deutsche Biographie, Bd. 21 (2003), S. 670-671.

358 Der Plan zu dieser Ausgabe trägt den Titel: Novellarum D. Iustiniani Sacratiss. Princ. Apotelesma Tripartitum (s. die folgende Fn.) und ist auf den 1. Januar 1609 datiert. Sie ist abgedruckt zu Beginn seiner Ausgabe Ioannis Antiqui Glossatoris Summa In Novellas Justiniani Imp. ... Ex Bibliotheca Et Recensione Cunradi Rittershusii, Frankfurt am Main 1615; s. dazu auch Biener (o. Fn. 9), S. 418-419.

359 Rittershausen plant eine umfassende methodische Erörterung der Novellen in drei Teilen (Absätze und Großschreibungen im Original sind hier weggelassen): Novellarum D. Iustiniani sacratissimi princ. Apotelesma Tripartitum cuius Pars Prima complectitur: Novellas ipsas Graecas ut a Justiniano primum scriptae promulgataeque sunt cinctas utrinque Latina translatione gemina: I. Vet. interpretis. II. Greg. Haloandri. His omnibus praemittit: Iuliani antecessoris epitome Latine, optimis quibusque editionibus inter se collatis emendatior atque auctior. Subijciuntur autem I. Paratitla Novellarum. II. Interpretatio verborum quorundam Iuliani, auctore Ant. Agustino. III. Glossarium, sive obscurorum verborum Juliani interpretatio, auctore Franc. Pithou IC. IV. Variae lectiones tum epitomes Juliani, tum Graeci textus Iustiniani. Rittershausen hatte diesen Plan anscheinend auch verschiedenen Juristenfakultäten zukommen lassen. Deren Stellungnahme sind dem posthum gedruckten Werk Iustinianeum, Hoc est, Novellarum Imp. Iustiniani Aug. Expositio Methodica, Auctore Cunrado Rittershusio, Straßburg 1615 vorangestellt (Elogia aliquot Germaniae academiarum inclutarum et virorum eruditione clarissimorum, quae ad commendationem Operis Juris Justinianei à D. Rittershusio adornati faciunt ...: Juristenfakultät Rostock [a. 1610], Tübingen [a. 1609], Frankfurt [a. 1609], Jena [ohne Datum]. S. aus dem Lob der Tübinger Fakultät: ... quàm ex 


\section{Handschriftenforschung}

Erst mit der historischen Rechtsschule begann wieder eine quellenorientierte Forschung zur Epitome Iuliani. Große Erträge auch für die Kenntnis der Epitome Iuliani brachte der Aufenthalt F. C. von Savignys in Paris von Anfang Dezember 1804 bis Ende 1805. Savigny konnte die Hs. Paris BN lat. 4568 als das Exemplar Ranconets identifizieren und untersuchte weitere Handschriften der Epitome Iuliani. Seine Aufzeichnungen bildeten die Grundlage für das erste Verzeichnis von Handschriften der Epitome durch C. J. Haubold im Jahre 1819. Im Jahre 1822 entdeckte F. Bluhme bei einer Studienreise nach Vercelli die Hs. Vercelli Bibl. Cap. CXXII in der Kapitelsbibliothek $^{360}$. Im selben Jahr wurde die Hs. Wien ÖNB lat. 2160 (vormals Salzburg 360) der wissenschaftlichen Öffentlichkeit bekannt ${ }^{361}$. Die Handschriften war-

praedictis litteris tuis intelligamus, te non tantùm, quo ad textum Novellarum constitutionum nostrarum, fundamentum loco, ad faciliorem earundem intellectum, coniungenda coniunxisse omnia, Epitomen scilicet latinam Iuliani, \& textum Graecum cum versione gemina Berguntionis (!) Pisani, \& Gregorii Haloandri, sed in illustratione etiam constitutionum istarum in eam sedulo incubuisse curam, ut quae in illis sparsim \& confusè habentur, diligenter colligeres, ac novo quodam modo in ordinem nequaquam inconcinnum disponeres, quindecim in universum constitutis partibus sive classibus, ad quas pleraque omnia, quae in toto Novellarum opere extant, commodè referri, ac velut per locos communes dividebantur, ita ut si maximè nulla expositio accessisset alia, vel eo ipso ordine solo, magnam partem obscuritatis praedictae jam sublatum esse appareat, non possumus non magnum \& praeclarum ab hoc opere fructum expectare, eoque nomine etiam juris studiosis, quam iura profitentibus, in foro stantibus gratulari ... Weniger aussagekräftig ist insoweit die Laudatio der Jenaer Juristenfakultät: ... Huius [Rittershausen] enim opera futurum est, ut quem à lectione antea deterruit taediosa Nomothetae prolixitas, nunc invitet astricta Juliani brevitas: Quem avertit insidens linguae peregrinitas: nunc alliciat genuina sermonis suavitas: quem prius turbaverat confusio, jam teneat ingeniosa dispositio: qua vel sola totum hoc opus reddere poterat commendatissimum. Vgl. auch Hänel, Iuliani epitome (o. Fn. 7), p. XXXIII Fn. 13.

Blu(h)me war nach Vercelli gereist, da sich dort nach dem Hinweis von A. Peyron eine alte Handschrift der Leges Langobardorum (Hs. Vercelli, Bibl. Cap. CLXXXVIII) befinden sollte, s. F. Blume, Lex Dei sive Mosaicarum et Romanarum legum collatio e codicibus manuscriptis Vindobonensi et Vercellensi nuper repertis auctam atque emendatam edidit notis indicibusque illustravit Fridericus Blume, Bonn 1833, p. XXVIII. Blu(h)me hielt sich vom 27. Oktober bis 19. November 1822 in Vercelli auf; s. auch Kaiser, Die Epitome Iuliani (o. Fn. 7), S. 122.

Der Bibliothekar der Wiener Hofbibliothek, B. Kopitar, machte den Berliner Rechtsprofessor K. W. von Lancizolle auf die Handschrift aufmerksam (zu Lancizolle s. nur H. Brandt, Art. Lancizolle, in: Neue deutsche Biographie 13 [1982], S. 474-475), vgl. Hänel, Iuliani epitome (o. Fn. 7), p. VI. Biener publizierte kurz darauf noch unbekannte Stücke aus den Anhängen dieser Handschrift, s. F. Biener, Nachricht über einige ungedruckte Stücke in der Wiener Handschrift von Julian's Novellenauszug, in: Zeitschrift für geschichtliche Rechtswissenschaft 5 (1825), S. 338-357. Friedrich Blu(h)me konnte die Handschrift für die Edition der Lex Dei heranziehen (nach einer Abschrift, die für Savigny angefertigt worden war und die ihm Savigny überlassen hatte), s. Blume (o. Fn. 360), p. XXVII-XXVIII. 
en vornehmlich für die Lex Dei von Interesse ${ }^{362}$, erst Hänel verwertete sie für die Epitome Iuliani. Hänel, der anscheinend bereits früh den Plan zu einer Neuedition des Julian gefaßt hatte ${ }^{363}$, kollationierte auf seinen ausgedehnten Bibliotheksreisen in den Jahren 1821-1829 $9^{364}$ auch die Pariser Handschriften des Julian mit der Edition des Miraeus (1828). Auf die Skt. Gallener Fragmente, die bislang ältesten Textzeugen der Epitome, scheint er erstmals aufmerksam gemacht zu haben ${ }^{365}$. Hänel konnte im Jahre 1825 in Rom von einem Buchhändler die Hs. Leipzig UB Hänel 6 erwerben $^{366}$. Im Jahre 1826 entdeckte er in der Bibliotheque municipale von Tours sowie von Troyes bis dato unbekannte Julianhandschriften ${ }^{367}$. Auf dieser Grundlage publizierte Hänel 1835 ein verbessertes Handschriftenverzeichnis zur Epitome Iulia$\mathrm{ni}^{368} .1837$ konnte Hänel bei der Versteigerung der Bibliotheque de Rosny die Hs. Berlin Staatsbibl. lat. fol. 269 für die königliche Bibliothek zu Berlin erwerben, die aus dem Besitz von Pierre Pithou stammte ${ }^{369}$ und die Francois Pithou für die Edition der Epitome Iuliani benutzt hatte. Aus derselben Auktion rührt auch die Hs. Berlin Staatsbibl. lat. fol. 271 her, ebenfalls aus dem Besitze von Pierre Pithou. Von der Kapitelsbibliothek zu Udine ${ }^{370}$ kaufte Hänel (privat) gegen Ende des Jahres 1869 oder zu Beginn des Jahres 1870 die Hs. Leipzig UB Hänel 8+9 (Codex Utinensis) ${ }^{371}$. Die Rechtmäßigkeit des Erwerbs dieser Handschrift und der Hs. Leipzig UB Hänel

362

363

S. Blume (o. Fn. 360), p. XXVIII-XXXIII.

S. seine Bemerkung in: Nachtrag zu Haubolds Litteratur-Geschichte (o. Fn. 9), S. 357.

S. dazu Hänel-Landsberg (o. Fn. 7), S. 752. Hänel veröffentlichte die Ergebnisse seiner Reisen, s. G. Hänel, Catalogi librorum manuscriptorum qui in bibliothecis Galliae, Helvetiae, Belgii, Britanniae Maioris, Hispaniae, Lusitaniae asservantur, Leipzig 1830 (Nachdruck Hildesheim - New York 1976).

S. Hänel, Catalogi (o. Fn. 364), Sp. 729 sowie ders., Nachtrag zu Haubolds LitteraturGeschichte (o. Fn. 9), S. 359 (Nr. 13).

S. Hänel, Nachtrag zu Haubolds Litteratur-Geschichte (o. Fn. 9), S. 358 (Nr. 8).

S. Hänel, Iuliani epitome (o. Fn. 7), p. XV.

Hänel, Nachtrag zu Haubolds Litteratur-Geschichte (o. Fn. 9).

S. zu dem Erwerb G. Hänel, Die Handschriften der Bibliothek der Herzogin von Berry, in: Kritische Jahrbücher für die Rechtswissenschaft 1 (1837), S. 375-384. Zu der Epitome s. nur F. Blume, Über Pithou's Handschrift der Lex Dei oder Legum Mosaicarum et Romanarum Collatio, in: Zeitschrift für geschichtliche Rechtswissenschaft 10 (1842), S. 298-308. Große Bedeutung kam auch dem Berliner Institutionen- und Pandektenfragment zu, s. nur Hänel, Über das alte Pandektenfragment in der königlichen Bibliothek zu Berlin, in: Berichte über die Verhandlungen der königlich sächsischen Gesellschaft der Wissenschaften zu Leipzig, phil.-hist. Klasse, Leipzig 1850, S. 73-89. Zum Berliner Institutionen- und Pandektenfragment s. Kaiser, Die Epitome Iuliani (o. Fn. 2), S. 387-415 sowie jetzt Radding-Ciaralli (o. Fn. 22), S. 275 (Handschriftenregister).

S. dazu näher Kaiser, Authentizität und Geltung (o. Fn. 2), S. 7 Fn. 2.

S. Kaiser, Epitome Iuliani (o. Fn. 2), S. 106. Hänel hatte die Handschrift bereits zuvor ausführlich untersucht, s. G. Hänel, Über die Handschrift zu Udine mit der Lex Romana, in: Berichte über die Verhandlungen (wie oben Fn. 369), Leipzig 1852, S. 65-89; ders., Nachträgliche Bemerkungen zu dem Berichte über die Handschrift zu Udine mit der Lex Romana, in: Berichte über die Verhandlungen (wie oben Fn. 369), Leipzig 1856, S. 303 - 305.; 
6 (ursprünglich wohl in San Croce di Gerusalemme in Rom) durch Hänel war später umstritten ${ }^{372}$.

Hänel waren für seine Edition insgesamt 19 Handschriften bekannt, von denen er die meisten selbst einsehen und kollationieren konnte ${ }^{373} .1873$ erschien seine bis heute nicht ersetzte Edition der Epitome ${ }^{374}$. Ihr Vorwort legt Zeugnis ab von der immensen Arbeit und Mühe, die Hänel in die Edition investierte.

Im 20. Jhd. kamen noch einige Handschriftenfragmente hinzu, so die Hss. Guttaring Pfarrarchiv s. n. ${ }^{375}$ und Karlsruhe Badische Landesbibl. Aug. Fragm. 145, sowie die Exzerpte aus der Epitome in der Collectio Gaudenziana ${ }^{376}$, in den "Sacra privilegia",377 im Klagenfurter Fragment ${ }^{378}$ (s. auch den Nachtrag S. 353).

Erste Ansätze zur Erfassung der Editionen der Epitome Iuliani finden sich bereits in dem monumentalen Werk Ernst Spangenbergs aus dem Jahre 1817. Schließlich legt Haubold (1819) die kritische Zusammenstellung vor, die bis zur Edition durch Hänel maßgeblich bleiben soll. Das Verzeichnis der Novellenausgaben bei Biener (1824) erfaßt auch Editionen der Epitome Iuliani.

\section{Das Verständnis der Epitome Iuliani}

Für das Verständnis der Epitome Iuliani war die Darstellung bei Biener (1824) ${ }^{379}$ prägend, die bis heute nachwirkt. Biener stellt zunächst die Abfassungszeit der Epi-

S. dazu F. Patetta, Come il manoscritto udinese della cosi detta „Lex romana raetica curiensis“ e un prezioso codice sessoriano siano emigrati dall'Italia, in: F. Patetta, Studi sulle fonti giuridiche medievali, Turin 1967, S. 957-971 (erstmals 1911) und ders., L'esodo dall'Italia del „Codex Utinensis“ e la sua rivendicabilità, in: Studi, S. 973-997 (erstmals 1912) sowie die Erwiderung von R. Helssig, Der Erwerb des Codex Utinensis und einer anderen Julianhandschrift durch Gustav Hänel, in: Zentralblatt für das Bibliothekswesen 29 (1912), S. 97 116 und ders., Nochmals der Erwerb des Codex Utinensis durch Gustav Hänel, in: Zentralblatt für das Bibliothekswesen 29 (1912), S. 510-519.

S. dazu näher Kaiser, Die Epitome Iuliani (o. Fn. 2), S. 382-383.

Auf die Eigenheiten der Edition wurde schon auf anderer Stelle eingegangen, s. Kaiser, Die Epitome Iuliani (o. Fn. 2), S. 381-386.

Veröffentlicht durch H. Malloth, Ein karolingisches Rechtsdenkmal aus Guttaring, in: Carinthia I, 157 (1967), S. 258-275; dazu Kaiser, Die Epitome Iuliani (o. Fn. 2), S. 33-35.

Auf die Kapitel wies bereits teilweise Gaudenzi hin, s. A. Gaudenzi, Un'antica compilazione di diritto romano e visigotico con alcuni frammenti delle legge di Eurico tratta da un manuscritto della biblioteca di Holkham, Bologna 1886, S. 40- 41, 43, 49-50; s. dazu ausführlich Kaiser, Die Epitome Iuliani (o. Fn. 2), S. 706-708, 709-713, 830-837.

Die Existenz des Kapitels erwähnt bereits G. Hänel, Ein unedirtes Gesetz des Kaisers Justinus II. Eine Sammlung von Stellen der Julian'schen Epitome Novellarum, in: Berichte über die Verhandlungen (wie oben Fn. 369), Leipzig 1857, S. 1-21, S. 11; s. zu dem Text Kaiser, Authentizität und Geltung (o. Fn. 2), S. 434-441.

Erstmalig bekanntgemacht durch $\mathrm{H}$. Menhardt, Ein Bruchstück der Lex Visigothorum aus einer dem Codex Holkhamensis 210 verwandten Handschrift, ZRG GA 46 (1926), S. 360364 (1 Tafel); s. dazu ausführlich Kaiser, Die Epitome Iuliani (o. Fn. 2), S. 638-653.

S. F. A. Biener, Geschichte der Novellen Justinians, Berlin 1824 (Nachdruck Aalen 1970). 
tome Iuliani richtig, von der man überwiegend annahm, sie sei um 570 entstanden $^{380}$. Er erkannte auch, daß die Epitome ein Produkt des justinianischen Rechtsunterrichts war $^{381}$. Biener vermutet, daß die Epitome Iuliani dazu bestimmt war, die (griechischen) Novellen in dem rückeroberten (lateinischsprachigen) Italien bekannt zu machen ${ }^{382}$. Diese Auffassung blieb bis zur Mitte des 20. Jahrhunderts herrschend ${ }^{383}$ und findet sich noch heute in Lehrbüchern des römischen Rechts ${ }^{384}$. Je-

380

381

382

S. Biener (o. Fn. 9), S. 75.

S. Biener (o. Fn. 9), S. 233-235.

S. Biener (o. Fn. 9), S. 75-76: ,... Im Ganzen bleibt es freilich immer sonderbar, daß ein Constantinopolitanischer Professor eine lateinische Bearbeitung der griechischen Novellen unternahm, während seine Zeitgenossen von allen Seiten griechische Bearbeitungen der lateinischen Rechtsbücher für nötig hielten und dergleichen verfaßten. Gewiß konnte er auch nicht auf den Gebrauch im griechischen Reiche gerechnet haben, wie denn auch wirklich bei den griechischen Juristen keine Spur davon sich findet, aber wir dürfen vermuthen, daß diese Arbeit für lateinische Länder, besonders für das neueroberte Italien bestimmt war. Diese Vermuthung wird auch sehr unterstützt durch die Zeit, in welcher wahrscheinlich diese Arbeit gemacht wurde (denn gerade damals war Justinian zum ruhigen Besitz von Italien gelangt), so wie durch mehrere Stellen, welche nachweisen, dass der Verfasser für Nicht-Griechen arbeitet, z. B. cap. 15. 29. 32. ..." sowie S. 232-233: “... Endlich aber ist es sogar möglich, daß Julian seine Bearbeitung der Novellen, welche zu den Bedürfnissen des orientalischen Reichs schlechterdings nicht passt, bestimmt für Italien unternommen hat, wenigstens für den Unterricht in den Rechtsschulen daselbst. Aus diesen Rechtsschulen kann dieselbe dann sehr leicht in die gewöhnliche Praxis übergegangen sein".

S. etwa A. Schweppe, Römische Rechtsgeschichte und Rechtsalterthümer, 3. Aufl., Göttingen 1832, § 126a (S. 249-250): “... Vielleicht war die Sammlung für das eroberte Italien bestimmt, da sie mit dem erlangten ruhigen Besitz von Italien schließt und keine Spuren des Gebrauchs bei den Griechen, desto mehr aber im Abendlande vorkommen. ..."; Cramer, Sendschreiben des Herrn Ober-Bibliothekar Cramer, in Kiel, an den Professor Klenze in Berlin, in: Zeitschrift für geschichtliche Rechtswissenschaft 8 (1835), S. 132-152, 137: „War, wie man annehmen darf, die ganze Sammlung für den Occident berechnet und für die lateinisch redenden Völkerschaften des Reichs ..."; A. F. Rudorff, Römische Rechtsgeschichte, Bd. 1, Leipzig 1857, S. 319-320: „Die älteste [Novellensammlung; W. K.] ist die, welche der lateinischen, muthmasslich für Italien bestimmten sogenannten Epitome Iuliani ... um 556 zum Grunde liegt ..."; O. Karlowa, Römische Rechtsgeschichte, Bd. 1, Leipzig 1885, S. 1021: „Vermutlich war Julians epitome nicht für den Gebrauch in den griechischen Ländern berechnet, sondern für die lateinischen Länder, namentlich für das wiedereroberte Italien bestimmt.“; Krüger (o. Fn. 12), S. 401: Sie [die Epitome Iuliani; W. K.] war also für die lateinisch redenden Provinzen bestimmt, wahrscheinlich für Italien, wo kurz zuvor (554) die Novellen publiziert worden"; H. Kreller, Römische Rechtsgeschichte, 2. Aufl., Tübingen 1948, S. 99-100: „Von ihnen [den Novellen; W. K.] sind außer einer von einem Konstantinopler Rechtslehrer namens Julianus nach dem Gotenkrieg für Italien veranstalteten Epitome zwei Sammlungen erhalten ..."; W. Kunkel, Römische Rechtsgeschichte, Willsbach-Heidelberg 1947, S. 120: ,... in lateinischer Sprache, noch unter Justinian selbst von einem gewissen Julianus verfasst, der Rechtslehrer in Konstantinopel war (sog. Epitome Juliani). Sie war vermutlich für den Gebrauch im wiedergewonnenen Italien bestimmt und ist dort auch das ganze Mittelalter hindurch bekannt gewesen." (entsprechend auch in der 2.-6. Auflage, 1956-1972; die 7.-12. Aufl. 1972-1990 sind Nachdrucke der 6. Auf1.); M. Kaser, Römische Rechtsgeschichte, 2. Aufl., Göttingen 1967, S. 255: “a) die Epitome Iuliani, 124 Novellen von 535-555 in einer wohl für Italien bestimmten lateinischen Bearbeitung, ein Werk des Rechtslehrers Julianus aus Konstantinopel ..."; H. F. Jolowicz-B. Nicholas, Historical Introduction to the Stu- 
doch erkannte bereits Zachariae von Lingenthal im Jahre 1843 die Bestimmung des ¿id $\delta_{1} \xi$. Julian hielt in Konstantinopel einen Novellenunterricht für lateinischsprachige Studenten, die aus dem Westen nach Konstantinopel kamen ${ }^{385}$. Dies bestätigen dann auch die Untersuchungen von Noailles (1912) ${ }^{386}$ und Scheltema $(1963)^{387}$.

dy of Roman Law, $3^{\text {rd }}$ ed., Cambridge 1972, S. 497: "Its [der Epitome Iuliani; W.K.] author, Julianus, is described as a professor in Constantinople, and it must date from Justinian's reign, for he is referred to as imperator noster. ... The latest constitution included dates from 555 , and this fact, together with the use of Latin, makes it probable that the work was intended for use in Italy, where promulgation of the Novels had been ordered in 554."; G. Härtel-E. Pólay, Römisches Recht und Römische Rechtsgeschichte, Weimar 1987, S. 122123: „Die wichtigsten privaten Novellensammlungen sind: 1. Die Epitome Iuliani, eine wohl für Italien bestimmte lateinische Bearbeitung von 124 Novellen aus der Zeit von 535 bis 555, hergestellt vom Rechtsgelehrten Iulianus aus Konstantinopel ...”; O. Tellegen-Couperus, A Short History of Roman Law, London 1993, S. 147: „Epitome Juliani, an abbreviated version of a collection of 122 constitutions, which was produced during the reign of Justinian. The edition was probably intended for use in Italy. This is indicated by two factors: the language of the texts is Latin and the last constitution dates from the year 555, i.e. one year after Justinian had introduced his legislation into Italy."; Lange (o. Fn. 91), S. 81: "Julians Vorlage ist in griechischer Sprache geschrieben gewesen. Er hat in seine offensichtlich für die lateinischen Länder, insbesondere für das wiedereroberte Italien bestimmten Sammlung alles Griechische in das Lateinische übersetzt"; F. Wieacker, Römische Rechtsgeschichte, Zweiter Abschnitt, München 2006 (Stand 1994), S. 323: "Bereits um 555 verfertigte der griechische Rechtslehrer Julian in Konstantinopel offenbar aus Anlaß der Einführung der Novellen in Italien und vielleicht im amtlichen Auftrag einen lateinischen Auszug der Novellen."; P. Stein, Roman Law in European History, Cambridge 1999, p. 40: ,, a sixth-century Latin abbreviation of Justinian's Novels, known as the Epitome Juliani and intended to be applied in Italy ..." - Vorsichtiger aber M. Conrat (Cohn), Geschichte der Quellen und Literatur des Römischen Rechts im früheren Mittelater, Bd. 1, Leipzig 1891, S. 122: ,... ein lateinisches Produkt der byzantinischen Literatur [die Epitome Iuliani; W. K.], obschon doch wohl für den Occident bestimmt (Fn. 3: Mit Sicherheit lässt sich dies nicht sagen, vgl. Haenel a. a. O. p. XXXIX, XL.) ...“

S. W. Waldstein-M. Rainer, Römische Rechtsgeschichte, 10. Aufl., München 2005, § 43 I 7a (S. 246 Rn. 16): „Die sog. Epitome Iuliani ist eine verkürzende Bearbeitung von 124 Novellen aus den Jahren 535 bis 555 in lateinischer Sprache (wohl für den Westen), die den Rechtslehrer Iulianus aus Konstantinopel zum Verfasser hat." (so bereits G. Dulckheit, Römische Rechtsgeschichte, München und Berlin 1952, S. 248). Die Neubearbeitung des Kunkelschen Lehrbuchs durch M. Schermaier vermeidet hingegen diesen Fehler: s. W. Kunkel-M. Schermaier, Römische Rechtsgeschichte, 13. Auflage, Köln u. a. 2001, S. 222: „,.. in lateinischer Sprache, noch zu Lebzeiten Justinians von einem gewissen Julianus verfasst, der Rechtslehrer in Konstantinopel war (sog. Epitome Juliani). Alsbald nach der Wiedereroberung Italiens muss sie dort Eingang gefunden haben; sie blieb in Italien während des ganzen Mittelalters bekannt."

S. C. E. Zachariae von Lingenthal, Anekdota, Leipzig 1843, S. 207: „... Initio latino potissimum sermone usus esse videtur, sive quo melius eorum utilitatibus prospiceret, qui legibus Romanis viventes latina lingua tamquam patria uterentur, sive propterea, quod scholae eius praesertim a discipulis ex Occidente advenientibus freqentarentur (Fn. 47: Illa ratio Bienero placuit (Gesch. d. Novellen p. 75sq.), haec mihi probabilior videtur.). ..."; s. auch ders., Zur Geschichte des Authenticum und der Epitome Novellarum des Antecessor Julianus, in: Kleine Schriften zur römischen und byzantinischen Rechtsgeschichte, Bd. 2, Leipzig 1973 , S. 117-127 (erstmals 1882), S. 119: „... wird anzunehmen sein, dass die Veröffentlichung der gesammelten Novellen ... etwa gegen Ende des Jahres $556 \ldots$ in Italien erfolgt ist. Um diesel- 
Zu S. 310 Fn. 67:

Neben der Hs. Karlsruhe Badische Landesbibl. Fragm. Aug. 145 ist noch die Hs. Paris BN Baluze 270 ff. 68-69 (s. VIII) zu ergänzen (erwähnt bei Radding - Ciaralli [o. Fn. 22], S. 37). Zu beiden Handschriftenfragmenten wird ein Beitrag des Verf. in der ZRG RA 126 (2009) erscheinen.

Zu S. 311 Fn. 81:

Zur Überlieferung der Lex Dei s. jetzt R. Frakes, The Manuscript Tradition of the Lex Dei, in: ZRG R.A 124 (2007), S. 290-304.

\section{Zu S. 313 Fn. 93:}

J. Trede, Die juristischen Handschriften des Stadtarchivs Köln, Köln 2005, S. 90-92, 90 datiert die Hs. Köln Stadtarchiv W 328 (olim X 8) in die Mitte der ersten Hälfte des 12. Jhds. (mit Nachträgen aus der Mitte der zweiten Hälfte), Radding - Ciaralli (o. Fn. 22), S. 119 in das beginnende zwölfte Jahrhundert (wohl zutreffend). Die Handschrift dürfte in Oberitalien entstanden sein.

Zu S. 313 Fn. 97:

Zu der Hs. Köln Stadtarchiv W 328 (olim X 8) s. jetzt ausführlich Radding - Ciaralli (o. Fn. 22), S. 118-131, 275.

Zu S. 350:

Als weiteres Fragment der Epitome, das Hänel noch nicht kannte, ist die Hs. Paris BN Baluze 270 ff. 68-69 zu nennen.

be Zeit hat Julianus, Antecessor zu Konstantinopel, von 122 Novellen, die ihm in einer von ihm angelegten oder doch ergänzten und vermehrten Sammlung vorlagen, eine Epitome in lateinischer Sprache herausgegeben. Die jüngste von ihm epitomirte Novelle - const. CLXV (Nov. 159) - ist vom 1. Juni 555. Die Epitome ist also erst abgefasst, nachdem Justinian die Geltung der Novellen für Italien angeordnet hatte: wahrscheinlich ist sie durch diese Anordnung geradezu veranlasst worden. Sie steht aber ausser allem Zusammenhang mit einer in Italien erfolgten Gesammt-Publication der Novellen." S. Noailles (o. Fn. 38), S. 156-160, 160: ,Julien a voulu mettre la législation des Novelles à la portée des étudiants de langue latine que le succès des armees byzantines en Italie avait attirés à Constantinople." Noailles folgt auch L. Wenger, Die Quellen des Römischen Rechts, Wien 1953, S. 669: ,,... mit der kurz zuvor erfolgten Wiedereroberung Italiens und der Einführung des Novellenrechts ... 554 in ursächlichen Zusammenhang gebracht. Und es ist ja plausibel, daß ein Konstantinopler Rechtslehrer italischen Studenten, die ... [nach Konstantinopel; W. K.] zum Rechtsstudium gezogen kamen, auch die jüngsten römischrechtlichen Quellen in der alten, ihnen ... geläufigen lateinischen Rechtssprache darbot. S. oben Fn. 11. 